


$$
\text { DR. } 448
$$

\section{OAK}

- RIDGE

- NATIONAL LABORATORY

\section{UNION}

CARbide

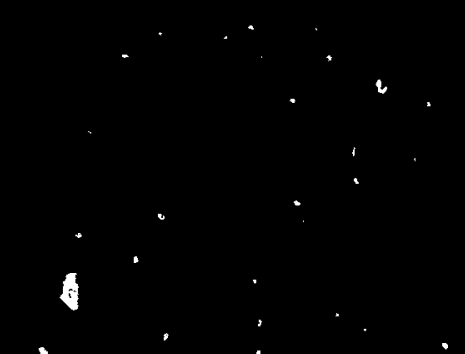

:

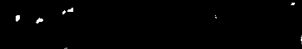

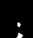

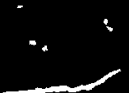

1
F. F. Haywood

W. A. Goldsmith

P. M. Lantz

W. F. Fox

W. H. Shinuaugh

$H$ iM. Hubbard. Jr.
OPERATED BY

UNION CARBIOE CORPOBATION

FOR tHE UMITEO STATES DEPARTMENT" OF ENERGY 


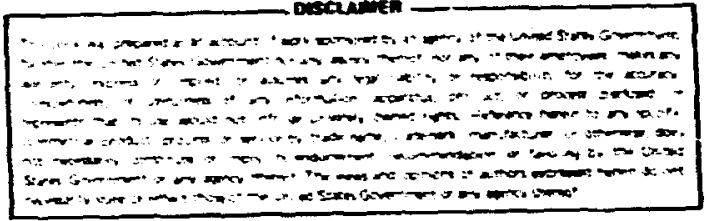

GRNL $-5 \div 47$

Dist. Category UC-41

Contract No. W-7405-eng-26

Health and Safety Research Civision

AS?CSSMENT OF THE RADIC:OGICAL IMPACT OF-THE INACTIVE URANIUM-MILL TAILIYGS AT SHIPROCK, NEW MEXICO

F. F. Haywood, W. A. Goldsmith, P. M. Lantz, W. F. Fox, W. H. Shinipaugh, and H. M. Hubbarci, Jr.

Dote Published: December 1979

Appendix I in this document is a direct reproduction of a previously unpublished report of the Phase I interagency site visit prepared by Lucius Pitkin, Inc., under AEC Contract AT(05-1)912

OAK RIDGE NAT, VAL LABORATORY

Oak Ridge, Te ressee 37830

cper. ted by

UNION CARBII: CORPORATION

for the

DEPARTMENT OF ENERGY 
LIJT OF REPORTS CF OAR RIOGE MIIOMAL LABOAATORY RAOIOLOGICAL SURVEYS AT IMACTIVE URAMIUA-MILL SITES

moer

and -5448 nill Tailings at Mexican Hat, Utah

JiNL-54e9 Mill Iailings piles at homent

r.: $\mathrm{NL}-5450$ Tuba City, Arizona

2adologicai Survey of the Inactive Uranium-will Tailings at Durango, Colorado

OQhL -5451

Rc.i, ${ }_{j y}$ ical Survey of the Inactive Uranim-Mill Tailings at

$08041-54.72$ Slick Ro:k, Colorado

OPAL -5453 Gumison, Colorado

Radiological Survey of the Inactive Lraniun-Mill Tailings at Maturita, Colcrado

OR4L-5454

Radiological Survey of the Inactive Uranium-Mill Tailings at Rifle, Colurado

ORHL -5455

Radiologica I Survey of the Inactive Uraniun-Mill Tailings at Maybell, Colorado

ORML-5456

Assessment of the Radiological Impac: of the Inactive Uranil nwill Tailings at Grand Junction, Colorado

ORNL -5457

Radiological Survey of tre Inactive Uranium-hill Tailings at Ambrosia lake, Mew mexico

Radiological Survey of the Inactive Uraniun-MIIl Tailings at Green River, Utah

Radiolocical Survey of the Inactive Uranium-Mill Tailings at the Spook Site, Converse County, Wyoming

Radiological Survey of the Iractive Uranium-Mill Tailings at Riverton, Wroming

Rad'slogical Survey of the Inactive Uran?um-kill Tailings at falls City, Texas

Radiological Survey of the Inactive Uranium-Mill Tailings at Ray Point, Texas

Radiological Survey of the Inactive Uranium-Mill Iailings at Lakeview, Orapon

Radiological Survey of the Radioactive Sands and Residues at Lowen, idaho

ORNL -5458

ORNL - 545y

ORILL-5460

ORNL-5461

ORML -5462

ORNL -5463

ORNL -5464

ORNL - $\$ 465$ 


\section{CONTENTS}

Page

LIST OF FIGURES ................. iv

LIST OF TABLES ...................

ACKNOWLEDGEMENTS ...................... vi

ABSTRAC: .................

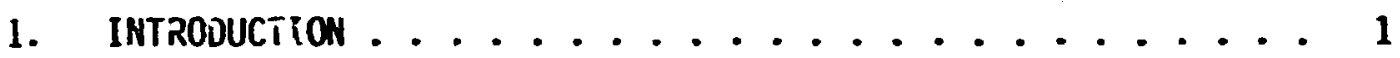

2. SITE OESCIIPTION .................. 3

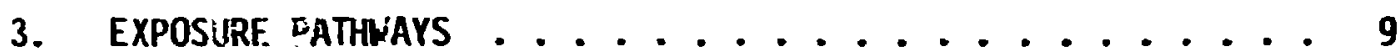

4. SAMPLING TECHNIQUES ANI RADIOLOGICAL MEASUREMENTS .... 9

5. RESULTS OF MEASUREMENTS $\ldots \ldots \ldots \ldots$

5.1 Background Radioactivity ........... 10

5.2 Di rect Gamma-Ray Exposure Rates ......... 10

5.3 Radionuclide Concentrations in Surface Soil and Sediment Samples.............. 13

5.4 Radicchemical Analysis of Water ......... 19

5.5 Raden Daughter Measurements .......... 20

5.6 Concentration of ${ }^{226} \mathrm{Ra}$ in Soil Bene th the Surface . . 20

5.7 ioncentration of Airborne Radionuclides ...... 23

6. HEAitH EFFECTS AITRIBUTABLE TO THE SHIPROCK TAILINGS . . . 30

6.1 Kadon Diffusion Pathway ........... 30

6.2 Exposure to jamma Radiation .......... 33

6.3 Heilth Effects Attributable to Aquatic and Food Pathways .................. 34

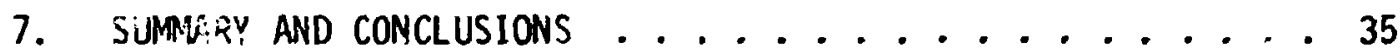

REFERENCE; ....................... 37

APrENDIX 1, PHASE 1, Report on Conditions of Uranium Mill

Site and Taflings at Shiproik, New Mexico ....... 39

APPENDIX :I, Soil Sampling Techniques and Radiological

Messurements ................. . 59

APPEND $x$ III, Water Sampling and Analysis ........ 73 


\section{LIST OF FIGURES}

Figure

Page

1 Aerial phctugraph of Shiprock site $\ldots \ldots \ldots \ldots \ldots \ldots \ldots$

2 Locations of holes drilled at the Shiprock site ....... 5

3 Plot plan for EPA Minimu Renedial Action Plan ........ 7

4 EPA work plan for decontamination of the Shiprock uraniu mill site $\ldots \ldots \ldots \ldots \ldots \ldots \ldots \ldots \ldots \ldots \ldots \ldots \ldots, 8$

5 Locations of externa! gama measurewents and background soil samples

6 Direct gama-ray measurements 1 above the ground at and near the mill site $\ldots \ldots \ldots \ldots \ldots \ldots \ldots \ldots$

7 Direct gama-ray measurements $1 \mathrm{~m}$ above the ground off the tailings pile ................. 15

8 Locations and identifications of environmental samp'es

9 Radon and radon daughter concentrations in and near the NECA office building at Shiprock on February 28-29, 1976

10 Calculated concentrations of ${ }^{228} \mathrm{Ka}$ in holes 9 , 10,11 , and 12

11 Calculated concentrations of ${ }^{226}$ Ra in holes 13, 15,16 , and 17

12 Calculated concentrations of ${ }^{226} \mathrm{Ra}$ in holes 18 , 20,22 , 31:t 23 26

13 Calclip'-1:d concentrations of ${ }^{226} \mathrm{Ra}$ in holes 24, 25,26 , and 27

14 Calculared concentrations of ${ }^{226} \mathrm{Ra}$ in holes 28 , 29,30 , and 32

15 Calculated concentrations of ${ }^{226} \mathrm{Ra}$ in holes 33 , 34 , and 35 


\section{LIST OF TABLES}

Table

Page

1 Background radiation levels and background concentrations of radionuclides in surface soil near Shiprock, New Mexico ................ 12

2 Concentration of ${ }^{226} \mathrm{Ra}$ and ${ }^{232} \mathrm{Th}$ in surface and near-surface soil $\ldots \ldots \ldots \ldots \ldots \ldots \ldots \ldots \ldots \ldots$

3 Results of measurements of airborne radon daughters in the NECA office building, February 28-29, 1976

$4 \quad 222 R n$ concentration resultiny from the Shiprock tailings piles with a calculated point source of $1.9 \times 10^{8} \mathrm{pCi} / \mathrm{sec}$ 


\section{ACKNOWLEDGEMENTS}

The authors of this series of reports wish to express their deep appreciation to the fullowing persons: to L. J. Deal and R. H. Kennedy, Department of Energy, Wastington, D. C., for their encouragement and support during the field orerdions phase of this project; to Dr. Charles J. Barton of Science Applications, Inc. (SAI), Oak Ridge, for his diligent work in preparing, under subcontract, the drafts of this series, and to Wii..la Minor, also of SAI for typing the manuscripts; to the many memkers of the Health and Safety Research Division who provided technical reviews of the individual reports; to Jenny Vinson, Health and Safety Research Division Technical Editor, special thanks is extended for her careful review of each manuscript, esbecially for helping ensure that a uniform format was followed; to Dr. Barry Berven for his assistance in organizing the final drafts. Appreciation is extended to John G. Themelis and Frank McGinley, Department of Energy, Grand Junction Operations Office, for their support and advice during the conduct of this project; to Charles Brunner. Bendix Field Engineering Company, Grand Junction, Colorado, for his assistance in arranging for the gr inding of approximately 1600 soil samples which were collecte- during the project; also to Or. Vern Rogers and his staff, Ford, Bacon and Davis Utah Inc.: for assistance during the field operations phase of this project. Finally, the authors wish to acknowledge the efforts of Mr. Ev Haldane, Departrient of Energy, Grand Junction who was associated with the uranium mill tailings proguam from its earliest days. Ev passed away suddenly on June 30,1979, and it is to his memory that this series of reports is dedicated. 


\title{
ASSESSMENT OF THE RADIOLOGICAL IMPACT OF THE INACTIVE URANIUH-MILL TAILINGS AT SHIPROCK, NEW MEXICO
}

F. F. Heywood, W. A. Goldsinith, P. M. Lantz, W. F. Fox W. H. Shinpaugh, and H. M. Hubbard, Jr.

\begin{abstract}
Uranium-mill tailings at en inactive site near Shiprock, New Mexico, contain an es imated 950 curies ( $C i$ ) of ${ }^{226}$ Ra together with its radioactive daughters. A radiological survey was conducted at this site in February 1976. Extensive decor.tamination work and tailings stabilization perfnrmed at the site since that time have greatl ${ }^{-}$changed conditions there and, consequently, little effort was applied to quantification of potentiai health effects in comparison to the earlier consideration of the site at Salt Lake City. The present report delineates the radiological conditions that existeu at the time of the survey including information on the surface and below-surface distribution of ${ }^{226} \mathrm{Ra}$. The data presented support the conclusion of earlier studies that diffusion of radon and inhalation of radon daughters is the principal mode of exposure of offsite population groups. However, from radon dispersion calculations and population statistics, it was found that few people live in the directions from the tailings where the maximum calculated annual average radon concentrations occur (southwest, west-solithwest and west sectors). In these sectors, the contribution of the tailings to the average ambient radon concentration is less than the assumed annual average background radon concentration $(0.5 \mathrm{pCi} / 1 \mathrm{iter}$, based on longterm measurements at Durango, Colorado, by other investigators) at dijtances greater than $2.3 \mathrm{~km}(1.4 \mathrm{mi})$ and is less than $10 \%$ of the background value at $7 \mathrm{~km}(4.4 \mathrm{ni}$ ) and beyond. Computer modeling of radon transport from the site indicates a maximum incremental increase in lung cancer of 2 to $3 \%$ per year. Direct gamma exposure of the same population group is estimated to increase cheir risk of death from all cancers by $0.18 \%$ year. Offsite doses from external gamma-rays resulting from displaced tailings are believed to be not significantly higher than those received from exposure to the averane regional background radiation level $(10 \mu R / h r)$. A limited examination of potential population exposure through aquatic and terrestrial pathways led to the conclusion that it is likely that doses received through such exposure modes will be small as compared to those received through the racon diffusion pathway.
\end{abstract}




\section{INTRODUCTION}

This report is the second of a series on results of radiological surveys of uranium-mill tailings at inactive mill sites in the western United States that attempts to assess the spread of contamination from the sites and, in some -ijez, potential health effects of on- and offsite radiation. A complete list of the reports in this series is found at the front of this report. The previous report ${ }^{1}$ discusses the site at Salt Lake City, Utah, and it contains background information on the uranium-mill tailings problem that will not be repeated here. A general account of the mill-tailings survey work has been published. ${ }^{2}$ The present document deals with a site on land owned by the Navajo Natiun near Shiprock, New Mexico. The radiological survey sas conducted by an Oak Ridge National Laboratory (ORNL) survey team during February 23-29, 1976, in cooperation with a team from Ford, Bacon and Davis Utah Inc. (FB\&DU). That company has reported results $0:$ an engineering assessment of the uranium-mi!l tailings at the Shiprock site, including estimated costs of various methods of decontaminating the site and thus reducing potential health effects. ${ }^{3}$ This present assessment is based, in part, on results of the ORNL measurements that are included in the FB\&DU document. ${ }^{3}$ The present report serves as technical back-up for the engineering assessment, and it describes the equipment and techniques used to ohtain the data. Some of the data are presented in greater detail than in the earlier publication. ${ }^{3}$ Radiological data obtained by FB\&DU in the course of their engineering assessment, principally data en subsurface distribution of ${ }^{226}$ Ra, part of which have not been previously report.ed, are included here. Appendix I contains the complete report on a. 1974 site visit by Haldane and others, as well as a history of uranium operations at this location. Information irom the Haldane et al. report is summarized in the FB\&OU document. ${ }^{3}$ General discussions of the uranium-mill tailings problem and the assessinent. of the radiological impact of the radionuciides that the tailings contain are included in several publications. 4-7 
The Environmental Protection Agency (EPA) and other federal agencies were asked by the Navdjo Tribal Chairman, in November 1973, to provide assistance in stabilizing the tailings at the Shiprock site and in developing procedures for site decontamination. In response to this request, the EPA conducted radiation surveys around the site in April 1974 and, in October 1974, provided a tailings stabilization and decontamination plan to the Navajo Tribe. This plan, which is included as an appendix in Ref. 3, was later formalized by a staff memcer from the EPA's Of:ice of Radiation Programs-Las Vegas Facility (ORP-LVF) in a "Work Plan for the Decontamination of the Shiprock Uranium Mill Site" that divides the work into ten separate tasks (see Sect 2). Implementation of the plan was expedited by utilization of equipment and manpower already available at this site where the Navajo Engineering and Construction Authority (NECA) was training Navajo students to operate earth-moving equipment. In fact, prior to EPA involvement at the site in 1974, tailings in the lower (southern) tailings pile were moved around in the course of the student training program.

The status of the EPA work plan for the site is discussed in more detail in Sect. 2 of this report. It shoulc be recognized that this report presents an evaluation of site conditions as they existed in February 1976 when remedial action was already underway and that the radiulúgical hazards, both on and off the site, are quite different at the present as compared to conaitions at the time of the survey. The reader is referred to EPA-ORP-LVF, which is maintaining continuing surveillance of the site, for current information. Since the tailings piles were not removed from the site, data on the distribution of ${ }^{226} \mathrm{Ra}$ in the piles presented in this report are still relevant. 


\section{SITE DESCRIPIION}

In the aerial photograph of the Shiprock site (Fig. 1) the tailings site is shown in relation to nearby residential areas. The closest residential areas are approximately $0.8 \mathrm{~km}(0.5$ mile) west and soutmest from the tailings, whereas the center of Shiprock is approximately $1.6 \mathrm{~km}$ ( $1.0 \mathrm{mile}$ ) to the north.

The ore processing mill on this site was constructed by Kerr-McGee 0 il Industries, Inc., on land leased from the Navajo Nation and operated ty this company from 1954 to 1963 (Appendix I). From 1963 to mid-1968, the mill was operated by the Vanadium Corporation of America and its successor, Foote Mineral Company. During the life of the will, approximately 3366 metric tons of $\mathrm{U}_{3} \mathrm{O}_{8}$ in concentrat.e were produced from about 1.36 million metric tons of ore containing an average concentration of $0.25 \% \mathrm{U}_{3} \mathrm{O}_{8}$. These figures, togethei with an estimated uranium recrvery efficiency of 67\%, lead to a calculated value of $950 \mathrm{Ci}$ of $226 \mathrm{ra}$ in the tailings. Vanadium concentrate was also produced by the mill in 1955 and from 1960 to $1968 .^{3}$ Or expiration of the lease on this site in 1973, control of the site reverted to the Navajo Nation.

Figure 2 is a labelled photograph showing the location of drilled holes where data were obtained on subsurface distribution of ${ }^{226}$ Ra (see Sect. 5). The tailings are in two separate piles labelled upper ard lower tailings piles. The upper (north) pile is said ${ }^{3}$ to occupy an area of about 10.5 hectares ( 26 acres), to vary in depth from 4.3 to 12.2 in (14 to $40 \mathrm{ft}$ ), and to contain $64 \%$ (0.87 million metric tons) of the total amount of tailings on the site. The lower (south) pile is report$\mathrm{ed}^{3}$ to occupy an area of about 18.6 hectares ( 46 acres), to average $4.6 \mathrm{~m}(15 \mathrm{ft})$ in depth, and to contain $36 \%$ of the tailings ( 0.49 million metric tons).

In addition to surface and subsurface contamination by the mill tailings, large areas adjacent to the former mill building were contaminated by ore storage (Appendix I, Fig. 3). Before the time of the survey, most of the upper tailings pile had been stabilizea by application of 0.15 to $0.6 \mathrm{~m}(0.5$ to $2 \mathrm{ft})$ of pit-run soil and gravel which supported some natural plant growth. The entire surface of the lower 


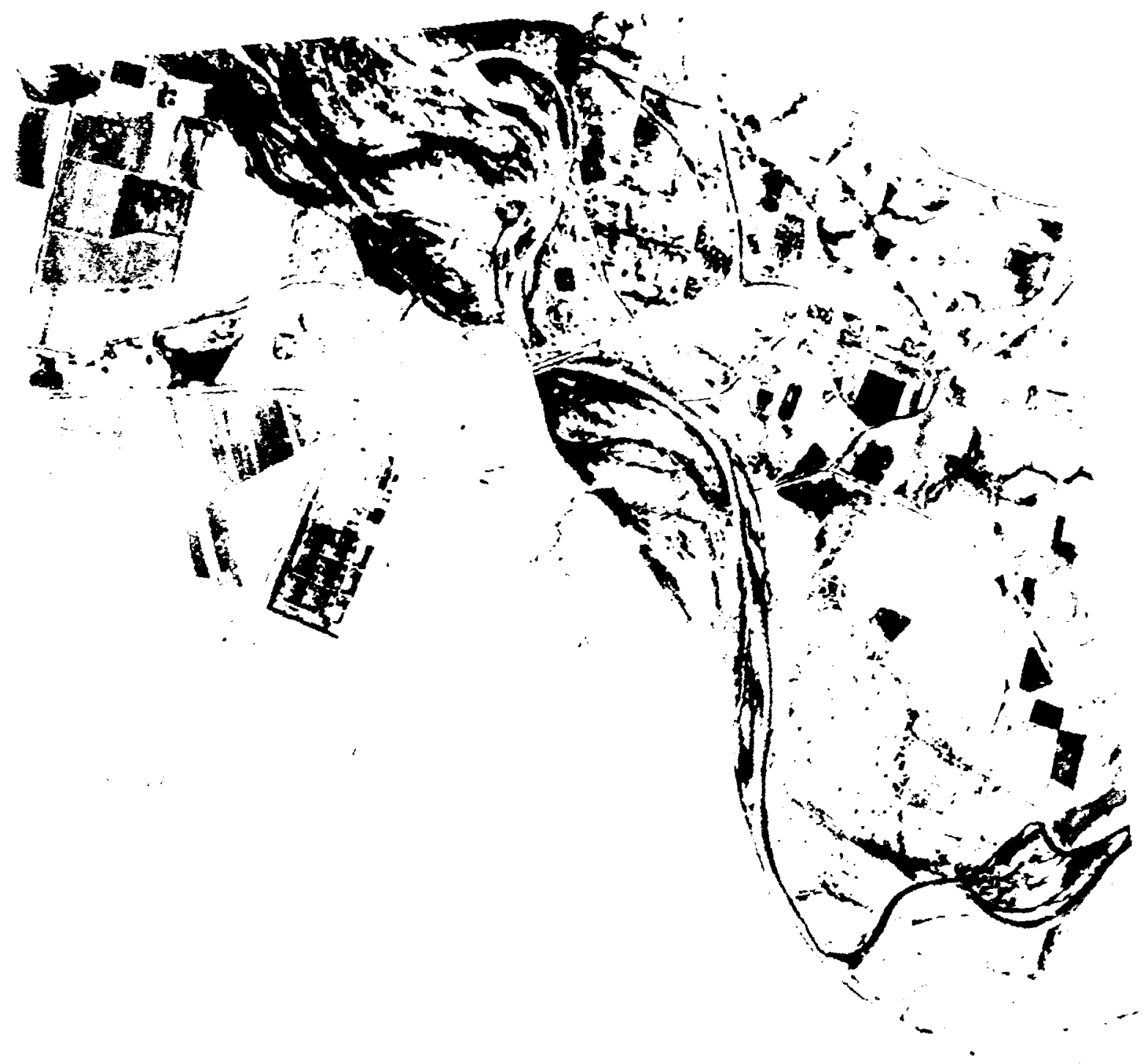

rose, ine. 
ORNL-Pho to 0415-79

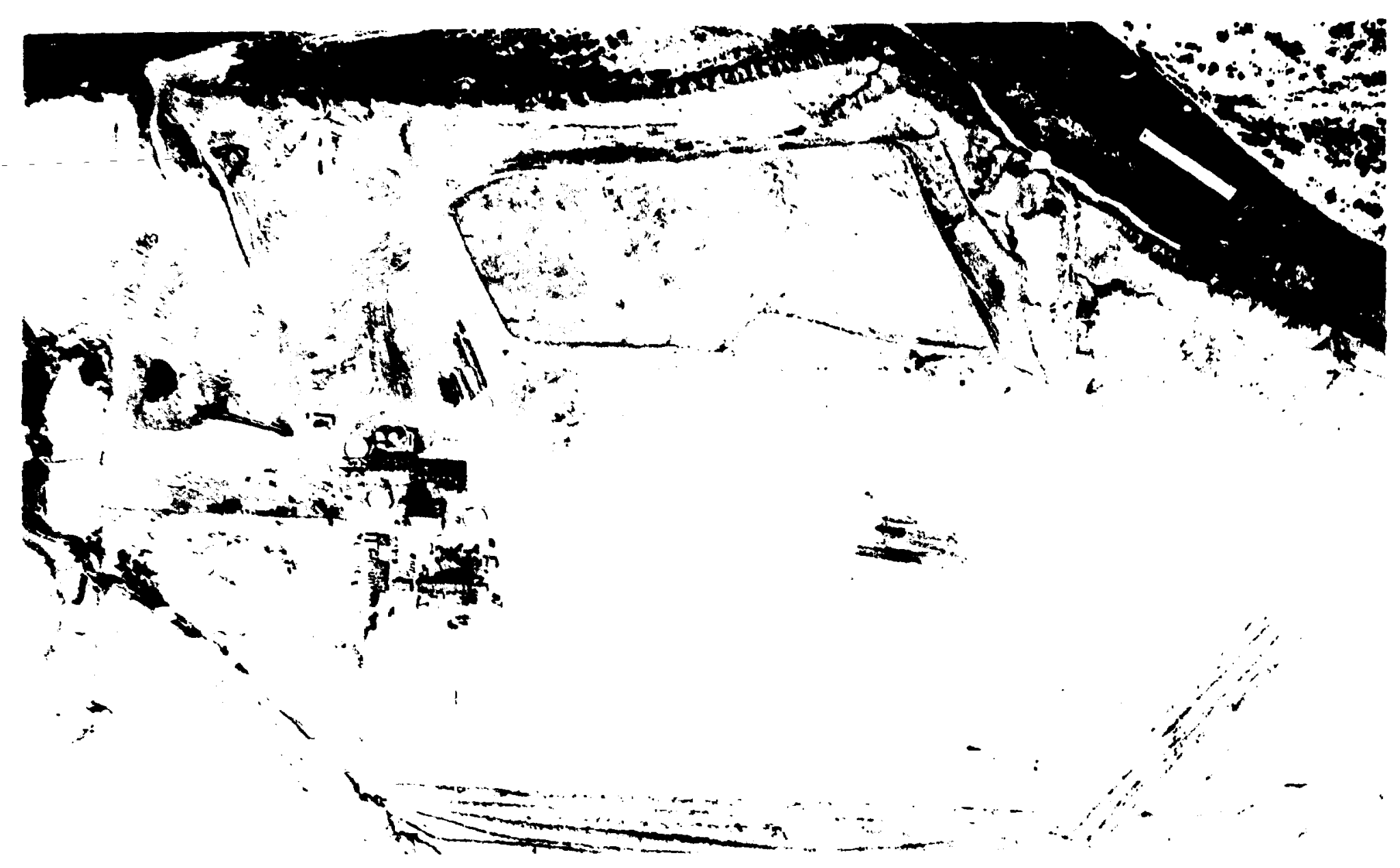

Fig. 2. Locations of holes drilied it the Shiprock site. uriginal photo by EG\&G, Inc. 
pi le was exposed at that time, and it had recently been disturbed by moving tailings around for practice purposes and by an adjustment of the western edge of the pile in the first stage of the ErA work program discussed below.

The diagram of the mill site shown in Fig. 3 indicates the areas to be decontaminated. This diagram, in conjunction with the block diagram of the EPA worx plan in Fig. 4, indicates the extent and the progression of tasks to be accomplished. At the time of the EPA progress report in May 1976 (ref. 3, Appendix B-2), it was estimated that the decontamination work was $70 \%$ complete and that Tasks 1 through 8 would be completed in September 1976. Altogether, it was estimated that completion of all tasks in the work plan would require movement of $430,000 \mathrm{~m}^{3}(562,000$ $y^{3}$ ) of material.

Unpublished information ${ }^{8}$ indicated that all of the planned decontamination work at this site had been completed by February 1978 with the exception of Area B (Fig. 3) and an area northwest of the fenced area plus the removal of one building (st.orage shed) in Area $D$ and $2.4 \mathrm{~m}$ $(8 \mathrm{ft})$ of soil underneath that building. Contaminated dirt from other areas of the site was used to cover the lower tailings pile to an average depth of $1.1 \mathrm{~m}(3.5 \mathrm{ft})$. Also, clean fill dirt was used to cover jome small areas of the upper pile where raw tailings were exposed. The dike on the river bluff side of this pile (Fig. 2) was completely rebuilt with contaminated soil from the ore-storage yard and a steep wash was partially filled and reinforced to prevent breakthrough of impounded water.

In summary, a large fraction of the decontamination work that was in progress at the Shiprock site at the time of our radiological survey in February 1976 has been completed and potential adverse health effects among people living around the site and among those working on the site has apparently been reduced as the result of this effort. It has been reported $^{9}$ that the average concentration of airborne tailings particles in Shiprock was reduced by a factor of 100 (presumably as compared to the results of a 1974 survey), direct gamma-ray exposure in the former 
ORNL-Photo $3004-79$

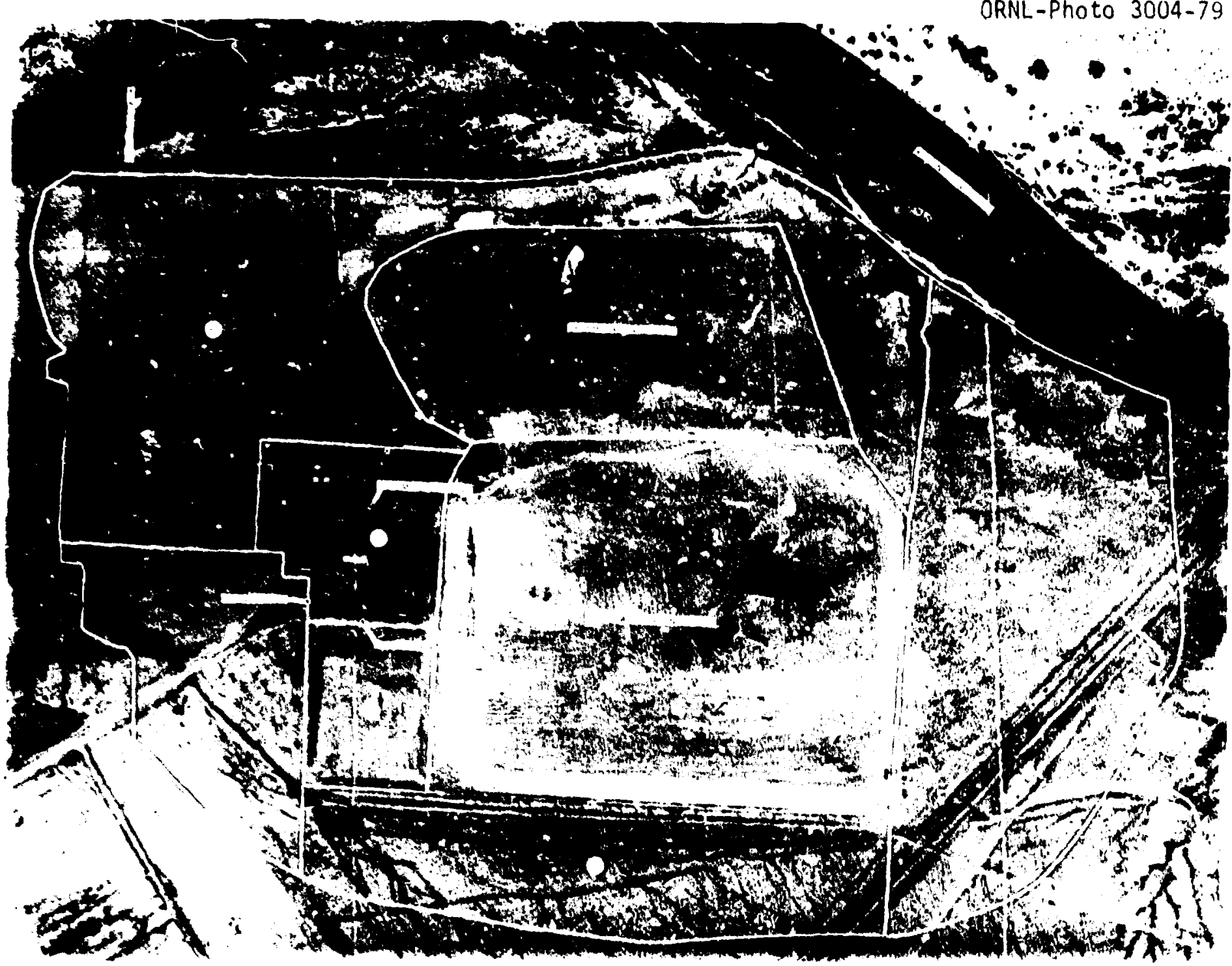

Fig. 3. Plot Plan for EPA Minimum Remedial Action Plan. Original photo by EG\&G, Inc 


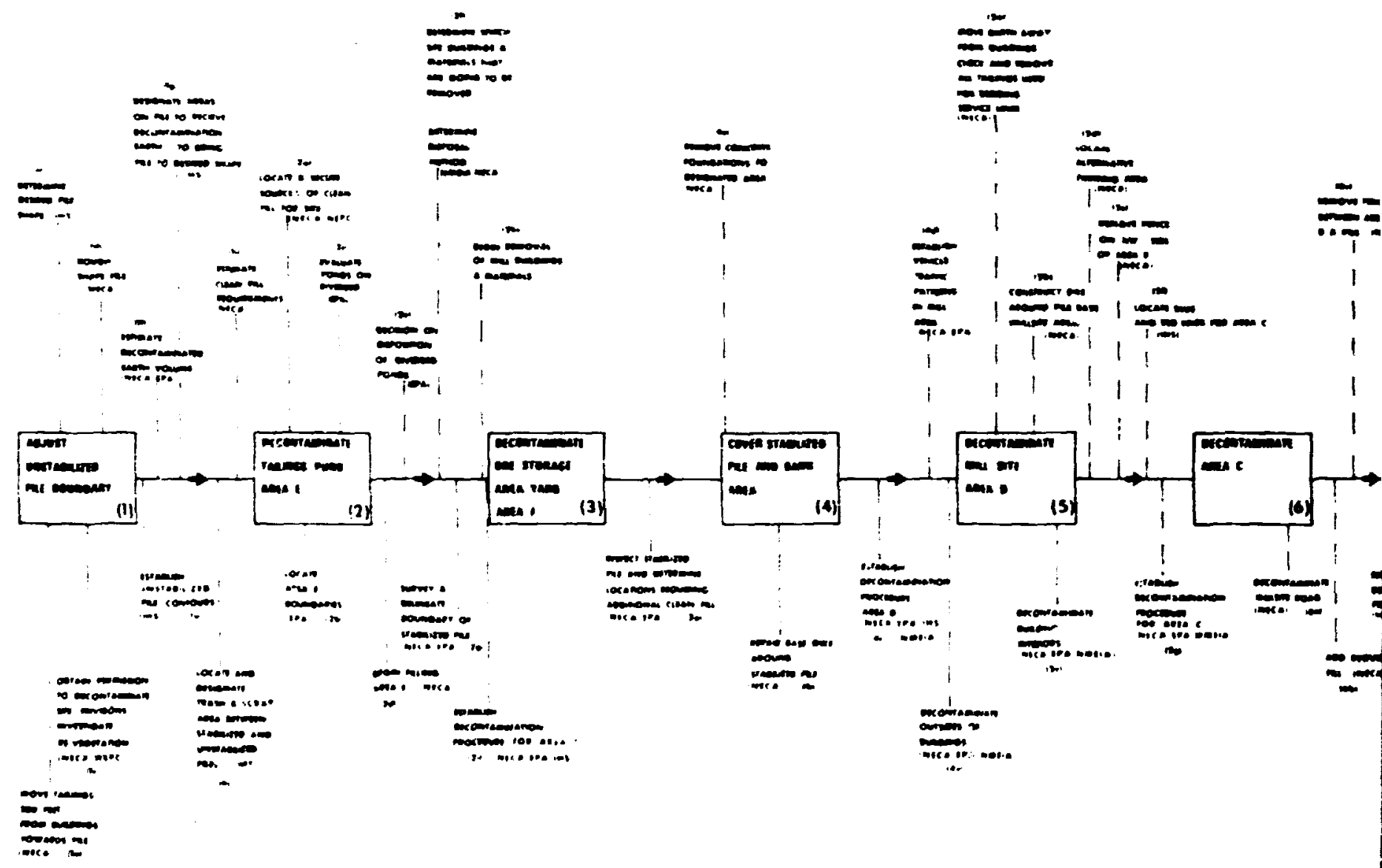

moca mavaso incimingme a comsteuction apimcentr

ins imoinw miactm stercel

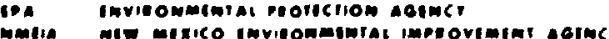

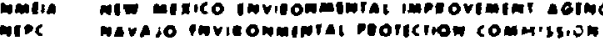

Fig. 4. EPA work plan for decontamination of the Sh Source: Ford, Bacon and Davis Utah Inc., Phase II - Title Assessment of Inactive Uranizon Mill Tailings, Shiprock Sit GJT-2 (March 1977). 
mill area was lowered by a factor of 3 to $30,:>$ and the radon source term for the tailings was reduced by a factor of 8.11

\section{EXPOSURE PATHWAYS}

The behavior of radionuclides in tailings piles and the potential modes of exposure of man to radiction from these radionuclides were discussed in a previous report, ${ }^{\prime}$ along with coverage of the pertinent literature. Briefly, the authurs' concurred with the conclusicir of earlier reports 4-7 $^{-7}$ that radon diffusion followed by inhalation of radon daughters is the most important exposure pathway. Other pathways involve: (1) inhalation of, iriu body surface contamination by, airborne tailings particles with ${ }^{230} \mathrm{Th}$ and ${ }^{231} \mathrm{~Pa}$ as the principal radionuclides of concern; (2) deposition of airborne tailings particles on soil or foliage followed by uptake by plants and/or intake by animals and consumption of contaminated plants, meat, and milk by man ( ${ }^{226} R a$ and $210 \mathrm{~Pb}$ are the principal radionuclides of concern in the terrestrial pathways); (3) dissolution of radionuclides in water and migration to water supplies where exposure to man could occur through consumption of contaninated drinking water, immersion il the water, uptake of nuclides by aquatic plants and animals followed by consumption by man $\left({ }^{226} \mathrm{Ra}\right.$ and $210 \mathrm{~Pb}$ are also the radionuclides of principal concern in the aquatic pathways); (4) and direct exposure to gamma radiation, principally from $2.5 \mathrm{Ra}$ and its daughters.

\section{SAMPLING TECHNIQUES AND RADIOLOGICAL MEAJURENENTS}

Sampling techniques as well as equipment and me chods used ror radiological measurements and for radiochemical analyses are descrited in Appendixes II and III.

\section{RESLLTS OF MEASUREMENTS}

Measurements were made at and near the Shiprock site to determine: (1) background external gamma radiation levels $1 \mathrm{~m}$ above the ground and 
the backgrourd radionuclide concentrations in soil samples; (2) external gamma exposure rates both on the site and in the area immediately arourd the site; (3) the radionuclide concentration in surface soil, sediment and water samples; (4) radon daughter corcentrations in occupied buildings on the former mill sice; (5) the subsurface distribution of ${ }^{226} \mathrm{Ra}$ and its daughters in tailings piles and in other contaminated areas as a function of depth; and (6) the concentration of airborne radionuclides Fesuits of these studies are discussed in separate sections below.

\subsection{Gackyround Radioactivity}

Knowledge of background external gama radiation levels and of background levels of radionuclides in soil is needed in order to mcasure the exteit of spread of tailings from the site and to Frovide data needed in implementing clean-up procedures. In Fig. 5, locations are given for nine points in the northwestern corner of New Mexico and one point in southern Colorado where the background external gamma exposure rate was measured at 1 : $(\sim 3 \mathrm{ft})$ above the gruund. Three or four ganma measurements were made at each location and surface soil samples were obtained. Data obtained at these ten locations are displayed in Table 1 , along with spezific information on the sample points. The average external gamma exposure rate measured $1 \mathrm{~m}$ above the ground $(10 \mu \mathrm{R} / \mathrm{hr}$ ) is equivalent tc a ccntinuous exposure rate of $88 \mathrm{millirem} / y e a r$. The ${ }^{226} \mathrm{Ra}$ concentration in surface soil samples ranoed from 1.1 to $2.6 \mathrm{pCi} / \mathrm{g}$ with an average of $2.2 \mathrm{pCi} / \mathrm{g}$. A larger range is noted in the $\$ 32$ Th concentration in the soil samples, 0.5 to $5.6 \mathrm{pCi} / \mathrm{g}$. If the latter, unusually high, result is excluded, the average drops from 1.5 to $1.0 \mathrm{pCi} / \mathrm{g}$, which is probably a more representative value for this region.

\subsection{Direct Gamma-Ray Exposure Rates}

Measurements were made of direct gamma-ray exposure rates, $1 \mathrm{~m}$ above tl.e ground, using the "Phil" gamma-ray dosimeter (see Appandix II), at 46-m (50-yd) intervals across the tailings piles and t.lrough the former mill area, and at $91-m(100-y d)$ intervals oute, de the fenced 


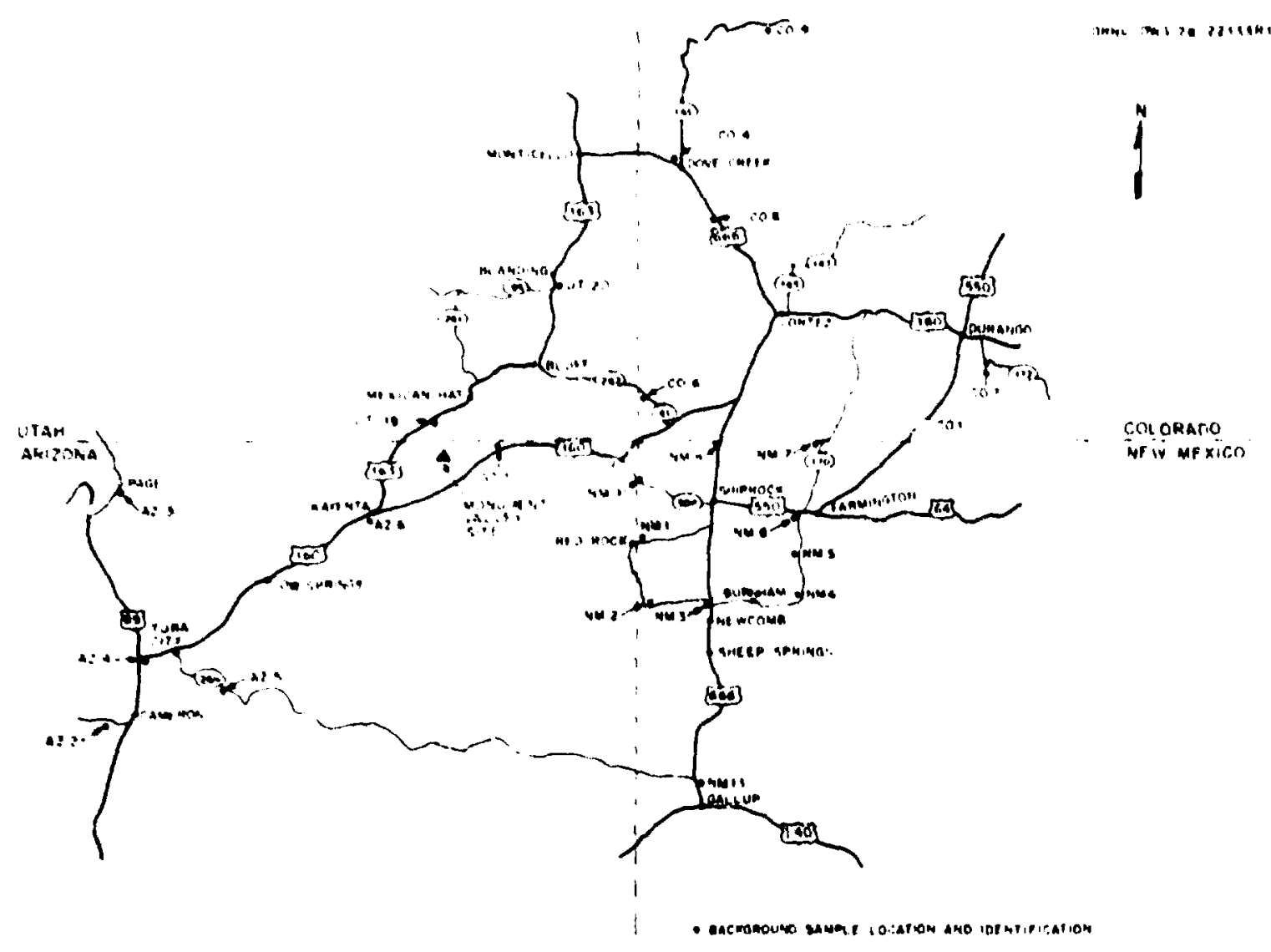

Fig. 5. Locations of external gamma measurements and background soil samples. 
Table 1. Background radiation levels and background concentrations of radionuclides in surface snil near Shiprock, New Mexico

\begin{tabular}{|c|c|c|c|c|c|}
\hline \multirow{2}{*}{$\begin{array}{l}\text { Sample } \\
\text { point }\end{array}$} & \multirow[b]{2}{*}{ Description of sample location } & \multirow{2}{*}{$\begin{array}{c}\text { External y } \\
\text { exposure rate a } \\
(\mu R / h r)\end{array}$} & \multicolumn{3}{|c|}{$\begin{array}{c}\text { Nucl ide Concuntration } \\
\text { in Soil (pCi/g) }\end{array}$} \\
\hline & & & $226 \mathrm{Ra}$ & $232 \mathrm{Th}$ & $238 U$ \\
\hline Nat 1 & $0.9 \mathrm{~km}$ east of Red Rock Trading Post $\sim 46 \mathrm{~m} \mathrm{~N}$ of road & 8 & 1.6 & 3.5 & 0.2 \\
\hline$m+2$ & $\begin{array}{l}\text { Road intersection at Beautiful Mountain overlooking } \\
\text { Sanostee }\end{array}$ & 15 & 2.6 & 1.8 & 0.7 \\
\hline MA-3 & $\begin{array}{l}\text { SW side of the intersection of Hwy } 666 \text { and road } \\
\text { to Sanostee }\end{array}$ & 10 & 1.1 & 0.9 & 0.4 \\
\hline$M-4$ & $\begin{array}{l}\text { About } 0.16 \mathrm{~m} \mathrm{~N} \text { of road intersection near Bitsi, } 91 \mathrm{~km} \\
\mathrm{~S} \text { of Farmington }\end{array}$ & 9 & 2.0 & 1.0 & 0.5 \\
\hline Na-5 & $\begin{array}{l}\text { Intersection of County Rd } 7 \text { and Farmington Rd at } \\
\text { La Vida Mission }\end{array}$ & 11 & 1.4 & 0.9 & 0.4 \\
\hline Mn-6 & Approx. $1.6 \mathrm{~km} \mathrm{~S}$ of river, SW of Farmington, $W$ side of h.vy & 8 & 1.3 & 1.0 & 0.4 \\
\hline $\mathbf{N A}-\mathbf{7}^{-}$ & $\begin{array}{l}\text { New Mexiru-Colorado border, } W \text { side of Hwy } 170 \text { in a } \\
\text { fence row }\end{array}$ & 9 & 1.9 & 1.3 & 0.5 \\
\hline NMA-8 & New Mexico-Colorado border, E side of Hwy 666 & 7 & 2.0 & 1.1 & 0.7 \\
\hline NM-9 & Arizona-New Mexico border, N side of thwy 504 & 6 & 1.3 & 5.6 & 0.5 \\
\hline \multirow[t]{2}{*}{ Col-1 } & $1.6 \mathrm{~km} \mathrm{~N}$ of Colorado-New Mexico border, E side of Hwy 550 & 14 & 11 & 1.1 & 0.4 \\
\hline & Average all locations & 10 & 1.7 & 1.7 & 0.5 \\
\hline
\end{tabular}

\footnotetext{
${ }^{z}$ One meter above ground.
} 
area. Results of these measurements are shown in Fig. 6 for the mill site and immediate area around it. Similar data are furnished by FB\&DU. ${ }^{3}$ Data obtained off the tailings area are displayed in Fig. 7.

If we assume that direct gamma-ray measurements significantly above the average area background value of $10 \mu R / h r$ are due to tailings containing ${ }^{226} \mathrm{Ra}$, it is apparent from Fig. 7 that contamination beyond the fenced area has spread in every direction except possibly toward the southwest. Raoiation leve?s in the former mill area are several times the background value. The need for decontamination of a rather large area in and around the mill site is apparent from the data in Fig. 6.

\subsection{Radionur lide Concentrations in Surface Soil and Sediment Samples}

Analysis of surface soil samples for ${ }^{226}$ Ra gives a more sensitive indication of spread of tailings and/or unprocessed ore than is prcvided by external gamma-ray measurement;. Therefore, surface soil samples were collecter at distances 180 to $914 \mathrm{~m}$ from the center of the pile (Fig. 8). Data in Table 1 show that the variation in concentration of ${ }^{226} \mathrm{Ra}$ in barkground soil samples was relatively small (max./min. $=2.3$ ). Thus, the data in Table 1 provide a reasonable base-line value for ${ }^{226} \mathrm{Ra}$ concentration $(1.7 \mathrm{pCi} / \mathrm{g})$. Since contaminated material can be moved by waier as well as by wind, sediment. sampies were obtained trom six locations on the San Juan River and at three spots in a dry wash near the northeast edge of the upper tailings pile (Fig. 8). At the latter points, samples were obtained at the surface and at $15 \mathrm{~cm}(0.5 \mathrm{ft})$ below the surface. Results for the above-mentioned soil samples are showr in Table 2.

Most of the data in Table 2 were reported earlier (ref. 3, Fig. 3-11), but the ${ }^{226}$ Ra concentration in the suriace portion of th dry wash sample nearest the river (SOW5) was erroneously shown as $0.4 \mathrm{pCi} / \mathrm{g}$ instead of 4.0 pciig.

The data in Table 2 confirm, in general, observations on the movement of tailings or ore based on measuremencs of direct gamma-ray levels 


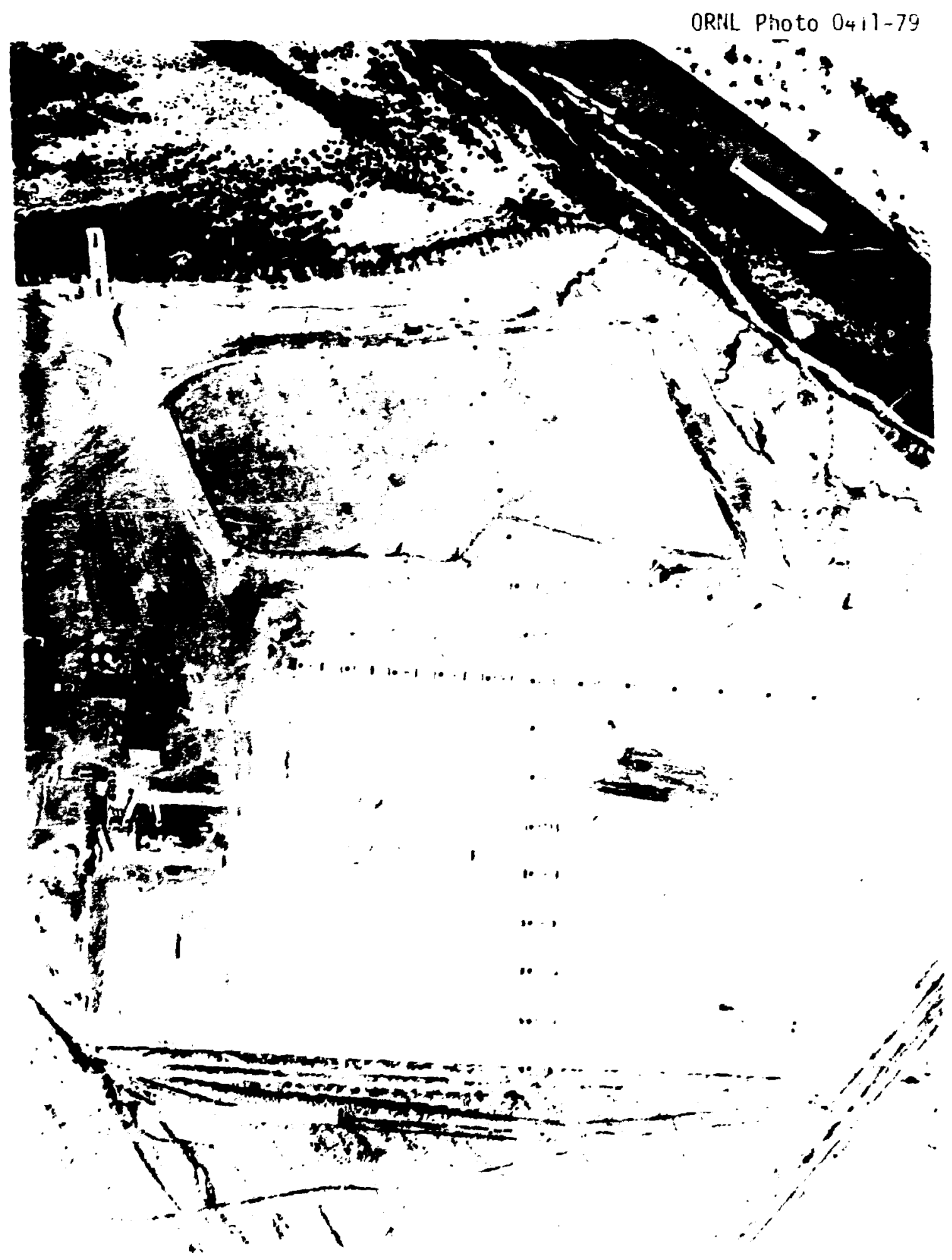

Fig. 6. Direct gamma-ray measurements $1 \mathrm{~m}$ above the ground at and near the mill site. Oriqinal photo by EG\&G. Inc. 


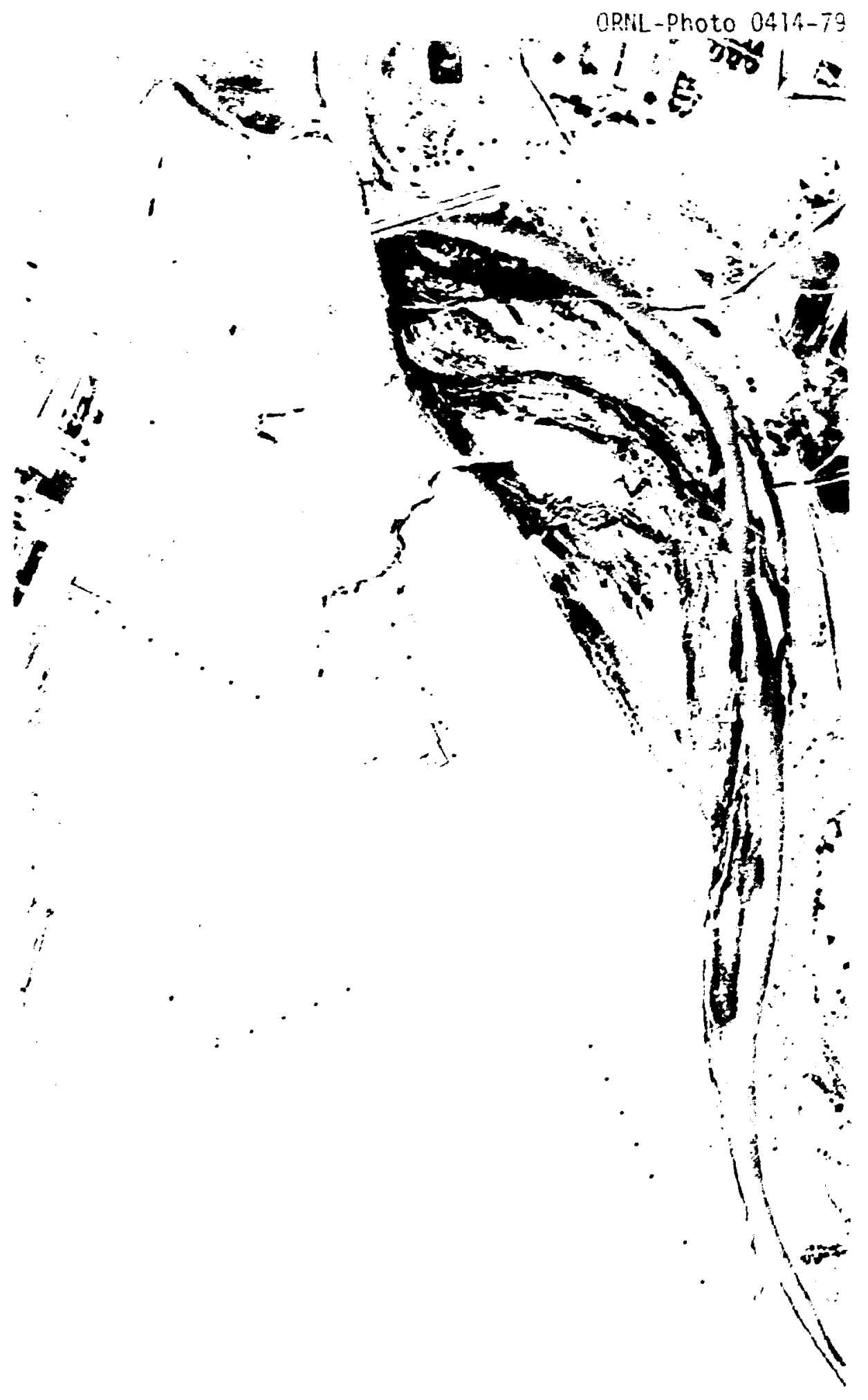

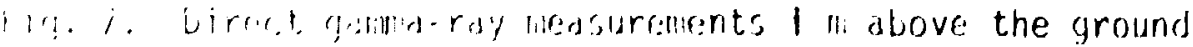

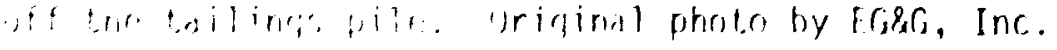




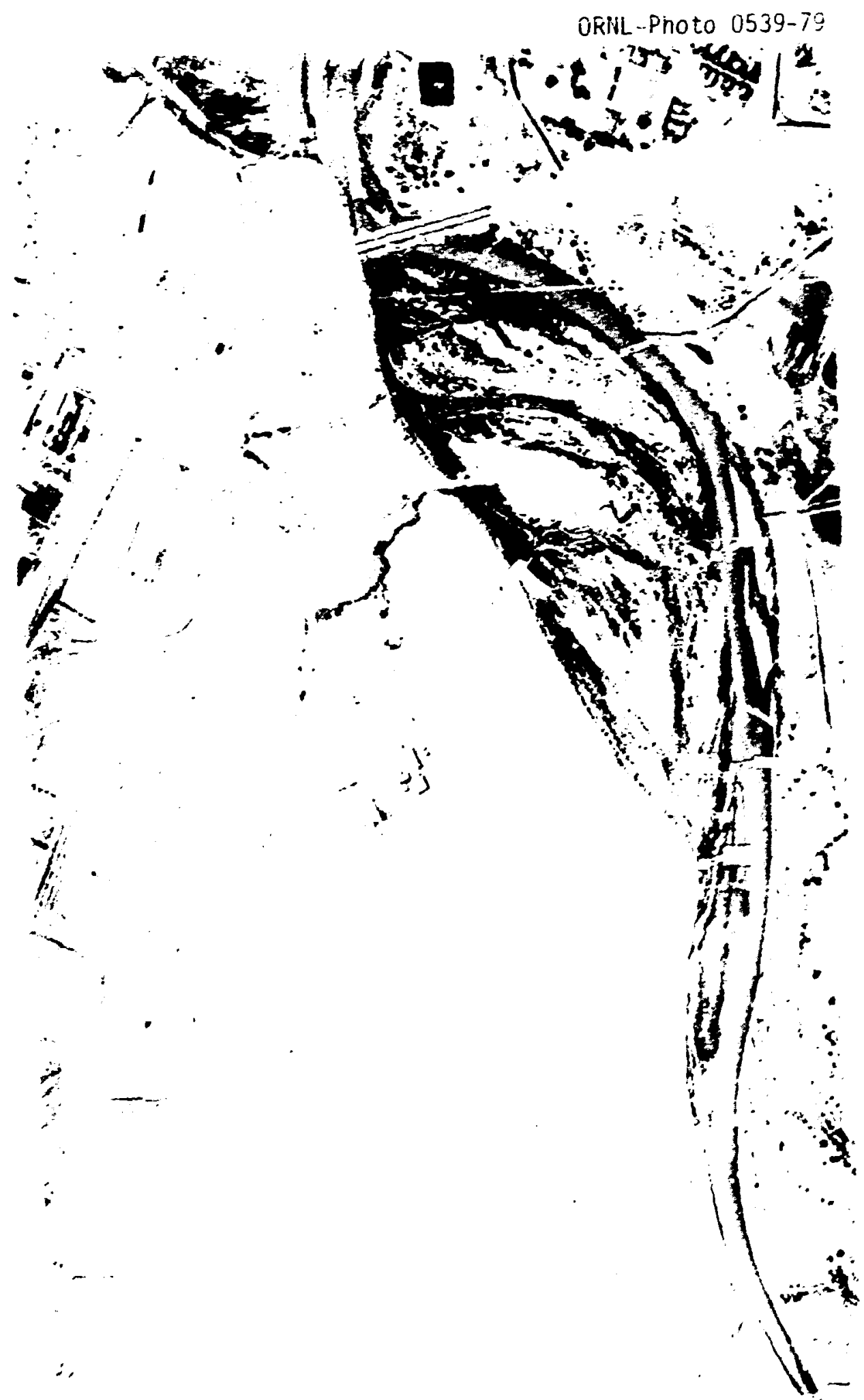

Fig. 8. Locations and identifications of envirormental samples. Orininai photo by FG\&G, Inc. 
Table 2. Concentration of ${ }^{226} \mathrm{Ra}$ and ${ }^{232} \mathrm{Th}$ in surface and near-surface soil

\begin{tabular}{|c|c|c|c|}
\hline \multirow{2}{*}{$\begin{array}{c}\text { Sample } \\
\text { designation }\end{array}$} & \multirow[b]{2}{*}{ Sample location and description } & \multicolumn{2}{|c|}{$\begin{array}{l}\text { Nuclide concentration } \\
(\mathrm{pCi} / \mathrm{g}) \\
\end{array}$} \\
\hline & & ${ }^{226} \mathrm{Ra}$ & ${ }^{232} \mathrm{Th}$ \\
\hline SRNMI & $\begin{array}{l}\text { Surface soil taken } 183 \mathrm{~m}(200 ;-\mathrm{d}) \text { from } \\
\text { southeast edge of tailings pile }\end{array}$ & 17 & 0.84 \\
\hline SRN:i*2 & $\begin{array}{l}\text { Surface soil taken } 365 \mathrm{~m}(400 \mathrm{yd}) \text { from } \\
\text { southeast edge of tailings pile }\end{array}$ & 7 & 0.79 \\
\hline SRNM3 & $\begin{array}{l}\text { Surface soil taken } 548 \mathrm{~m}(600 \mathrm{yd}) \text { from } \\
\text { scutheast edge of tailings pile }\end{array}$ & 3 & 0.70 \\
\hline SRNM4 & $\begin{array}{l}\text { Surface soil taken } 731 \mathrm{~m}(800 \mathrm{yd}) \text { from } \\
\text { southeast edge of tailings pile }\end{array}$ & 2.4 & 0.71 \\
\hline SRNM5 & $\begin{array}{l}\text { Surface soil taken } 183 \mathrm{~m}(200 \mathrm{yd}) \text { from } \\
\text { southwest edge of tailings pile }\end{array}$ & 1.4 & 0.75 \\
\hline SRNM7 & $\begin{array}{l}\text { Surface soil taken } 548 \mathrm{~m}(600 \mathrm{yd}) \text { from } \\
\text { southwest edge of tailings pile }\end{array}$ & 0.98 & 0.88 \\
\hline SRNM9 & $\begin{array}{l}\text { Surface soil taken } 548 \mathrm{~m}(600 \mathrm{yd}) \text { from } \\
\text { northwest edge of tailings pile }\end{array}$ & 2.2 & 0.74 \\
\hline SNRMIO & $\begin{array}{l}\text { Surface soil taken } 548 \mathrm{~m}(600 \text { yd) from } \\
\text { :.urthwest corner of tailings pile }\end{array}$ & 3.0 & 0.93 \\
\hline SRNM11 & $\begin{array}{l}\text { Surface soil taken } 731 \mathrm{~m}(800 \mathrm{yd}) \text { from } \\
\text { northwest corner of tailings pile }\end{array}$ & 2.1 & 0.83 \\
\hline S800E & $\begin{array}{l}\text { Surface soil taken } 731 \mathrm{~m}(800 \mathrm{yd}) \text { east } \\
\text { of tailings pile }\end{array}$ & 8.3 & $a$ \\
\hline SOW-1 & $\begin{array}{l}\text { Surface dry wash approximately } 22 \mathrm{~m} \\
(25 \mathrm{~d}) \text { from northeast corner of } \\
\text { tailings pile }\end{array}$ & 18 & $a$ \\
\hline SOW-2 & $\begin{array}{l}\text { Soil } 15 \mathrm{~cm} \text { below surface, same } \\
\text { point as SWD-1 }\end{array}$ & 470 & $a$ \\
\hline SDW-3 & $\begin{array}{l}\text { Surface dry wash } 228 \mathrm{~m}(250 \mathrm{yd}) \\
\text { east of tailing pile }\end{array}$ & 8.3 & 1.8 \\
\hline
\end{tabular}


Table 2. (continued)

\begin{tabular}{|c|c|c|c|}
\hline \multirow{2}{*}{$\begin{array}{l}\text { Sample } \\
\text { designation }\end{array}$} & \multirow[b]{2}{*}{ Sample location and description } & \multicolumn{2}{|c|}{$\begin{array}{l}\text { Nuclide concentration } \\
(\mathrm{pC} \mathrm{i} / \mathrm{g})\end{array}$} \\
\hline & & ${ }^{226} \mathrm{Ra}$ & $232 \mathrm{Th}$ \\
\hline SOW-4 & $\begin{array}{l}\text { Soil } 15 \mathrm{~cm} \text { b-low surface, same } \\
\text { point as SDW-3 }\end{array}$ & 6.1 & 1.7 \\
\hline SOW-5 & $\begin{array}{l}\text { Surface soil approximately } 46 \mathrm{~m} \\
\text { ( } 50 \text { yd) downstream from SDW-3 and } \\
\text { SDW-4, } 15 \mathrm{~m} \text { from river }\end{array}$ & 4.0 & 1.3 \\
\hline SDW-6 & $\begin{array}{l}\text { Soii } 15 \mathrm{~cm} \text { below surface, same point } \\
\text { as SOW-5 }\end{array}$ & 3.3 & 1.0 \\
\hline SWS-1 & $\begin{array}{l}\text { Sedimen:- sample } 914 \mathrm{~m}(1000 \mathrm{yd}) \\
\text { upstream from tailings pile }\end{array}$ & 46 & $a$ \\
\hline SWS-2 & $\begin{array}{l}\text { Sediment sample } 457 \mathrm{~m} \text { ( } 500 \text { yd) } \\
\text { upstream from tailings pile }\end{array}$ & 25 & $a$ \\
\hline SWS-3 & $\begin{array}{l}\text { Sediment where dry wash empties into } \\
\text { river from northeast of tailings pile }\end{array}$ & 5.2 & 1.4 \\
\hline SWS-4 & $\begin{array}{l}\text { Sediment northwest side of tailings } \\
\text { pile }\end{array}$ & 2.6 & 1.0 \\
\hline SWS-5 & $\begin{array}{l}\text { Sediment soil from half-way between } \\
\text { SWS- } 4 \text { and river bridge }\end{array}$ & 2.9 & 1.1 \\
\hline SWS-6 & $\begin{array}{l}\text { Sediment beneath bridge over San Juan } \\
\text { River }\end{array}$ & 17 & a \\
\hline
\end{tabular}

${ }^{a}$ This nuclide not sought. 
I $m$ above the ground (Fig. 7). Higher-than-background concentrations of $226 \mathrm{Ra}$ are noted in every direction from the tailings piles except toward the southeast. There is no obvious explanation for the observation of a higher ${ }^{226} \mathrm{Ra}$ concentration in the sediment sample taker: upstream from the tailings (SWSI) than at points SWS3 and SWS4 immediately downstream from the tailings where the level is only slightly higher than the average background soil value $(1.7 \mathrm{pCi} / \mathrm{g})$.

The high concentration of ${ }^{226} \mathrm{Ra}$ in dry wast sample SDW2 taken at a point $23 \mathrm{~m}$ ( $25 \mathrm{yd}$ ) from the upper tailings pile shows that tailings have moved toward the river and, unless preventative measures are adopted, will eventually be washed into the river.

The roncentration of ${ }^{232} \mathrm{Th}$ was measured in some of the soil and sediment samples. All measured values fell within the range observed in background samples (Table 1).

\subsection{Radiochemical Analysis of Water}

The positions from which two watei samples were removed for radiochemical analysis are shown in Fig. 8. One sample (SW2) was taken from a pond just to the north of the former mill buildings, whereas the other (SWI) was removed from a stagnant pond in the flood plain of the San Juan River at the northeast corner of the mill site. These samples were analyzed using the procedure outlined in Appendix III. Sample SWl contained $2.1 \mathrm{pCi}$ of ${ }^{226} \mathrm{Ra}$ per liter of water while SW2 contained $3.5 \mathrm{pCi} /$ liter. Results of chemical analys is of several wat.r samples have been reported by FB\&DU. 3

In contrast to the Vitro site at Salt Lake City ${ }^{l}$ where the water table is oniy a few feet below the surface, no water was observed in holes drilled at the Shiprock site for measurement of the subsurface distribution of ${ }^{226} \mathrm{Ra}$. 


\section{Radon Daughter Measurements}

Measurements of airborne radon daughters by ORNL at the Shiprock site were limited to a single determination in the NECA classroom build.ng in the former mill area and a series of measurements over a 21-hr period in the NECA office building. The school building measurement yielded a low daughter concentration $(0.0016 \mathrm{WL})$. The measurements in the NECA office building are plotted as a function of time in Fig. 9 along with results of simultaneous radon measureme.ts by $F B \& D U,{ }^{3}$ and the radon daughter data are presented in more detail in Table 3 where the statistical uncertainty in the calculated daughter concentration is shown in parentheses. The data show the normal diurnal variation in radon and radon daughter concentration.

Other radon measurements by FB\&DU ${ }^{3}$ on and off the site showed that the ${ }^{222} \mathrm{Rn}$ concentration outdoors varied from 0.7 to $12 \mathrm{pCi} / 1$ iter (the latter on the top of the upper tailings pile) with an average of 1.0 $\mathrm{pCi} /$ iter for offsite locations $1.2 \mathrm{~km}(0.75 \mathrm{mile})$ or more from the piles.

Calculation of a radon source term and flux for the tailings is discussed in Sect. 6 of this report. Measurements of radon exhalation flux from the tailings pile made at the time of the present survey and a few months later (June 1976) were compared ${ }^{3}$ with earlier EPA measurements. 12

The guidelines most frequently quoted for radon daughters in occupied areas are the remedial action criteria promulgated by the Surgeon General for the Grand Junction, Colorado, area. ${ }^{13}$

\subsection{Concentration of ${ }^{226} \mathrm{Ra}$ in Soil Beneath the Surface}

The location of holes drilled to varying depths by FB\&OU in order to measure the subsurface distribution of ${ }^{226} \mathrm{Ra}$ is shown in Fig. 2. Measurements of the gamma radiation level in these holes, as a function of depth, were also made by FB\&DU using the technique described in Appendix II. Subsurface soil samples obtained either by FB\&DU or ORNL 
ORNL-OWG $78-22312$

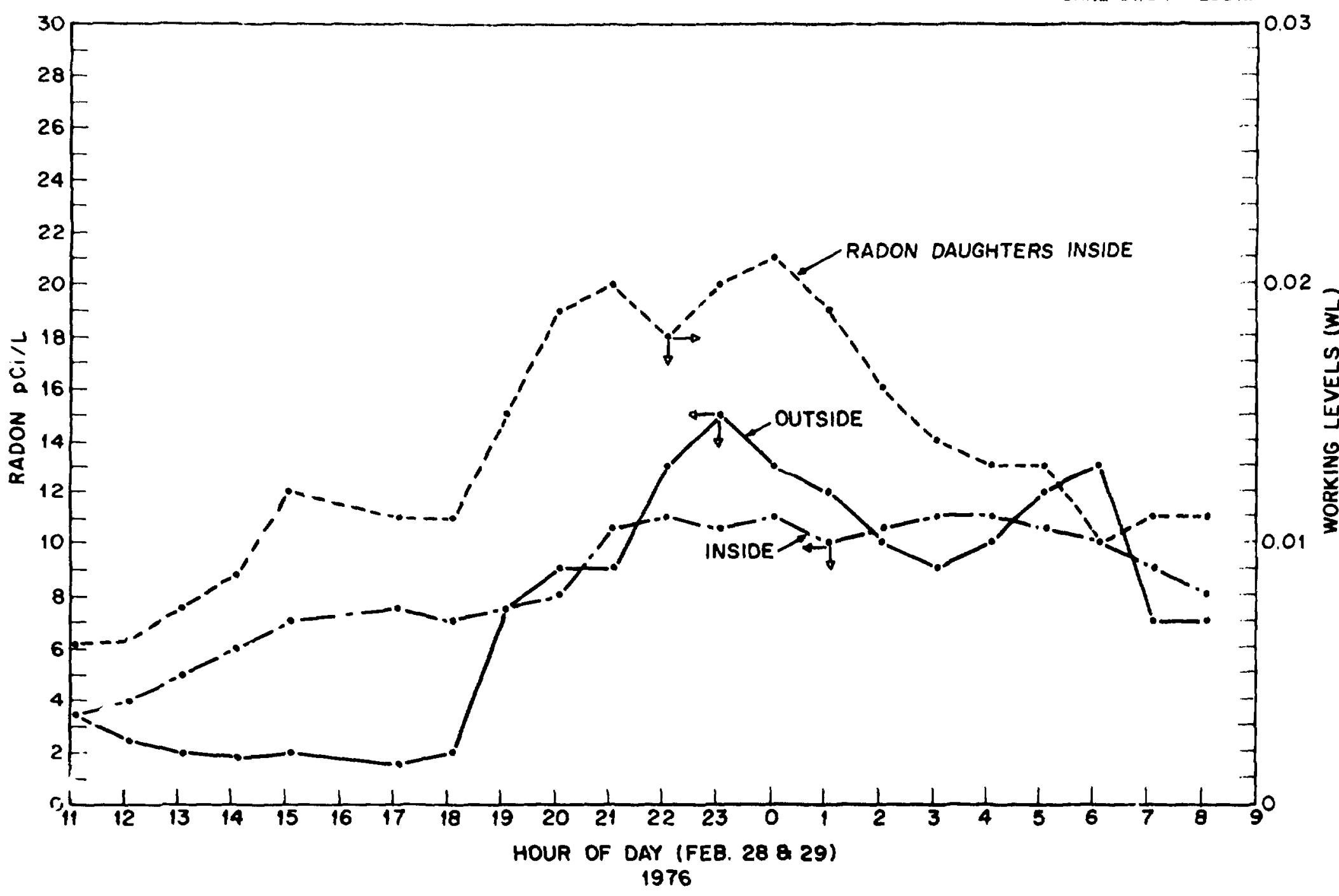

Fig. 9. Radon and radon daughter concentrations in and near the NECA office building at Shiprock on February 28-29, 1976. 


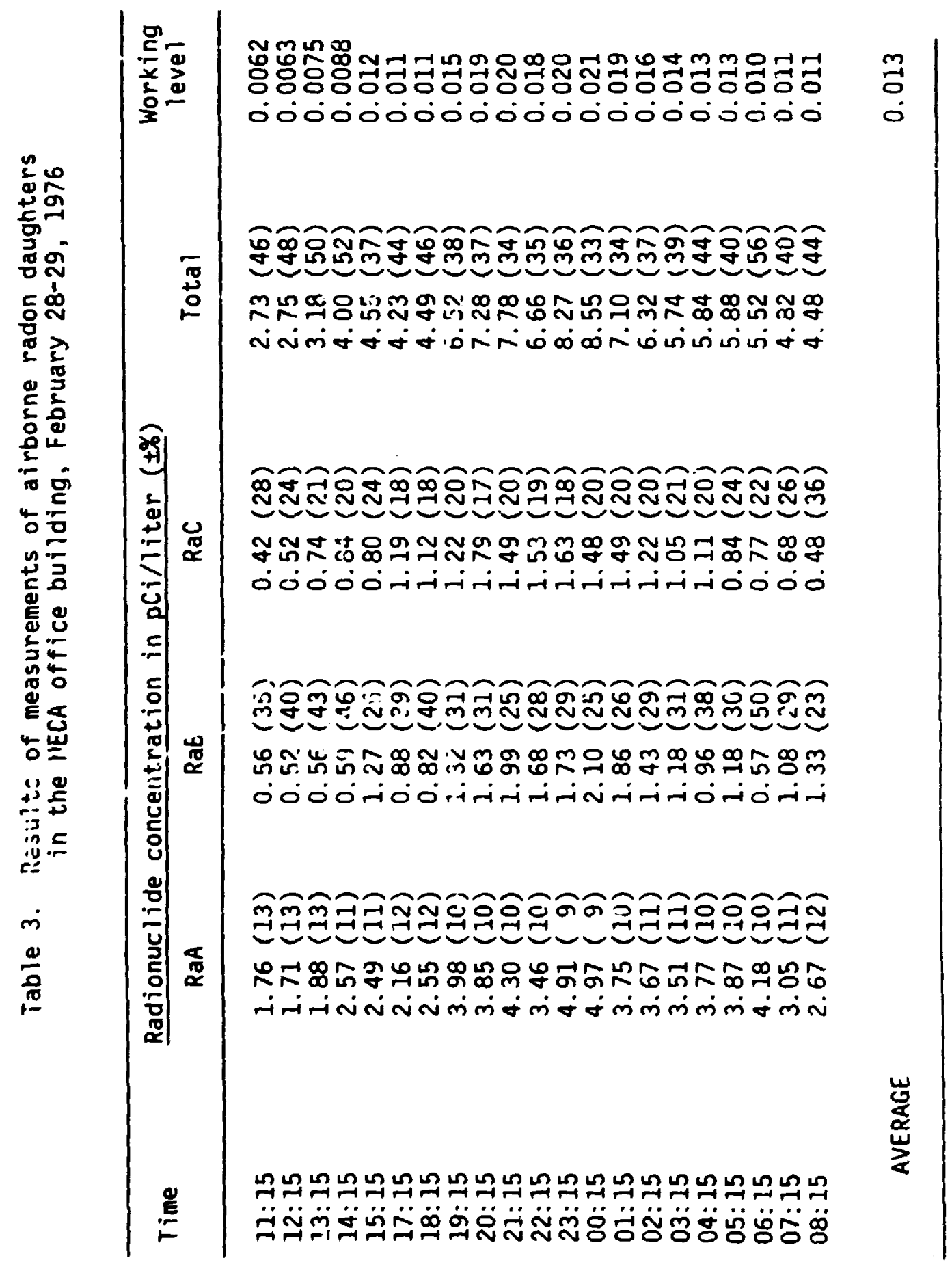


were analyzed at ORNL. For some holes, only composite samples were taken; but for others, samples were removed at identifiable depths below the surface. Since the garma radiation beneath the surface is due primarily to ${ }^{226} \mathrm{Ra}$ and its daughters, it is possibie to correlate the gamma monituring data with ${ }^{226} \mathrm{Ra}$ concentration hy use of the ORNL analytical dati. Plots of calculated ${ }^{226}$ Ra concentration as a function of depth for holes 23 and 15 (Fig 2 ) have been published by FBeDU (ref. 3, Fig. 3-12 and 3-13), along with ORNL analytical Jata, showing the extent of agreement between calculated and analyzed values.

The correlatio: of data is complicated by a change in gama probes that occurred late in the day on February 25. The new probe was considerably less sensitive than that used previously, but data from relogging of two holes (15 and '3) with the new probe permits a correction to be made for the change in probe sensitivity. The data from hole 15 are believed to provide a more reliable correction factor because the ratio (new probe $\mathrm{cpm} / \mathrm{old}$ probe $\mathrm{cpm}$ ) for corresponding depths varied from 0.44 to 0.70 with an average vaiue of 0.55 , while for hole 23 this ratio varied from 0.19 to 0.83 with an average of 0.48 .

Plots of calculated concentration of ${ }^{226} \mathrm{Ra}$ as a function of depth below the surface are displayed in Figs. 10 to 15, inclusive. Although a great deal of reliance should not be placed on the accuracy of the calculated concentrations, the gamma probe readings do provide a sensitive indication of the spatial distribution of ${ }^{226} \mathrm{Ra}$ beneath the surface. It should be recognized as was mentioned in sect. 1 that addition of dirt over all of the lower pile and part of the upper pile will require adjustment in the data for the holes with added cover dirt. Also, it should be mentioned that some of the cover dirt is contaminated :ith ${ }^{226} \mathrm{Ra}$.

\subsection{Concentration of Airborne Radionuclides}

The data in Fig. I demonstrate movement of tailings and/or ore particles in several directions. Efforts were made tn measure the concentration of airborne radioactive particles by collecting them on the 
ORNL-DWG 79-9407

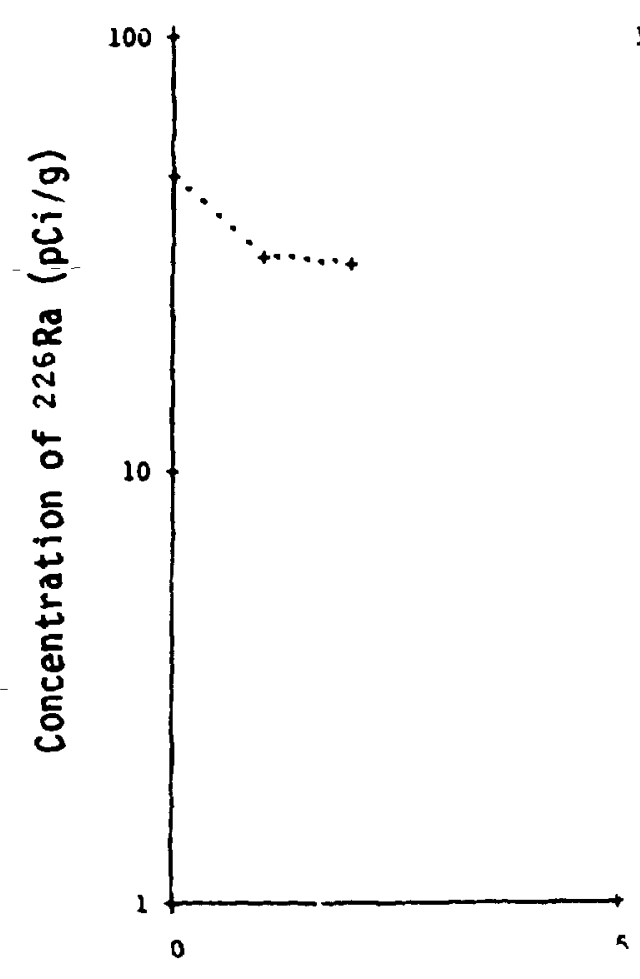

9

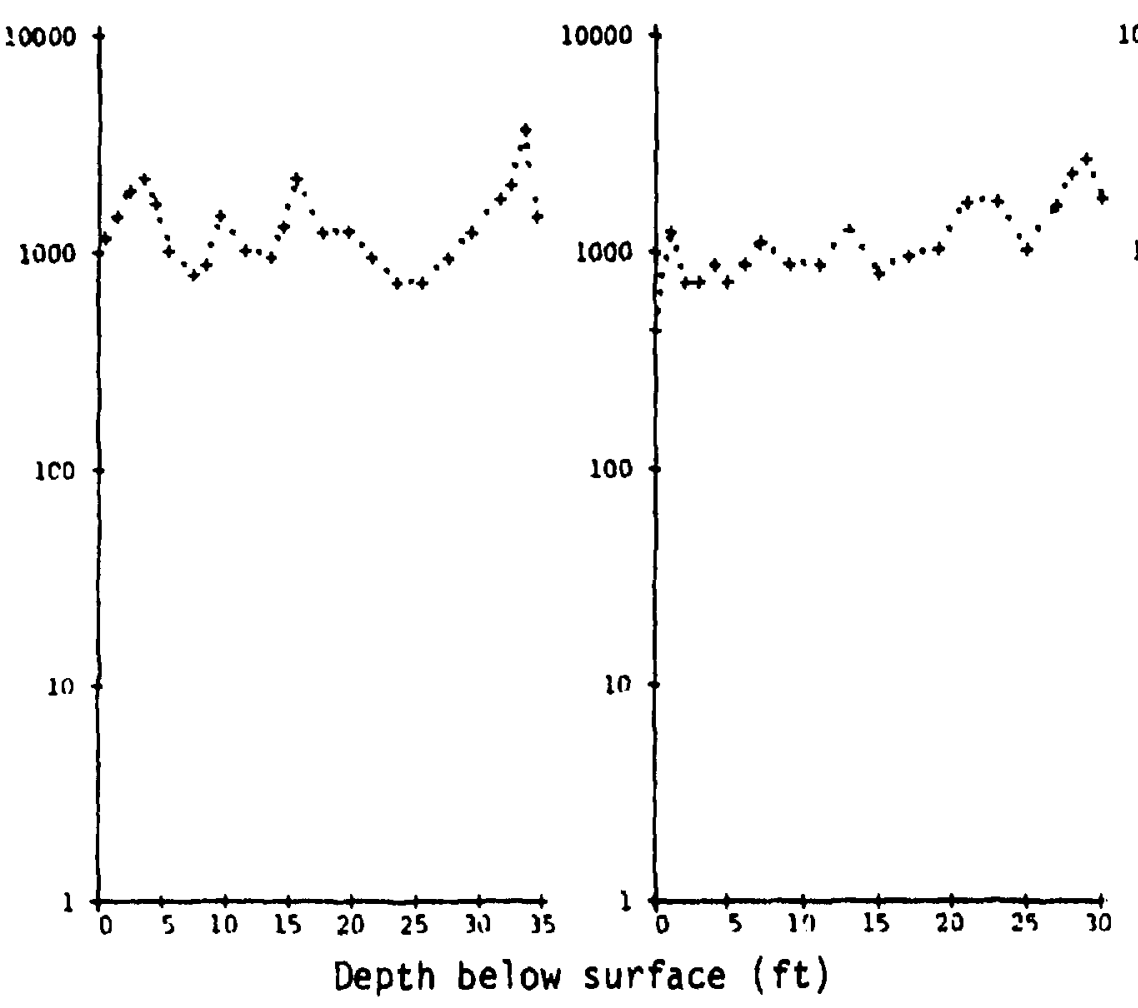

10

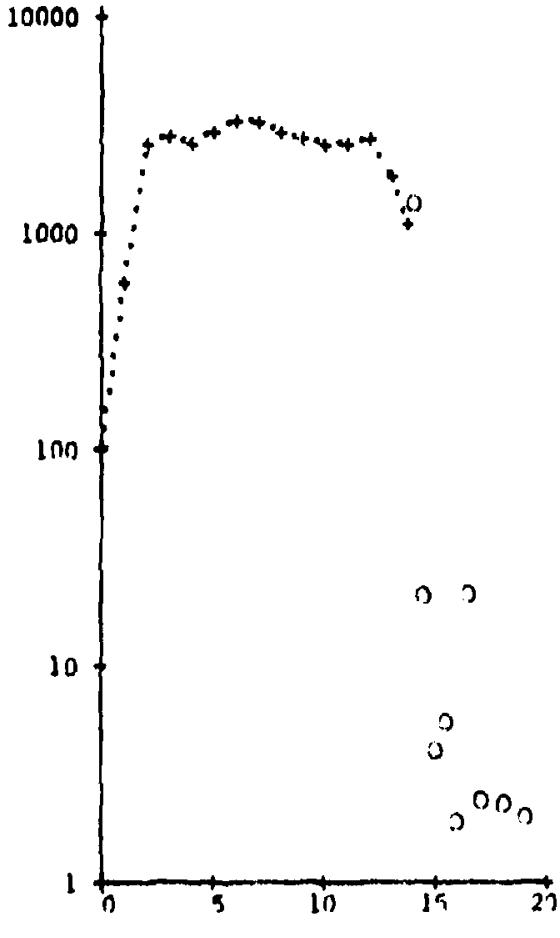

12

Fig. 10. Calculated concentrations of $226 \mathrm{Ra}$ in holes 9, 10, 11, and 12. (Values noted by circles in hole 12 represent data from the analysis of individual soil samples.) 
ORNL-DWG 79-9408

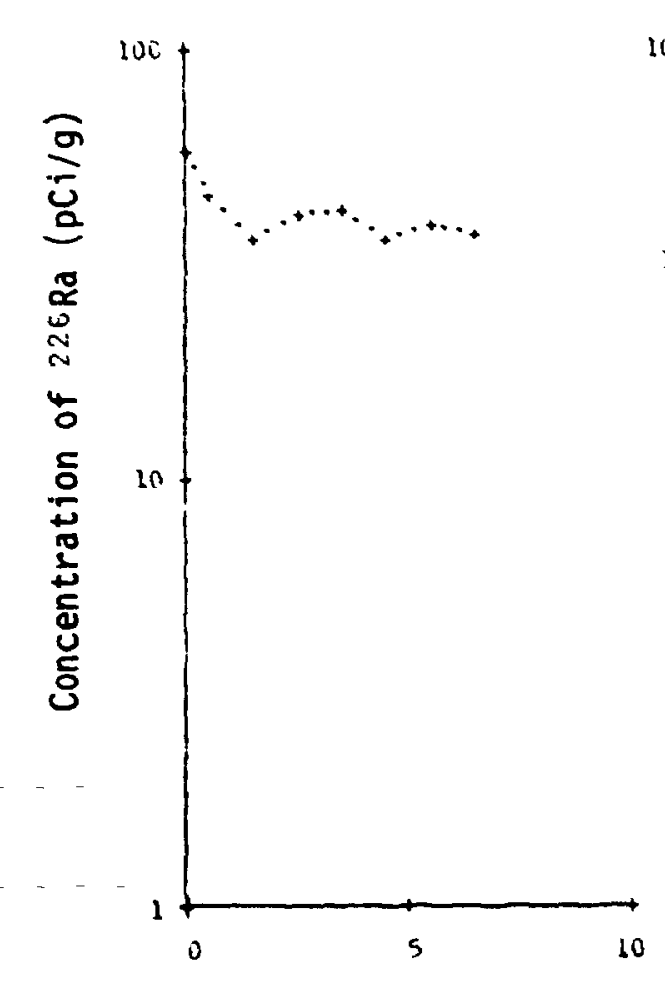

13

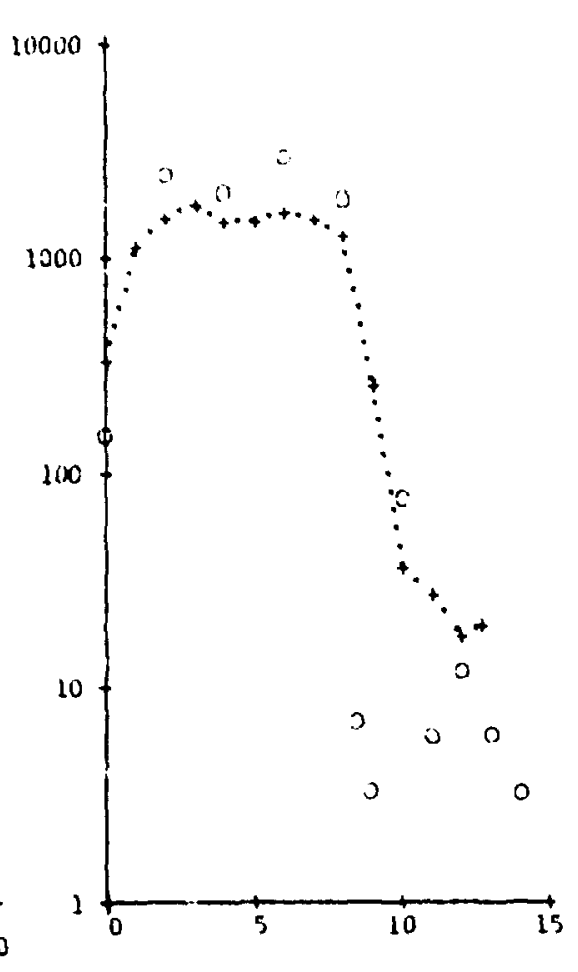

Depth below surface (ft)

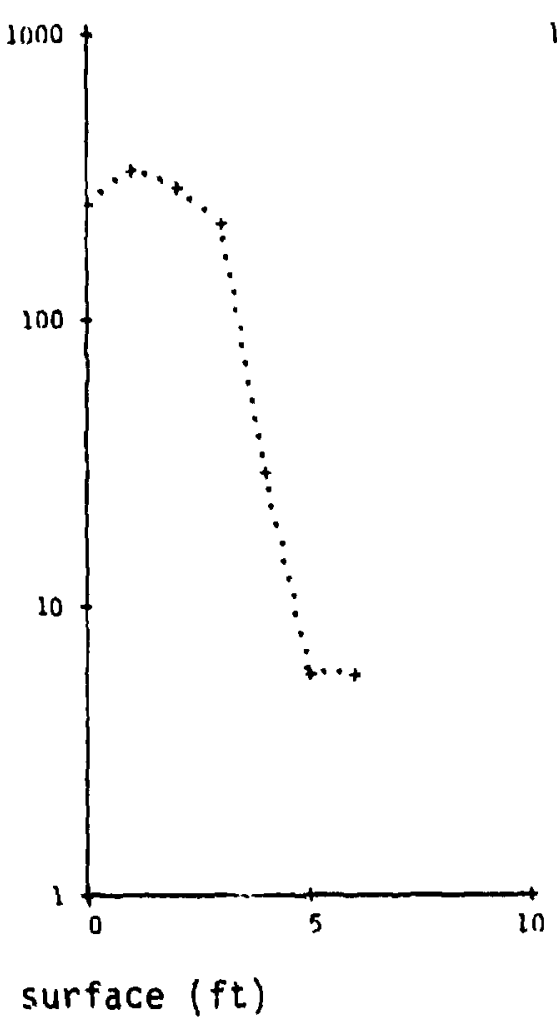

16

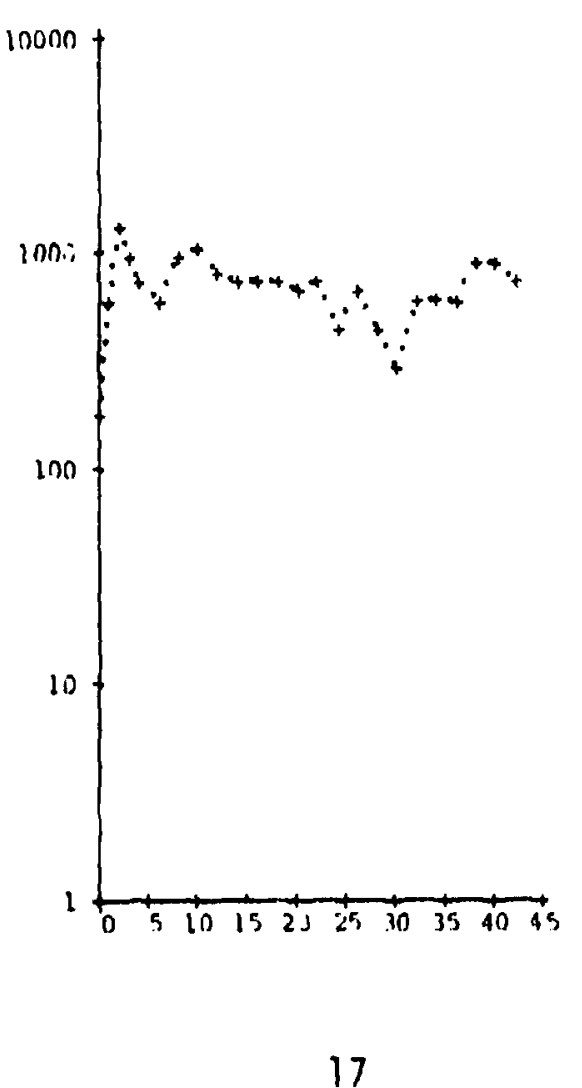

Fig. 11. Calculated concentrations of $226 \mathrm{Ra}$ in holes $13,15,16$, and 17 . (Values noted by circles in hole 15 represent data from the analysis of individual soil samples.) 


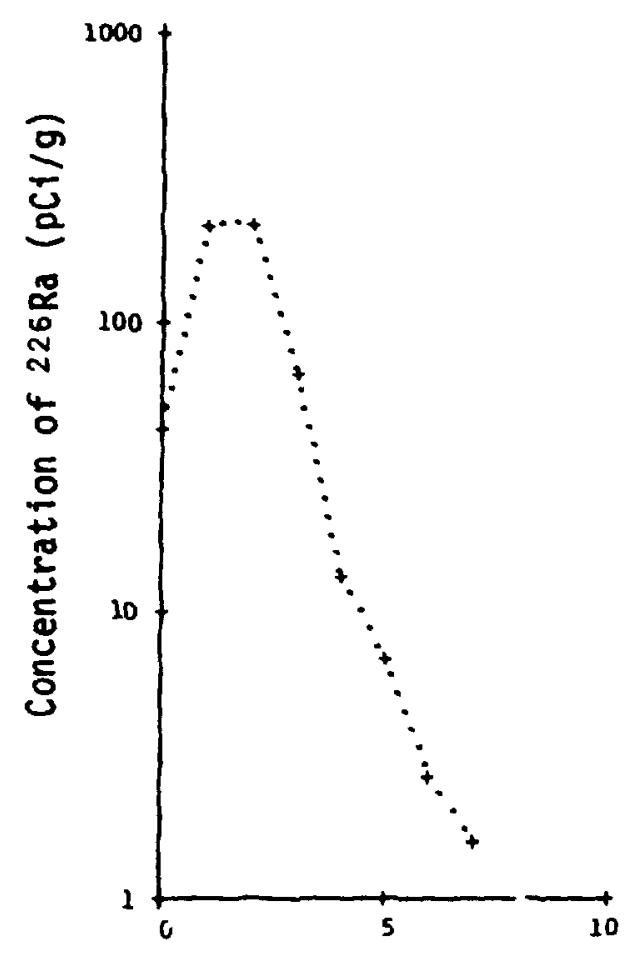

18
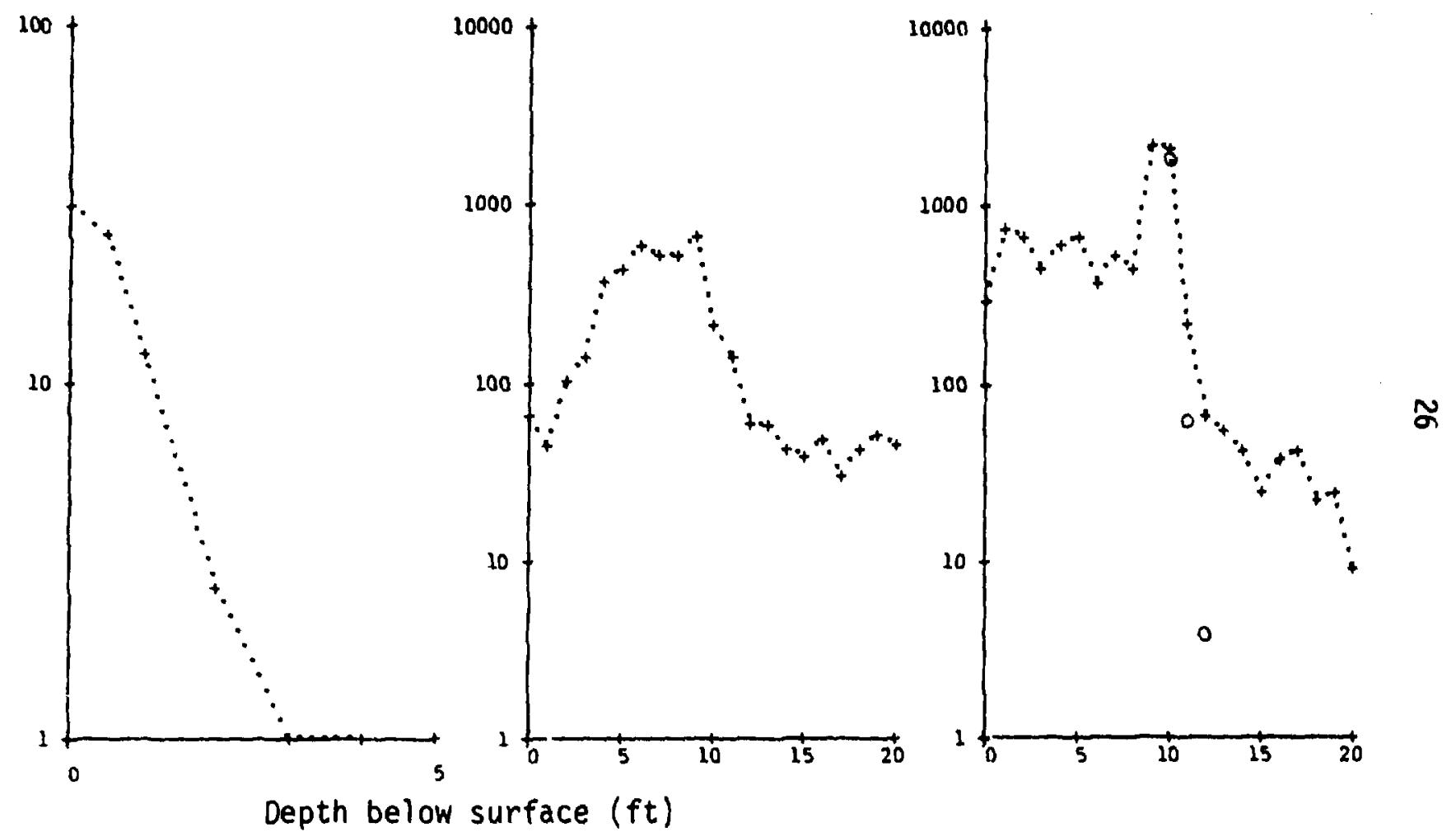

Fig. 12. Calculated concentrations of $22 \mathrm{G} R \mathrm{a}$ in holes $18,20,22$, and 23 . (Values noted by circles in hole 23 represent lata from the analysis of individual soii samples.) 


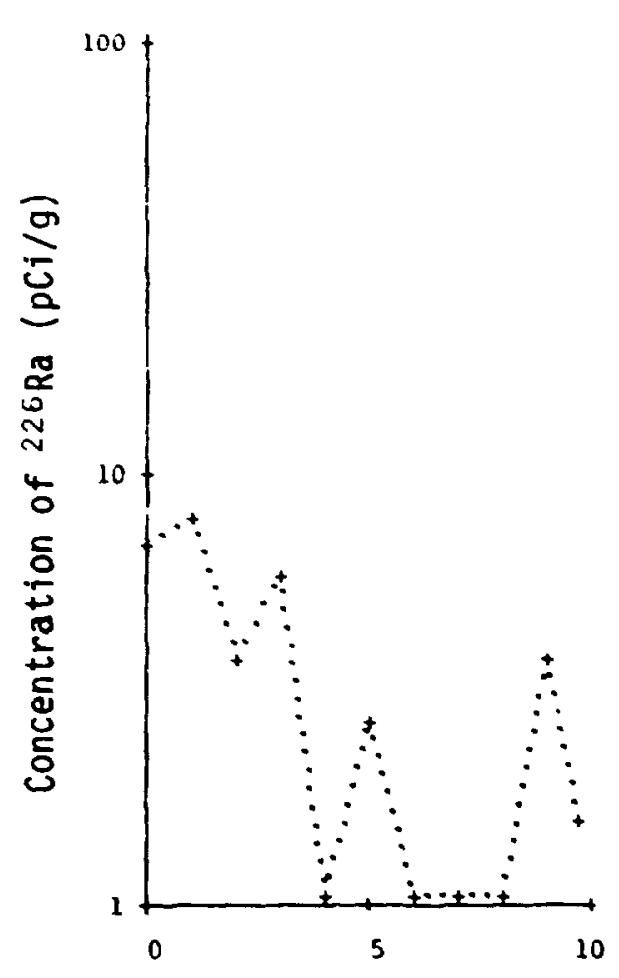

24

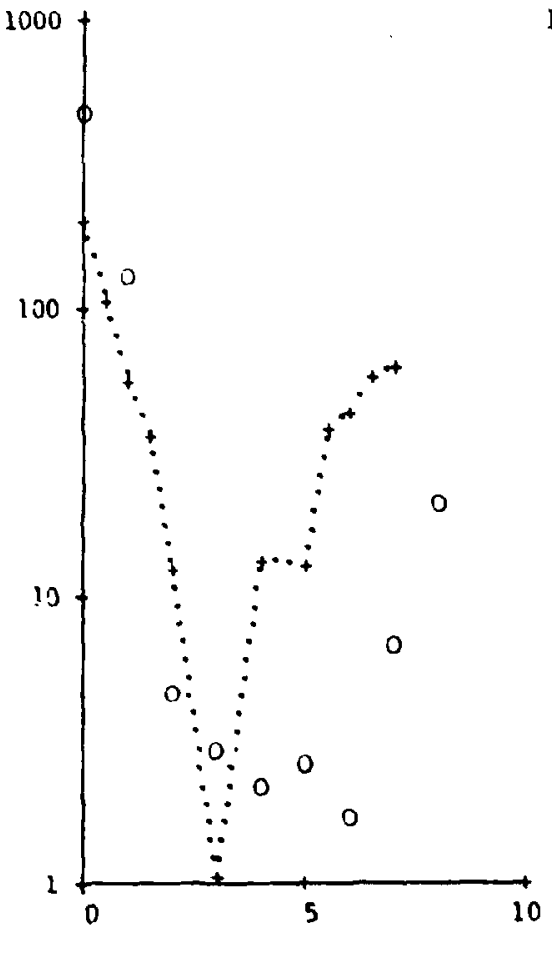

Depth below surface (ft)

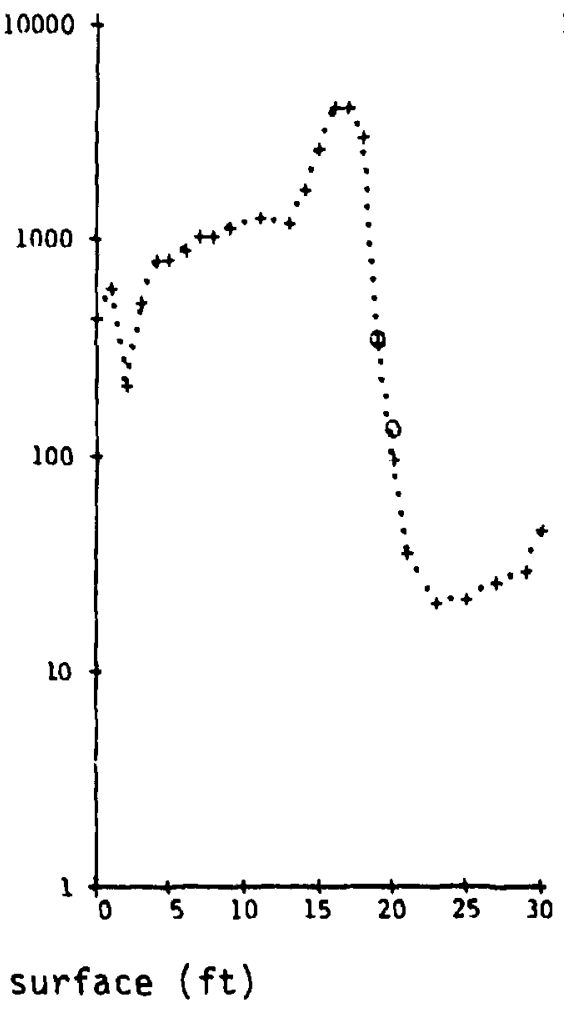

26

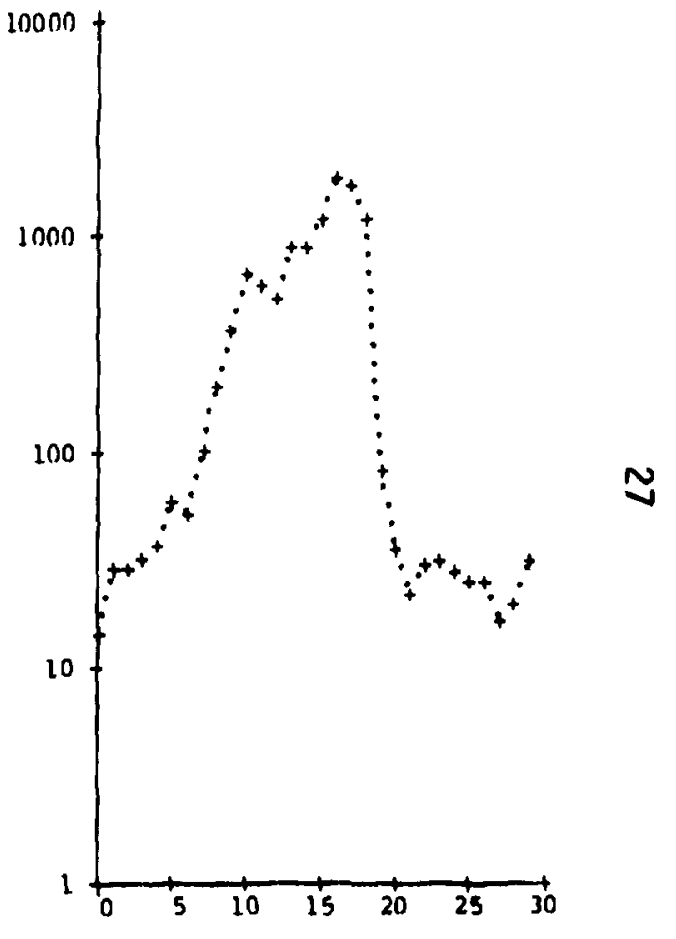

27

Fig. 13. Calculated concentrations of $226 \mathrm{Ra}$ in holes $24,25,26$, and 27 . (Values noted by circle in holes 25 and 26 represent data from the analysis of individual soil sámples.) 
ORNL-DWG 79-9411
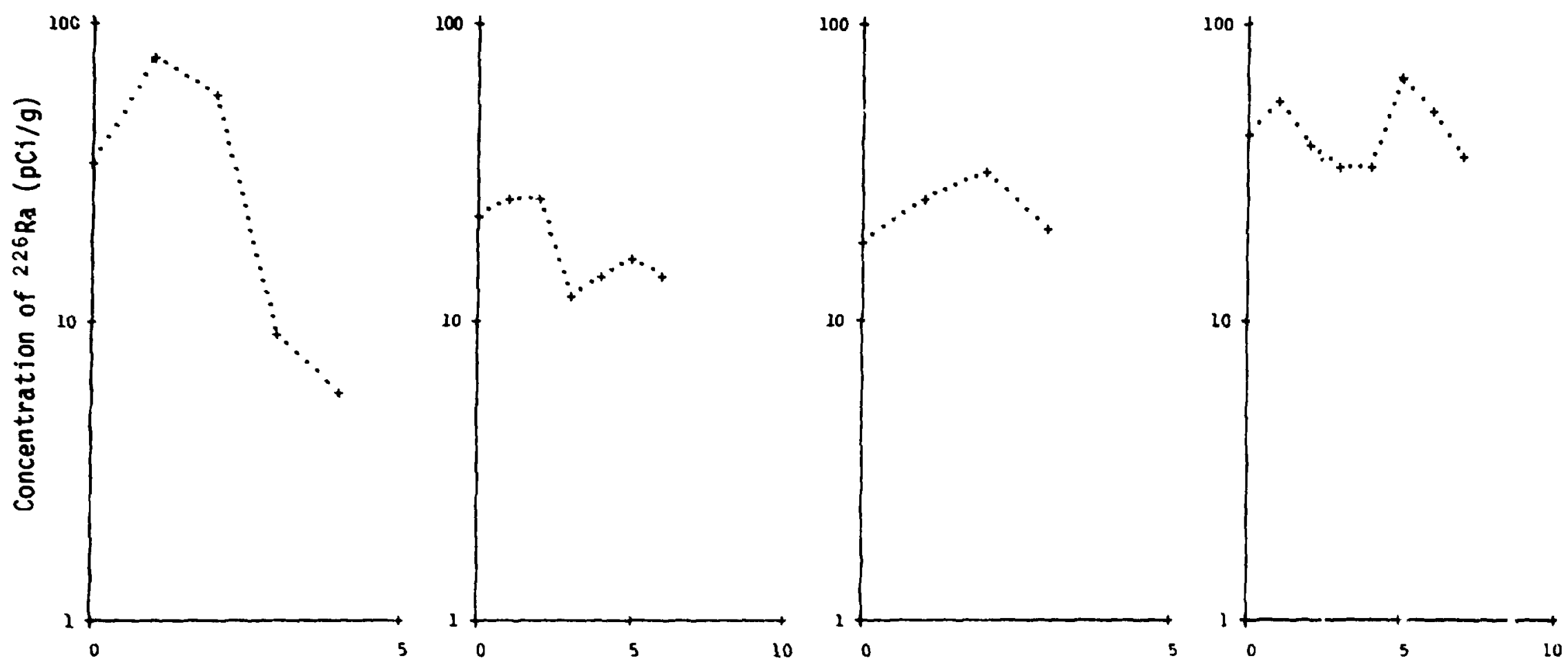

Depth below surface ( $f t$ )

Fig. 14. Calculated concentrations of 226 Ra in holes $28,29,30$, and 32 . 
ORNL-DWG 79-9412

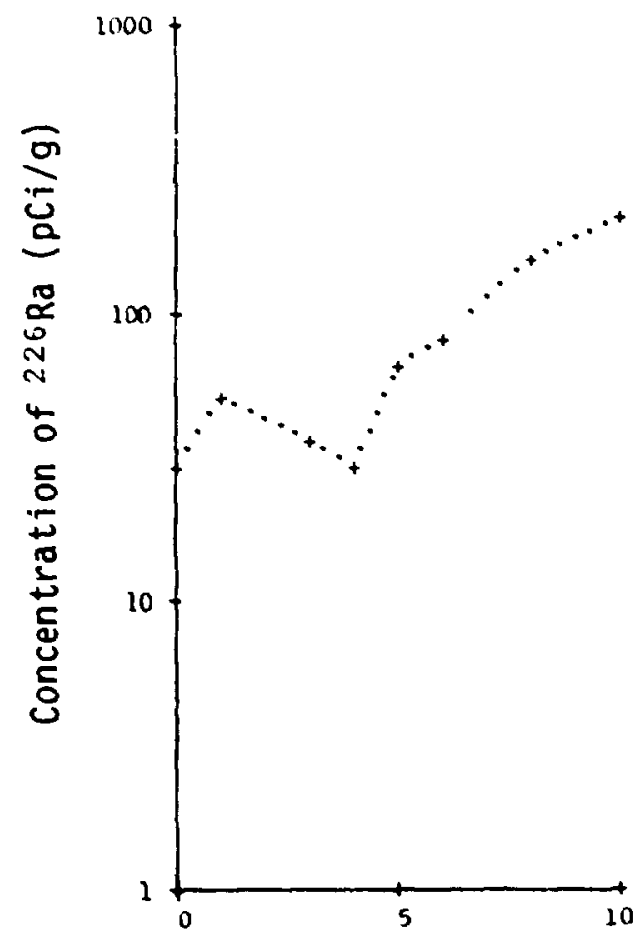

33

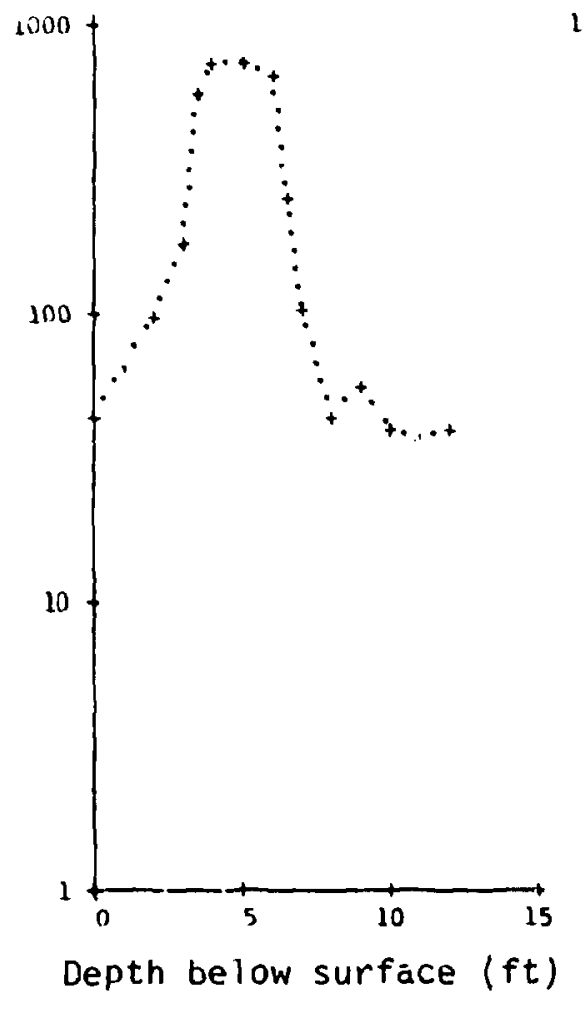

34

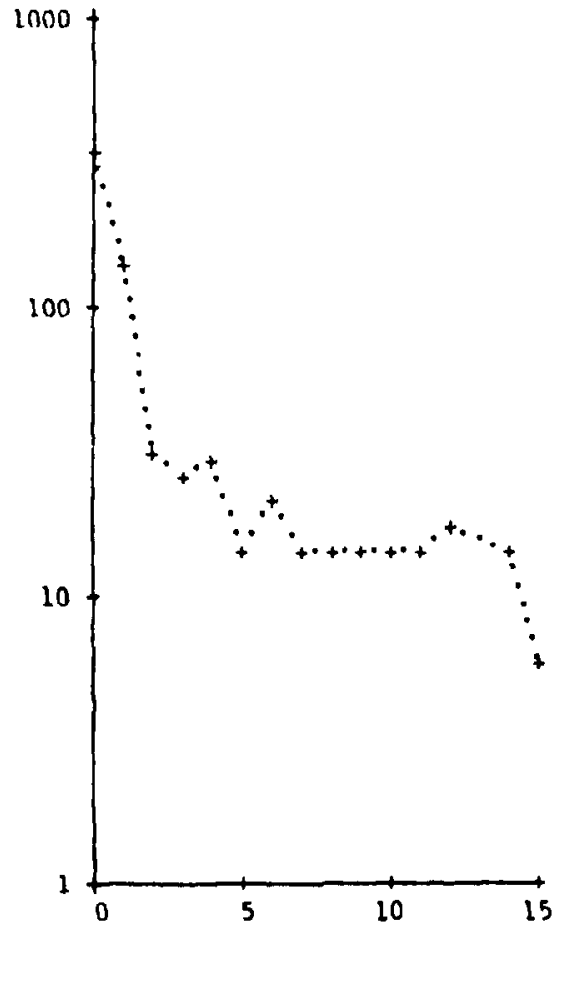

35

Fig. 15. Calculated coricentrations of $226 \mathrm{Ra}$ in holes 33,34 , and 35 . 
filter of Hi-Vol samplers operated downwind from the tailings from 4 to $7 \mathrm{hr}$ at an average air flow rate of $1.27 \mathrm{~m}^{3}\left(45 \mathrm{ft}^{3}\right) / \mathrm{min}$. No useful data were obtained from these tests because only a cursory examination of che filters was made and no ${ }^{226}$ Ra was detected. The detection 1 imit for ${ }^{226} \mathrm{Ra}$ was not established but it is believed to be less than $0.2 \mu \mathrm{Ci}$. Data obtained by Hans (EPA-LVF) during a 7-month period in 1974 and repurted by FB\&DU (Ref. 3, Table 3-4) indicate that the concentration of all airborne radionuclides found at three sampling stations in the vicinity of the tailings was several orders of magnitude below the concentration guide ( $C G_{a}$ ) values except for ${ }^{23 C}$ Th at one location.

\section{HEALTH EFFECTS ATTRIBUTABLE TO THE SHIPROCK TAILINGS}

Changes have occurred at the Shiprock site since the time of the survey reported here (Sect. 2). The assessment of potential health effects presented in this report is for conditions that prevailed at the time of the survey.

\section{1 Radon Diffusion Pathway}

Using methods described elsewhere, 1 a radon source torm of $1.9 \times$ $10^{8} \mathrm{pCi} / \mathrm{sec}$ and a flux of $750 \mathrm{pCi} / \mathrm{m}^{2} \mathrm{sec}$ were caiculated for the Shiprock tailings piles. An area source mode $]^{14}$ and data ${ }^{15}$ on the annual average wind profile and stability at Farmington, New Mexico, (the closest weather station to Shiprock) were used to calculate the dispersion of radon from the tailings piles at 10 distances and in 16 compass directions. Results of calculations are recorded in Table 4 where the ${ }^{222} \mathrm{Rn}$ concentration is given in picocuries per liter it distances ranging trom 0.32 to $40.2 \mathrm{~km}(0.2$ to $25 \mathrm{mile})$ in the 16 compass sectors.

The average annual background ${ }^{222} \mathrm{Rn}$ concentration has been raported by Shearer and Sill16 to be approximately $0.5 \mathrm{pCi} / 1 \mathrm{iter}$ at Durango, Colorado, the nearest sampling area to Shiprock that they examined. This is in fair agreement with the offsite results reported by FB\&DU ${ }^{3}$ which averaged $1.0 \mathrm{pCi} / \mathrm{liter}$ for a shorter period at distances greater than 
Table 4. ${ }^{22} R_{n}$ Concentration (pii/liter) resulting from the Shiprock

tailings
$1.9 \times 10^{3} \mathrm{pCi} / \mathrm{sec}\left(750 \mathrm{pCl} / \mathrm{m}^{2}-5 \mathrm{ec}\right)$

\begin{tabular}{|c|c|c|c|c|c|c|c|c|c|c|c|c|c|c|c|c|}
\hline $\begin{array}{l}\text { Distance } \\
\text { fram cen } \\
\text { of pile }\end{array}$ & & & & & & & & Compass & directi & & & & & & & \\
\hline an mile & N & NNE & NE & ENE & $E$ & ESE & SE & SSE & $s$ & $55 W$ & SW & WSW & $w$ & WNW & $N W$ & NWW \\
\hline$\frac{0.32}{0.20}$ & 2.4 & 2.7 & 4.7 & 5.1 & 4.9 & 4.0 & 3.4 & 3.0 & 5. 8 & 7.1 & 10.4 & 10.2 & 8.6 & 6.9 & 4.2 & 1.8 \\
\hline$\frac{0.53}{0.33}$ & 0.5 & 0.9 & 1.4 & 1.9 & 2.0 & 1.3 & 0.7 & 1.0 & 1.5 & 2.7 & 3.6 & 3.9 & 3.2 & 1.8 & 0.8 & 0.5 \\
\hline$\frac{0.97}{0.60}$ & 0.2 & 0.2 & 0.5 & 0.6 & 0.8 & 0.4 & 0.2 & 0.2 & 0.6 & 0.7 & .4 & 1.2 & 1.2 & 0.5 & 0.2 & 0.1 \\
\hline$\frac{1.34}{0.83}$ & 0.1 & 0.09 & 0.3 & 0.3 & 0.5 & 0.2 & 0.1 & 0.1 & 0.4 & 0.3 & 0.9 & 0.6 & 0.8 & 0.2 & 0.1 & 0.06 \\
\hline$\frac{2.25}{1.40}$ & 0.04 & 0.04 & 0.1 & 0.1 & 0.2 & 0.08 & 0.05 & 0.04 & 0.1 & 0.1 & 0.4 & 0.3 & 0.3 & 0.09 & 0.05 & 0.02 \\
\hline$\frac{3}{6} \cdot \frac{86}{40}$ & 0.02 & 0.02 & 0.05 & 0.06 & 0.08 & 0.03 & 0.02 & 0.02 & 0.06 & 0.06 & 0.2 & 21 & 0.1 & 0.03 & 0.02 & 0.009 \\
\hline$\frac{5.47}{3.40}$ & 0.009 & 0.009 & 0.03 & 0.03 & 0.05 & 0.01 & 0.01 & 0.01 & 0.04 & 024 & 0.09 & $0.0 i$ & 0.08 & 0.02 & 0.01 & 0.005 \\
\hline$\frac{1.08}{4.40}$ & 0.006 & 0.006 & 0.02 & 0.02 & 0.03 & 0.01 & 0.007 & 0.007 & 0.02 & 0.02 & 0.06 & 0.04 & 0.05 & 0.01 & 0.008 & 0.003 \\
\hline$\frac{10.9}{5.70}$ & 0.003 & 0.003 & 0.01 & 0.01 & 0.02 & 0.007 & 0.004 & 0.004 & 0.01 & 0.01 & 0.03 & 0.02 & 0.03 & 0.007 & 0.004 & 0.002 \\
\hline$\frac{40 \cdot 2}{25} \cdot \frac{2}{0}$ & 0.0006 & c. 0005 & 0.002 & 0.002 & 0.003 & 0.001 & 0.0007 & 0.0006 & 0.002 & 0.002 & 0.006 & 0.004 & 0.005 & 0,001 & 0.0007 & 0.0003 \\
\hline
\end{tabular}


$1.2 \mathrm{~km}(0.75 \mathrm{mile})$ from the tailings. The data in Table 4 show a maximum $222 \mathrm{Rn}$ concentration of $0.4 \mathrm{pCi} / \mathrm{liter}$ at $2.25 \mathrm{~km}$ ( $1.4 \mathrm{mile}$ ) from the center of the tailings piles, below the measured background level. At $7.1 \mathrm{~km}(4.4 \mathrm{mile})$ the maximum ${ }^{222} \mathrm{Rn}$ concentration $(0.05 \mathrm{pCi} / 1$ iter $)$ is approximately $10 \%$ of background.

In considering the data in Table 4 , it should be kept in mind that the radon source term and flux rate used are calculated values involving a number of assumptions. Measurements of radon exhalation flux from the tailings piles made in February and June 1976 and reported ${ }^{3}$ by FB\&DU show rates ranging from 5 to $157 \mathrm{pCi} / \mathrm{m}^{2}$-sec with an average value of 98 . This is a factor of nearly eight lower than the calculated value used in the Table 4 calculaticns. Also, Hans has reported ${ }^{17}$ more recent measurements of the source term for the Shiprock tailings, and the average of his "best" values for the source term is $3.5 \times 10^{7} \mathrm{pCi} / \mathrm{sec}$, down a factor of 5.4 from the Table 4 figure of $1.9 \times 10^{8} \mathrm{pCi} / \mathrm{sec}$. This apparent discrepancy may be Jue, at least in part, to the changes in surface conditions of the tailings piles. It should be pointed out that measurements which have been made by the various groups are few in number, were collected in small areas, and should not be presumed to be representative of average annual radon fluxes for the two piles. Radon flux measurements made over unstabilized Shiprock tailings earlier ${ }^{12}$ ranged from 440 to $2200 \mathrm{pCi} / \mathrm{m}^{2}-\mathrm{sec}$. The source term on which the dispersion data in Table 4 is based may be too high for present pile conditions and the radon concentration, on the average, may drop to the background level in a shorter distance than indicated in the table.

It has been shown ${ }^{1}$ that it is reasonable to assume that continuous exposure to $1 \mathrm{pCi} /$ iter of $222 \mathrm{Rn}$ is equivalent to an annual indoor radon daughter exposure of $0.25 \mathrm{WLM} /$ year. The data in Table 4 may be used to estimate annual exposure to radon daughters at various points surrounding the Shiprock tailings. As an example, in a structure located 0.32

${ }^{\star} A$ working level (WL) is defined as any combination of radon daughters in one liter of air that will result in the ultimate emission of $1.3 \times 10^{5} \mathrm{MeV}$ of alpha particle energy. A working level month (WLM) is exposure to $1 \mathrm{WL}$ for a duration of $170 \mathrm{hr}$. 
estimate annual exposure to radon daughters at various points surrounding the Shiprock tailings. As an example, in a structure located 0.32 $\mathrm{km}$ southwest of the center of the tailings, the annual radon daughter exposure would be 2.6 WLM/year for continuous occupancy.

Cumulative exposure to radon daughters may be equated to risk of death from lung cancer. Walsh ${ }^{18}$ has estimated that an increase of 1\%/ year in risk of death from lung cancer is associated with 1 WLM/year exposure to ruun daughters. Thus, continuous occupants of a building located C $32 \mathrm{~km}$ southwest of the center of tailings might be expected to have an increase in risk of death due to lung cancer by 2 to $3 \%$ per year. In a similar manner, the other ${ }^{222}$ Rn concentrations given in Table 4 may be used to estimate increase in risk at various locations in the Shiprock area. These risk estimates should be considered as upper limits because of the conservative assumptions used to estimate the radon daughter exposures.

The "relative risk" concept is used in this report to estimate health effects. This concept assumes that the incremental risk of a particular disorder which results from radiation exposure is related to the mortality rate of that disorder. An equally valid concept is that of "absolute risk" which assumes that the risk from radiation exposure is independent of local factors. An assessment of absolute risk for the Shiprock tailings site has been performed elsewhere. ${ }^{3}$ However, the absolute risk assessment used short-term measurements of radon around the Shiprock tailings; these measurements may not be representative of annual average conditions. Furthermore, the nomadic nature of the local population precludes the possibility of obtaining any representative data for population distribution around the site.

\subsection{Exposure to Gamma Radiation}

Data from the BEIR report 19 indicate that the relative risk of death from all cancers except leukemia is $0.2 \%$ per rem. For leukemia, this rate is $2.0 \%$ per rem. The U.S. annual death rate 20 from all types of cancer is $1791 / 10^{6}$ per year; for leukemia, this is $71 / 10^{6}$ per year. 
Thus, the total weighted risk per rew (ignoring differences in latency period) is $\frac{0.2 \times 179.1+2.0 \times 7.1}{186.2}=0.27$ or $0.3 \%$ increase in risk of death per ren.

The maximum gamma radiation level of approximately $300 \mu R / h r$ observed at several points on the tailings piles would give an annua? whole-body dose of more than 2.6 rem for continuous exposure. This is obviously a highly unlikely exposure situation. Exposure at the same rate for $2000 \mathrm{hr}$ would result in an annual dose of 0.6 rem for normal working hours. While this is also an unlikely exposure rate, it does set an upper limit for people working at the site. Using the abovementioned increased risk estimate, this upper-limit exposure rate would result in an increased risk of death from cancer of $0.18 \% /$ year. The average annual death rate is approximately $1 \%$ in the U.S. population from all causes, and the annual average (as of 1975) risk of death from all cancers is $0.15 \%$.

Data in Fig. 7 indicate that movement of contamilated material from the mill site has not been sufficient to raise the external gama dose rate significantly above the background rate of $10 \mu \mathrm{R} / \mathrm{hr}$ at distances greater than approximately $0.4 \mathrm{~km}(0.25 \mathrm{mile})$. No people live this close to the mill site and it appears, therefore, that the principal population at risk from direct gamma exposure is composed of workers at the site.

\subsection{Health Effects Attributable to Aquatic and Food Pathways}

Various other exposure pathways are mentioned in Sect. 3 of this report. The low annual rainfall in this region, coupied with site topography and the existence of man-made dikes between the tailings and the river, tends to minimize pollution of the river by radionuclides fiom the site as a result of water erosicn. Likewise, movement of radioactivity into underground aquifers is reported ${ }^{3}$ to be unlikely because the area is underlain by a thick aquiclude of Mancos Shale layer which serves as an effective barrier to migration of radionuclides. Also, the underground aquifers are artesian; any flow is more likely to 
be toward the surface than toward the aquifers. It appears from the preceding discussion that dose to man through aquatic pathways is probably small as compared to the radon diffusion and direct gamma exposure pathways. Additionally, two water samples taken from the site had concentrations of ${ }^{226}$ Ra below the EPA interim standard for drinking water (5 pCi/liter). ${ }^{21}$

Other possible exposure pathways that cannot be evaluated because of lack of data are the terrestrial pathways mentioned in Sect. 3. Since no people live in the erea showing significant levels of surface activity and it is unsuitable for agricultural use, it seems unlikely that vegetables or fruit will be contaminated by airborne particles from the site. However, consumption of contaninated plants by grazing sheep, goats, or cows, followed by consumption of milk or of animal meat by man will remain a possible exposure pathway. The statement is made ${ }^{3}$ that the area south of the site is being used for low-density grazing. The data in Fig. 7 show a low level of offsite migration of tailings has occurred in that direction. Thus, at the present time, pathways other than the inhalation of radon daughters and direct gamma radiation do not contribute any significant exposure to persons residing or working near the Shiprock tailings.

\section{SUMMARY AND CONCLUSIONS}

Results of a radiological survey of the Shiprock mill site made in February 1976 are presented in this report. Decontamination work and tailings stabilization carried out at the site since the time of the survey under the guidance of EPA-ORP-LVF have reduced potential health effects among offsite population groups as well as sccupants of the site. ${ }^{3-11}$ However, the results presented here confirm the need for the above-mentioned remedial actions.

Assessment of potential health effects based on radiological conditions existing it the time of the survey appeai to confirm the conclusion of previous reports ${ }^{1,3-7}$ that diffusion of radon off the site and 
inhalation of radon daughters is the principal exposure pathway. Calculations of radon dispersion around the tailings show that the concentration from this source will be less than the background level at distances greater than $2.25 \mathrm{~km}$ ( $1.4 \mathrm{mile}$ ).

Several fartors at the Shiprock site combine to make doses to man through aquatic pathways improbable. While data needed to evaluate possible terrestrial pathways are lacking, there is little reason to believe that significant population doses occur through such exposure modes.

In view of the changes at the Shiprock site, that have occurred since tine survey reported here was made, the data presented in this report represent radiological conditions and health effects assessments for a situation that no longer exists. Consequently, the data on distribution of ${ }^{226}$ Ra as a function or underground depth, particularly in the upper tailings pile where only minimal additional stabilization has occurred, are more relevant to present conditions than most of the other information presented here. Some of the data must be adjusted to take into account added cover dirt. If a decision is made to implement one of the tailings removal options discussed in the FB\&DU report, ${ }^{3}$ or some other removal scheme, these data would be helpful in planning and carrying out the work.

Because of the remedial actions that have occurred, and the absence of occupied dwellings or the site, discussion of the applicability of existing criteria, such as the Surgeon General's remedial action criteria for Grand Junction, 13 seems inappropriate in this documert. 


\section{REFERENCES}

1. F. F. Haywood, W. A. Goldsmith, P. T. Perdue, W. F. Fox, and H. H. Shinpaugh, Assess rent of Radiological Impact of the Inactive Uranim-1:1. Tailings Pile at Salt Lake City, Uiah, ORNL/TM-5251 (November 1977).

2. B. Lyon, Unanium Tailings in the Public Eye, Oak Ridge National Laboratory Review, 9 (3) (1976).

3. Ford, Bacon and Davis 'Jtah Inc., Phase II - Titze 1, Engineering Assessment of Inactive Uranium Mill Tailings, Shiprock Site, Shiprock, New Mexico, GJT-2 (March 1977).

4. U.S. Atomic Energy Commission, Environmental Survey of the Uranizon Fuel Cycle, WASH-1248 (April 1974).

5. U.S. Environmental Protection Agency, Environmental Analysis of the Uranizon Fuel Cycle, Part I, Fuel supply, PB-235804 (October 1973).

6. M. B. Sears, R. E. Blanco, R. C. Dahlman, G. S. Hill, A. D. Ryon, and J. P. Witherspoon, Correlation of Radioactive Waste Treatment Costs and the Enviromental Impact of Waste Effluents in the Nuclear Fuel Cycle for Use in Establishing "As-Low-As-Practicable" Guides -Milzing of Uranium Ores, ORNL/TM-4903, Vol. 1 (May 1975).

7. J. J. Swift, J. M. Hardin, and H. W. Calley, Potential Radiolcgical Impact of Airbome Releases and Direct Gonna Radiation to Individuals Living Near Inactive Urunium Mill Tailings Piles, EPA-520/1-76-001 (January 1976).

8. J. M. Hans, Jr., Environmental Protection Agency, Office of Radiation Programs, Las Vegas Facility, personal communication, February 9, 1978.

9. J. M. Hans, Jr., B. Benally, and G. G. Eadie, Airborme Radioactive Particulate Concentrotions Around the Former Shiprock, New Merico, Iranium Mill site, EPA report, in preparation.

10. J. M. Hans, Jr., E. Buris, and $T$. Gorsuch, Radioactive Waste Managemer.' is line Former Shiprock, New Mexico Uranium Mill site, EPA report, in preparation. 


\section{REFERENCES (continued)}

11. J. M. Hans, Jr., T. R. Horton, and D. Prochaska, Average 4ronuit Radon-222 Concentrations Amould the Fomer Shiprock, iew llexiso Uranium Mill Sïte, EFA report ORP/LV-78 (August 1978).

12. D. E. Bernhardt, F. B. Johns, and R. F. Kaufmann, Dadon Exalatior: from Uranitu Mill railings Diles, EPA Technical Note ORP/LV-75-7A (November 1975).

13. Grand Junction Remedial Action Criteria, 10 CFR Part 712, Federai Register, Vo1. 41, No. 252, December 30, 1976.

14. H. M. Culkowski and M. R. Patterson, A Compreriensive Atmospheric Transport and Difjusion ModeZ, ORNL-NSF-EATC-17 (1976).

15. U. S. Department of Commerce, NOAA, Environmer, 11 Data Service,

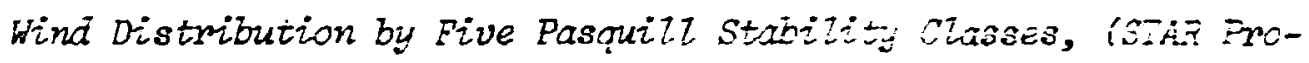
gram), Farrington, vew Hexico, Hais 1963 - Apriz 1964 , Job No. 12160, National Climatic Center, Asheville, N. C., August 28, 1970.

16. S. D. Shearer, Jr. and C. H. Sill, "Evaluation of Atmospheric Radon in the Vicinity of Uranium Mill Tailings," ieaz=ir Phis. I?, 77 (1969).

17. J. M. Hans, Jr., "Techniques for the Estimation of Radon-222 Source Terms for Uranium Mill Tailings Piles," in Proceedirgs o: the Workshop on Hethods for Measuming Radiation In and sround Uranium Milzs, AIF Program Report, Vol 3, No. 9 (August 1977).

18. P. J. Walsh, "Dose to the Tracheo-bronchial Tree Due to Inhalation of Radon Daughters," Proc. of the 10: "id-iear Topical Symposium, Health Phys. Soc., Saratoga Springs, N.Y. pp. 192-203, Octuber 11-1j, 1976.

19. Advisory Comittee on Biological Effects of Ionizing Radiation, NAS-NRC, The Effects on Populations of Emposure to ini levele of Jonizing Radiation. pp. 171 (BEIR Report) (November 1972).

20. U. S. Department of Health, Education and Welfare National Center for Health Statistics, Final Mortality Statistic3, 1375, Monthly Vital Statistics Report, Vol. 26, No. 13, Supplement (December 7 , 1976).

21. Code of Federal Regulitiona, Title 40, Part 141 (July 9, 1976). 


\section{APPENDIX I}

PHASE I

REPORT ON CONDITIONS OF URANIUN MILL SITE AND TAILINGS AT SHIPROCK, NEW MEXICO

Unpublished report on site visit on May 7, 1974 by: W. E. Haldane and Gordon T. Brown, Lucius Pitkin, Inc., (Contractor to USAEC), Grand Junction, Colorado; David E. Bernhardt, U.S. Environmental Protection Agency, Las Vegas, Nevada; and John C. Rodgers, State of New Mexico, Environmental Improvement Agency, Santa Fe, New Mexico.

This Phase I site investigation was conducted under a cooperative agreement among the Atomic Energy Commission, the Environmental Protection Agency, and the State of New Mexico. The report was prepared by Lucius Pitkin, Inc., under AEC Contract No. AT(051) 912, and is reproduced directly from the best available copy with color photographs from the original report changed to black and white. 


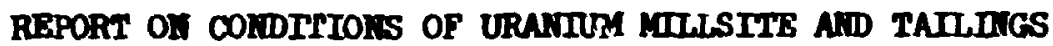

AT SHIPROCK, NIS MBXICO

\section{Introduction}

Pertinent information has been accumalated from avallable records of the $A B C$, EPA, the states and companies involved. An on-site visit was made to note current conditions, including the dilsite and the trilings disposal area, proximity to populated and industrialized areas, present ownership, and whether a need for corrective action exists. It is intended that this report will serve as a basis for deterwining the necessity of detailed engineering assessment (Phase II).

This repol - on the site at Shiprock, Hew Mexico, was prepared jointly by the AEC, the EPA, and the State of New Nexico's Environmental Improvement Agency.

Sunary and Conclusions

The Mavajo Mill at Shiprock, New Mexico, was operated from 1954 to 1963 by Kerr-McGee oil Industries, Inc., and from 1963 to 1968 by Vanadium Corporation of Anerica and its successor, Foote kineral Compeny, producing uranium and vanadium concentrates. After the termination of operations in 1968 the mill was dismantled. In 1973 the property reverted to the ownership and control of the Navajo Nation. The Navajo Engineering Construction Authority (RECA) obtained a lease and has estak lished a school on the site to train earth-woving machine operators.

The northeastern tailings pile is fairly weil stabilized with a cover of mixed soll and river gravel, but the tallings in the larger southern area is being used for training of heavy equipment operators and this loose material is readily wind-blown.

As a result of the site visit and review of available information, it is concluded that the public hesith and econome impacts of the following actions should be investigated in a Fhase II study of the Shiprock site:

I. Repair and/or build dike to divert surface water rmoff away from the tallings areas.

II. Move radioactive material (tailings, concrete, etc.) in the southern part of the fenced area, wind-blown radioactive material from surrounding areas, and residual radioactive meterial in the ore storage and ullsite areas into the southeastern part of the fenced area and grade, contour, and stabilize. 
III. Improve cover on the already stabilized northeastern tailings pile.

IV. Measure and evaluate radon dauphter concentration in the buildings and take counterneasures as necessary.

V. Remove the tallings to a more initable site if it appears from socio-econoulc projections and bealth hazard considerations that removel is desireable. Ho such location was identified; however, it has been suggested that the Iavajo vine (strip mine for coal) be considered.

In addition to Phase II effort, it is suggested that the fences be repaired and posted, that measures be taken to prevent further spread of tailings during training school activities, and that equipant operator activity be controlled to prevent destruction of the cover on the stabilized pile and of associated dikes and retention ponds. Any new structures should not be located on contaminated ground. Finally, there is need for a long-term land use planning program to lind developent around the site.

Location

The site of the Foote Mineral Company Ravajo M:ll is on the south side of the town of Shiprock, Hew Mexico, on the Hava.jo Indian Reservation and o: the south bank of the San Juan River, in Sections 25 and 36, Township 30 North, Range 18 Nest, New Mexico Principal Meridian, at $36^{\circ} 46^{\prime} 39^{\prime \prime}$ Horth latitude and $108^{\circ} 41^{\prime} 20^{\prime \prime}$ West longitude. The elevation is about 5,000 feet above sea level.

\section{ownership}

The Navajo Mill was originally designed and built by Kerr-McGee 011 Industries, Inc., and operated by that company from 1954 until 1963, when it was purchased by Vanadium Corporation of America. VCh was later werged into Foote Mineral Company. The will ceased operations in 1968 and has been dismantled although many of the buildiags remain. Foote's lease expired in 1973, and the control and omership of the site has now reverted to the Navajo Nation.

\section{History of Operations}

Ore was first fed to process in the Navajo 1111 in November 1954. The last ore was fed in June 1968 and the final finished product removed from the circuit in August 1968. 
During its operating life the mill processed 1.5 million short tons of ore, with an average grade of 0.25 percent $\mathrm{V}_{3} \mathrm{O}_{8}$ and 1.07 percent $\mathrm{V}_{2} \mathrm{O}_{5}$, and produced 3,711 tons of $\mathrm{U}_{3} \mathrm{O}_{8}$ in concentrate which vas purchased of the ABC. Vanadium concentrate whs also produced in 1955 and again from 1960 to 1968 and sold on the comercial market.

Ore was mostly sandstone, containing carnotite as the principal ore aineral. Ore was trucked to the mill from and mines. During the Kerr-kccee operation about 80 percent of the ore came fron compenycontrolled wines in northeastern Arizon and the rest from other swall mines mostly in northeastern Arizona and nortwestern New Mexico. After the change of ownership in 1963 wore than half of the ore supply cave from the Uravan Mineral Belt. The average distance hauled was probably about 100 miles.

Photographs 1 shows the plant as 1 appears in 1974. Figure 1 is a plot of the plant layout.

\section{Process Description}

Ore vas crushed and ground to mus 35 mesh, then fed to the leaching circuit. Leaching was in two ste; ies, with the strong acid solution produced in the second stage recirculated to the first stage for partial neutralization by the entering ore slurry. The high concentration of acid in the second stage was required for good vanadiu extraction. A bulk precipitate from heap leaching operations was added aneed of the first leaching stage. Old tailings containing vanadium which had not been exirected during processing for uranium recovery in the early years of operation were later fed to process in the second stage of leaching.

Pollowing leaching was a countercurrent washing system in wich the sands were washed in classiffers and aliwes were washed in thickeners. Urantum was recovered from the pregnant liquors by solvent extraction. The vanadium was then recovered in a second solvent extraction circuit. High grade uranium oxide and vanadium oxide products were recovered from the solvents.

Cailings from the vashing circuit were pumped to the disposal area. Residual raffinate i:-om solvent extraction was disposed of by evaporation in separate holding ponds. I/

Present Milsite

Photograph 2 shows the site as it eppeared during mill operation. Photograph 3 shows the site as it appeared during operations, looking Boutheasterly. 

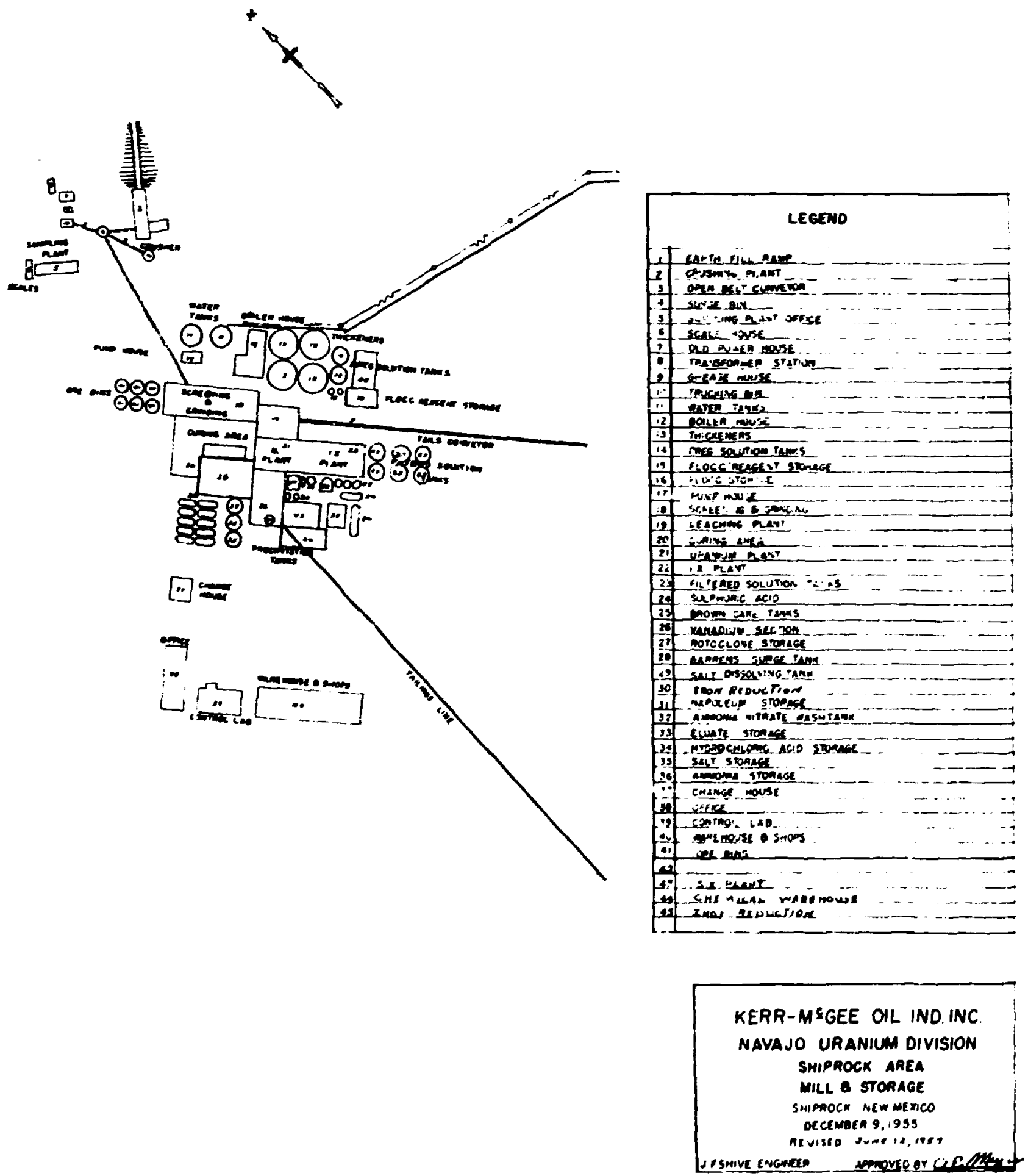

Figure 1. Plot of Plant Lanyout 
The Mavajo Bngineering and Construction Authority occupies the former plant office and shop buildings and operates training school on the site to teach Navajo students to operete earth-moving mchinery.

(Photographs 5 and 15). The nearest residents to the tailinge area are some of the 23 permanent instructors of the training school who telporarily reside four nights per week in trailers on the site. About 30 students at 3 time participate in a one-nonth training progran tut do not live on the site. Construction crews of about two to five people occesionally stay on the site.

The tailings are is about 80 acres lying east and south of the willsite. At its eastern corner it is within a few hundred feet of the San Juan River. The ground level there is about 60 feet higher than the river.

The main tailings pile covers about 20 acres to a depth of 20 to 30 feet in the eastern part of the area, extending for about a quarter of a mile along the biuff above the river on the nortineast side of the tract. (Photographs 4, 6, 7, 9, 11, 13). Wost of the southern part of the tailings area, southwest of the main tailings pile, has a shailow cover of old vanadium-bearing tallings. (Photograph 14). A substantial amount of fine material is easily moved when exposed to wind.

A barbed-wire fence encloses the mill and tailings areas except along the bluff on the northeast side above the river. The fence is in need of some matentence vork.

The WDCA uses the administration and shop buildings. The mill building is in poor condition with much of the steel structure showing acid erosion and sections of the cement foundations have been removed. IRCA has received Federal funds for construction of a new intenance shop. EPA has recommended not to build on the uillsite, but construction is scheduled for August 1974.

\section{Envi ronmental Considerations}

AEC records show that 1.5 million tons of ore with an average grade of 0.25 percent $\mathrm{U}_{3} \mathrm{O}_{8}$ were processed in the Shiprock plant. Assuning secular equilibrium, the theoretical concentration of Ra-226 is $700 \mathrm{pCi}$ per gram of tailings. The total Ra-22i inventory theoretically in the tailings is estimated to be 950 curies.

Results of the close-out survey by the ARC and the state of New Nexico on February 27, 1973, indicated that the buildings were deconteminated to the license criteria and that a considerable amount of contaminated material was buried in the tailings pile. Exposure levels over the piles and pond areas indicated exposure rates of about 0.25 to about $0.5 \mathrm{mh} / \mathrm{hr}$. 2/ 
Preliminary results from currsit EPA game radiation surveys indicate general contamination througk.out the fenced area and up to about 1,000 feet to the south, southeast, and northwest. Elevated radon daughter concentrations (fractions of working level) have been detected in the buildings used by the training school.

TI min northeastern tailings file is fairly well covered with aboxt six inches of soil and gravel, has sow. raiural plant growth, resists wind erosion, and is well diked to provent erosion by rain and snow runoff. (Photographs $6,7,8,9,10,13$ ).

On the other hand, the material in the southern part of the t3ilings area is loosi, uncovered, and continually being moved by the machines and student operators of the Navajo training school. (Photographs 14 and 15). Much blowing dust is visible in this area. The school plans to move this material away from the buildings into the sout:ieastern part of the area, then cover it and hold it there.

It has been observed at this and other inactive millsites that wherever bulldings exist there is always pressure to find a use for them. This training school was establisbed at the Shiprock site because the bulldings were available. If the site is to be occupled at all, it is probably better that it should be used by the Navajc Engineering and construction Authority than by any other tribal agency. Cleaning up the area and moving and stabilizing the tailings is a worthwhile project for the NBCA. and its students.

Mavajo iand is not omed by individuals but is beld by land use permits issued under the authority of the Tribal Council. The community of Shiprock is not an organized municipality and has no specific city limits. What may be thought of as the "town" of Shiprock is estimated to include about 10,000 people within about two miles of the millsite, genera'ly clustered along the San Juan Rive and the Highways, U. S. 550 and 6 iff. and state 504. (Photographs 2 and 3). The residential growth trend has been mainly easter ly along U. S. Highway 550, toward Farmiraton, on the oppos:te side of the river from the millsite.

The nearest offsite residence is across the rivar and about a half mile northeast of the stabilized main tailings pile. Thiprock High School is ahout two-thirds of a mile northeast of the same pile. Building: of the former helium plant on the west side of U. S. Highway 666 abo'it a half mile vest of the tailings site are used for storage. A Fairchild Electronics assembly plant is about a half alle southwest of the tailings site. The rodeo ground is about a quarter mile northwest of the fenced plant area and perhaps a half mile from the tallings piles.

There are farms with cuitivated fields within about a half mile of the site, and sheep and goats graze up to the fence line. 
EPA gam ratiation surveys of the Shiprock area indicate that only a small quantity of tallings has been rewored from the site and used in constriction in the comminity. Seven anomalies associated with tailings use were $t$ und in Shiprock. At four locations tailings were indicated within 10 feet of habitable structures and at tree locations tailings were used more than 10 feet from habitable structures.

Farmington, the largest comunity in the area, is about 25 air diles east of Shiprock. The only other residential axeas within a 25-wile radius of Shiprock are small settlements and trading posts. The Havajo Mine, the largest open pit coal mine in the United States, and the Four Corners Power Plant are about 15 miles east of Shiprock.

Populaticn projecticas have been made for the Shiprock area of up to 25,000 in 10 to 20 years. These projections are largely based on coel mining, power plants, and coal gasification. There is also possibility of increased farming as a result of proposed irrigation projects.

\section{Meteorology}

The average annual precipitation is about seven snches and the average annual temperature is about $53^{\circ} \mathrm{F}$. The strongest winds are from the northrest.

\section{Hydrology}

The uranium mill tailings at Shiprock are on a bluff adjacent to the southwest bank of the San Juan River. Being well gbove the river channel and floodplatin they are not in danger of flooding by the river.

The elluvium directly under the tailings is underlain by the Mancos shale, which is not an aquifer. Being thick, extensive, and poorly perweable, the Mncos shale is a prominent confinius bed below which the ground water is under artesian pressure. There is no likelihood of contand nation of potable ground vater to date or in the ruture as a result of the mill effluent and remaining tailings. Dowmard migration of radionuclides through the thick shale and against an upwand flow gradient is essentially imposaible.

Though better water is aval lable, potable water for the town of Shiprock is diverted from the San Juan River. It is very hard and both iron and sulfate commonly exceed the maximum $1 i$ mits recomended by the $U$. S. Public Henlth service. 
Site Visit

The Shiprock site was visited on ray 7, 1974, by the following personnel (team) in the company of Chris Eastin of the irvajo Babineering and Construction Authority:

W. E. Haldane and Gordon T. Brown, Luclus Pitkin, Inc., (Contractor to USAEC), Grand Junction, Coloredo,

David E. Bernhardt, U. S. Environmental Protection Agency, Les Vegas, Nevada, John C. Rodgers, State of Hew Mexico, Bnvironmental Improvement Agency, Santa Fe, Hew Mexico.

\section{References}

1. Merritt, Robert C., The Extractive Metallurgy of Uranium, Colorado School of Nines Research Inst., USAle Contract, 1971, pp. $422-428$.

2. Memo from G. D. Brown (AEC) to Gen. W. Roy (ABC-DRO-HQ), March 30, 1973. 


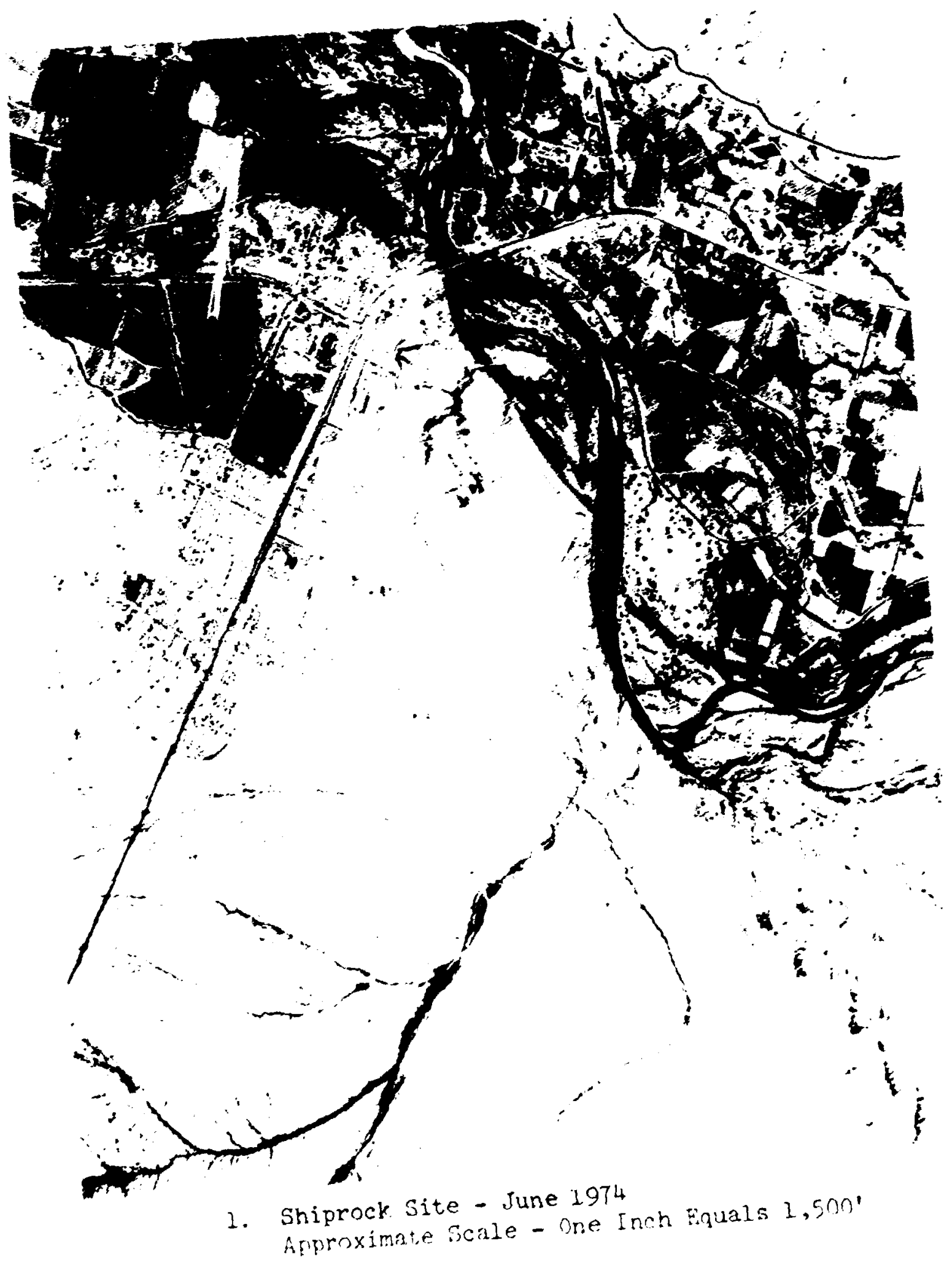




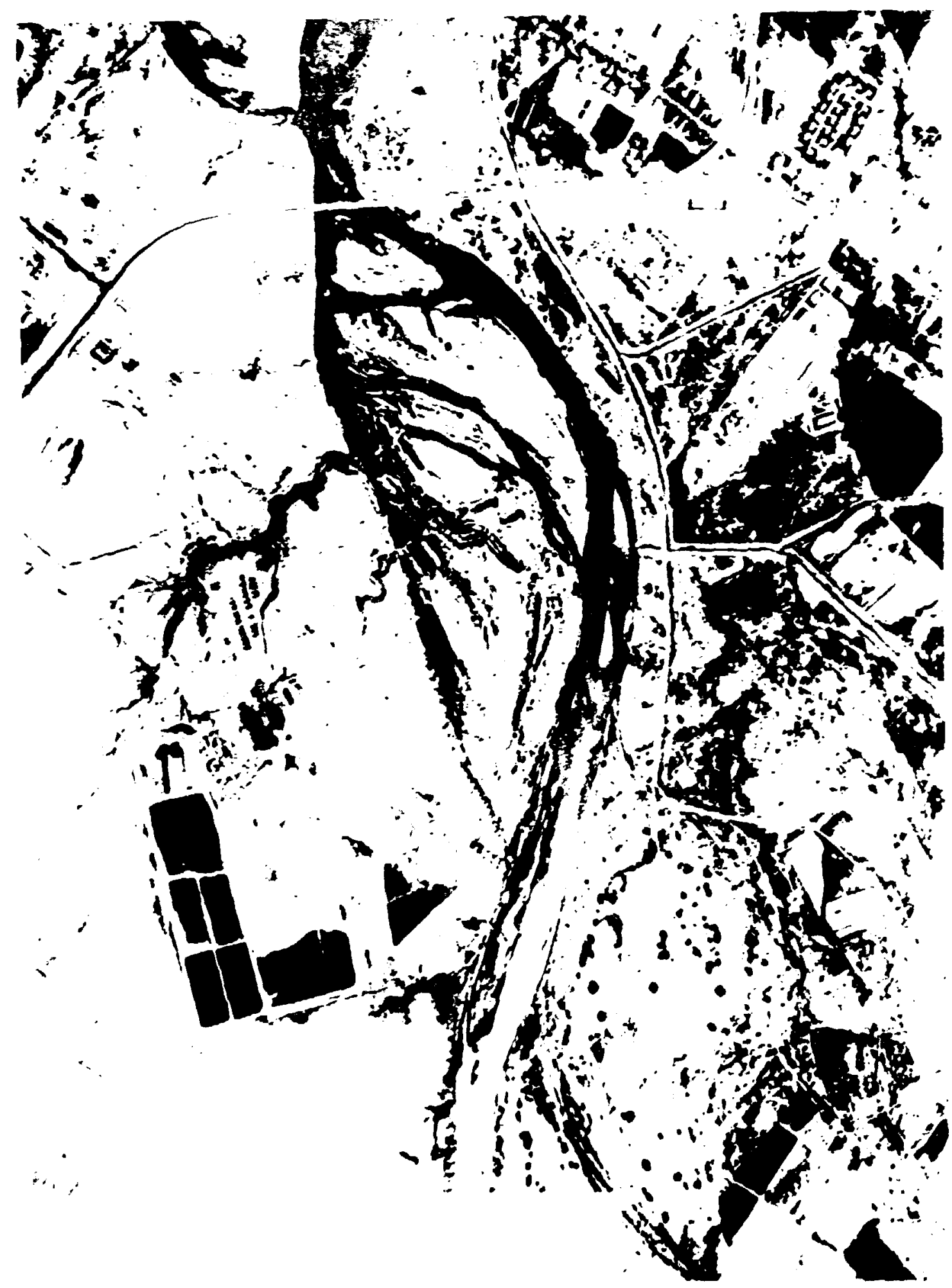

2. Aerial view of Shlprock ste in operating period.

SHIPROCK - Vanadium Corporation of America Approximate Scale - one inch equals 1000 feet 


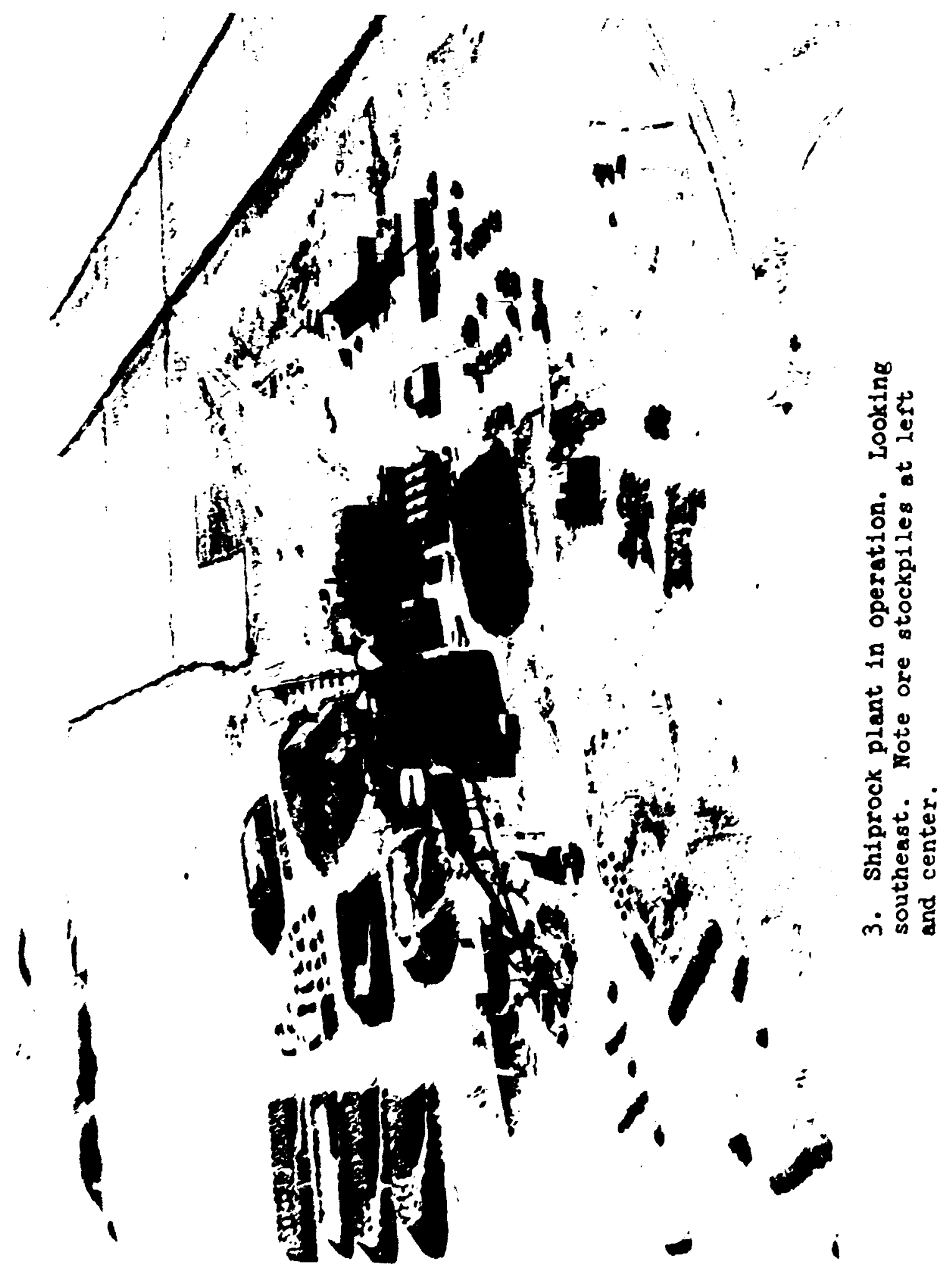




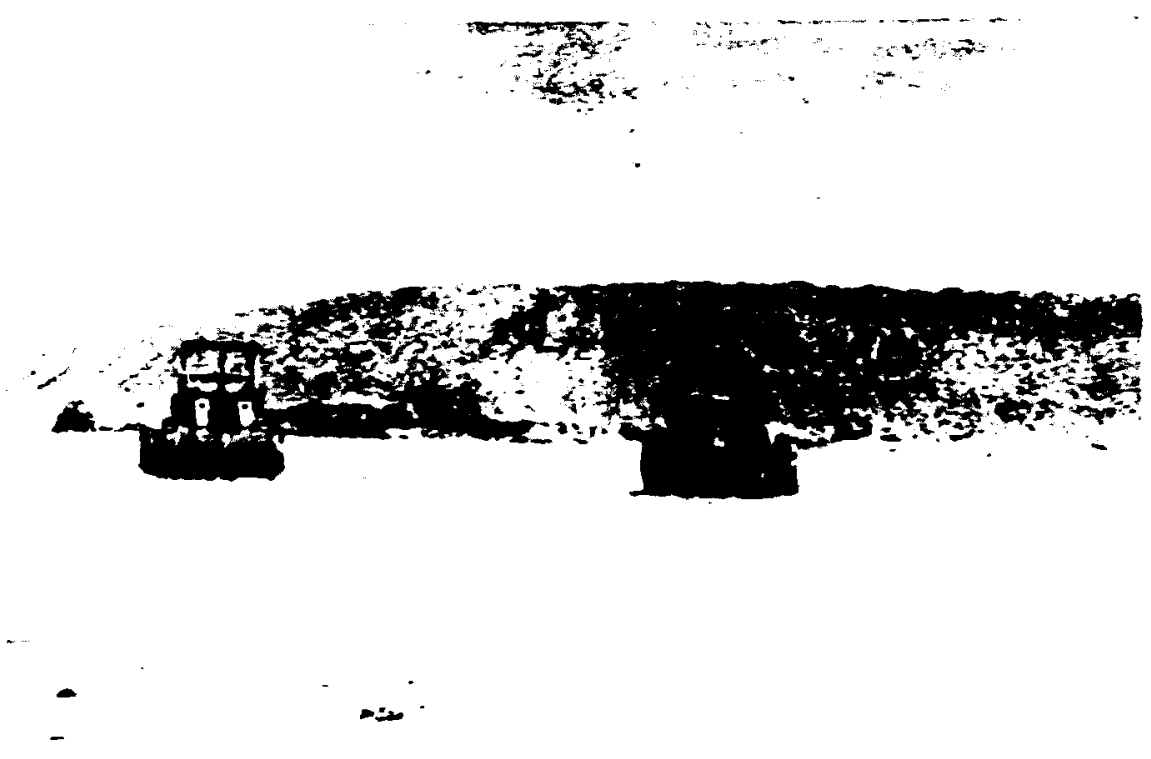

4. Main Tailings pile. Looking northeast from mill area.

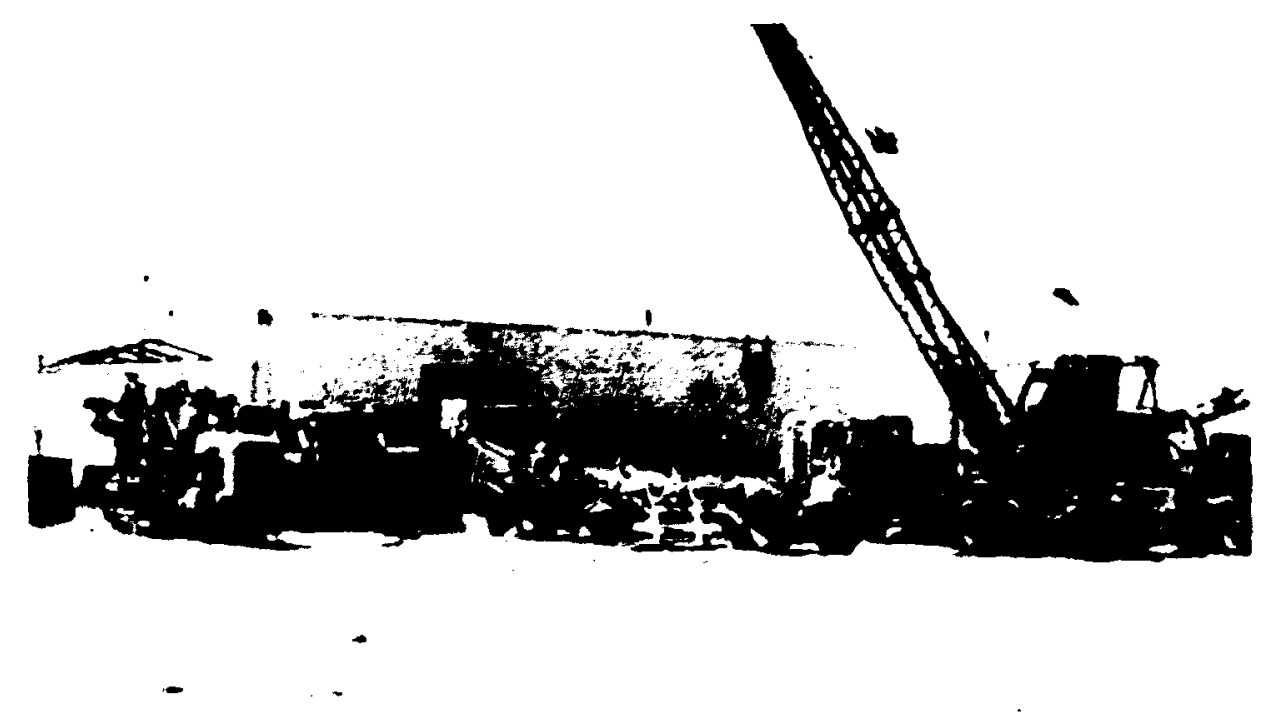

5. Shop building. Looking southwest. 


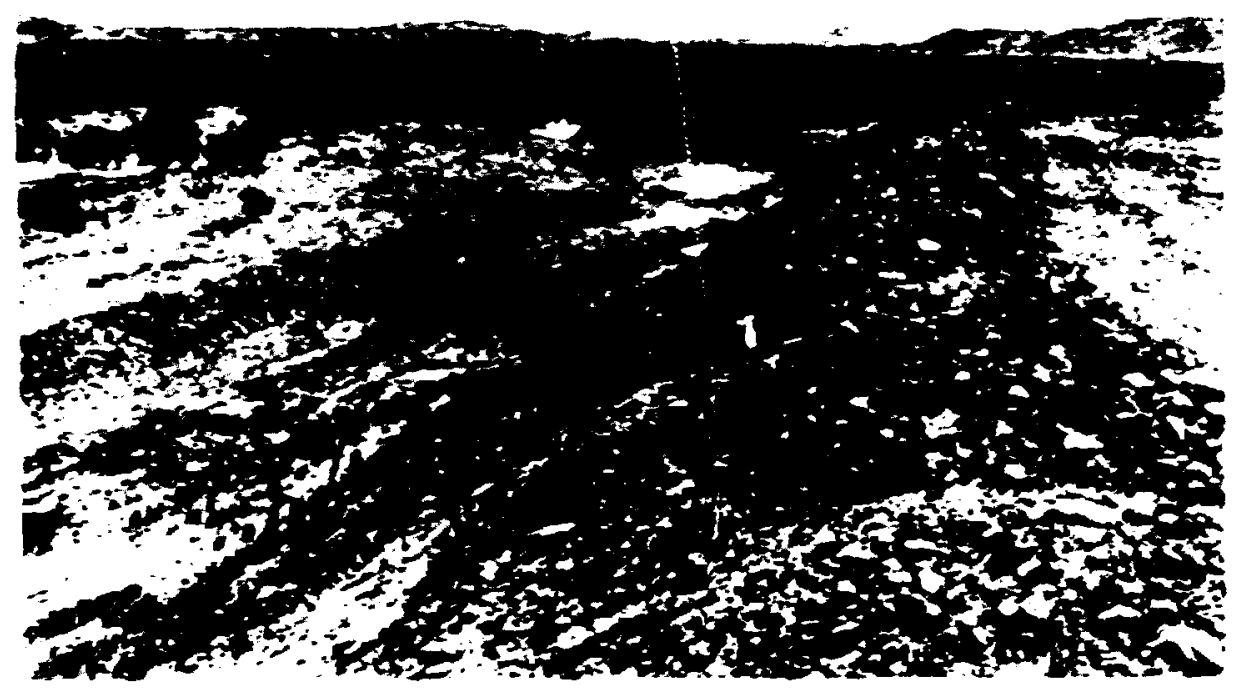

6. Berm along northeast side of main tailings pile. Looking southeast.

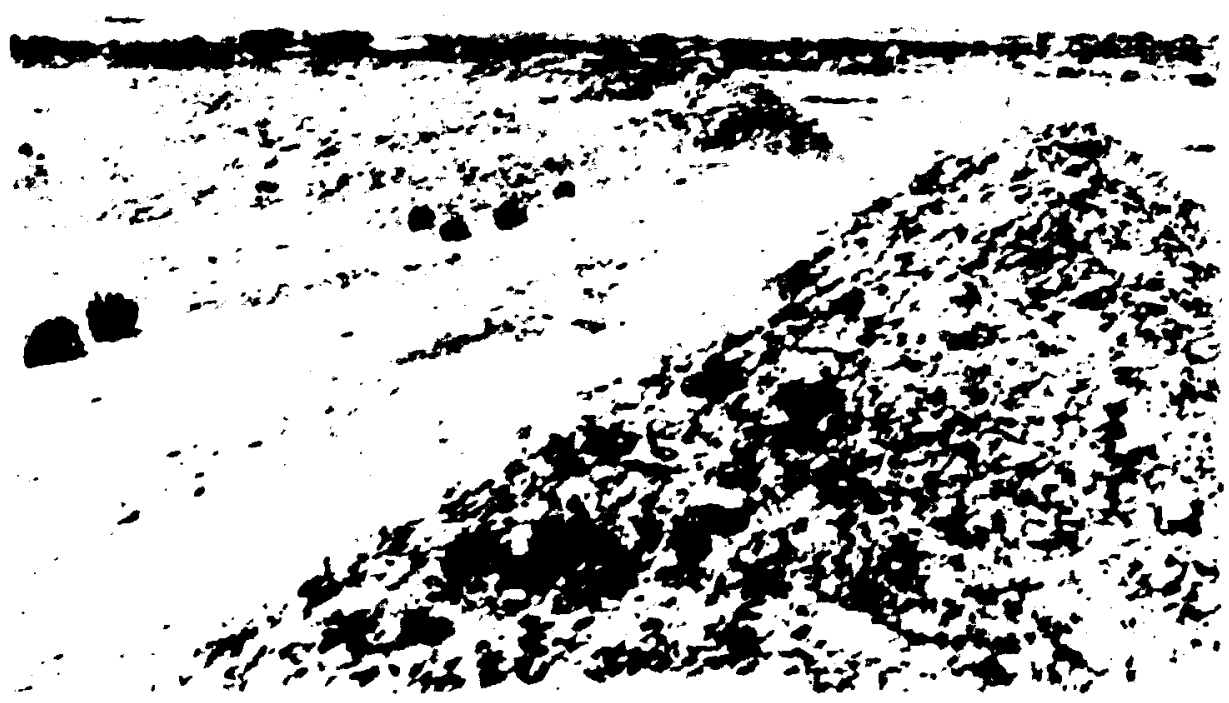

7. Road trrough berm to top of main tailings pile ncar northwest cornor. sooking northwest. 


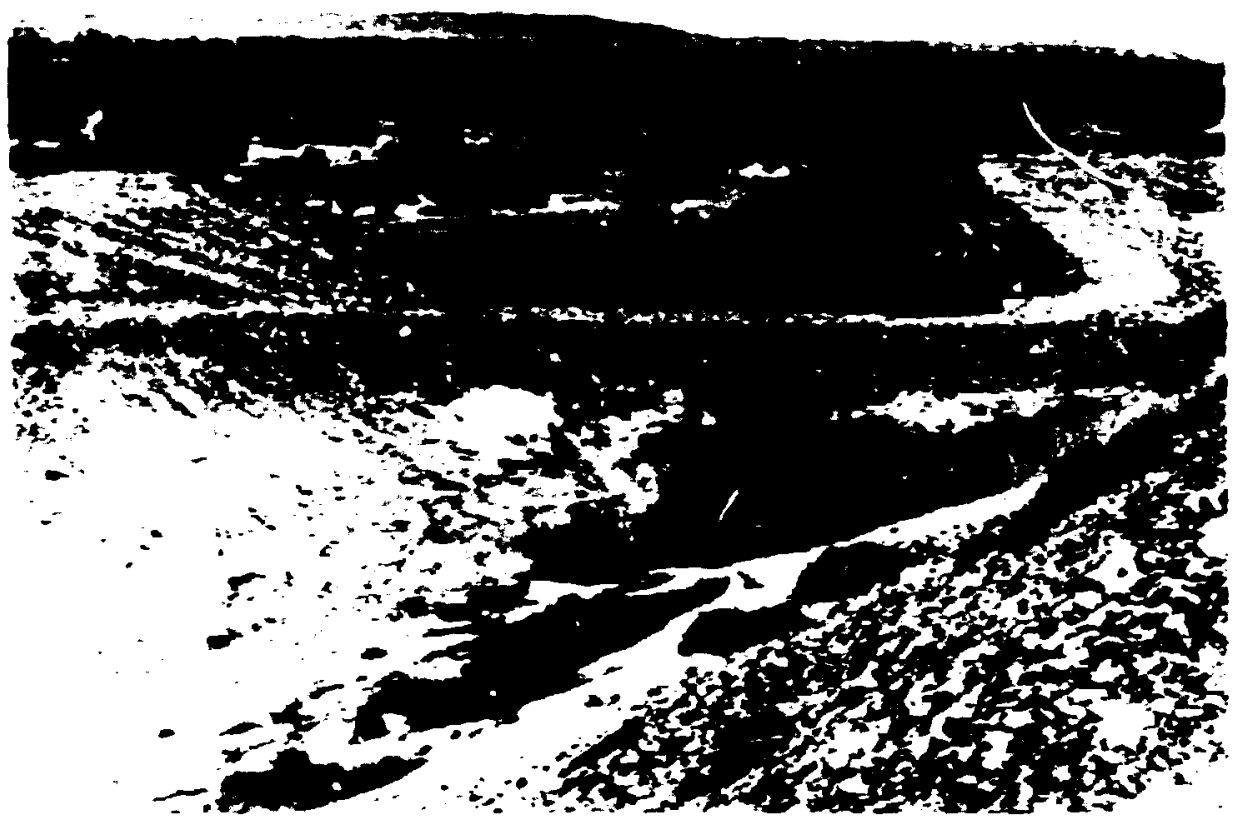

8. Dike and basin on northeast side of main tailings pile. Looking east.

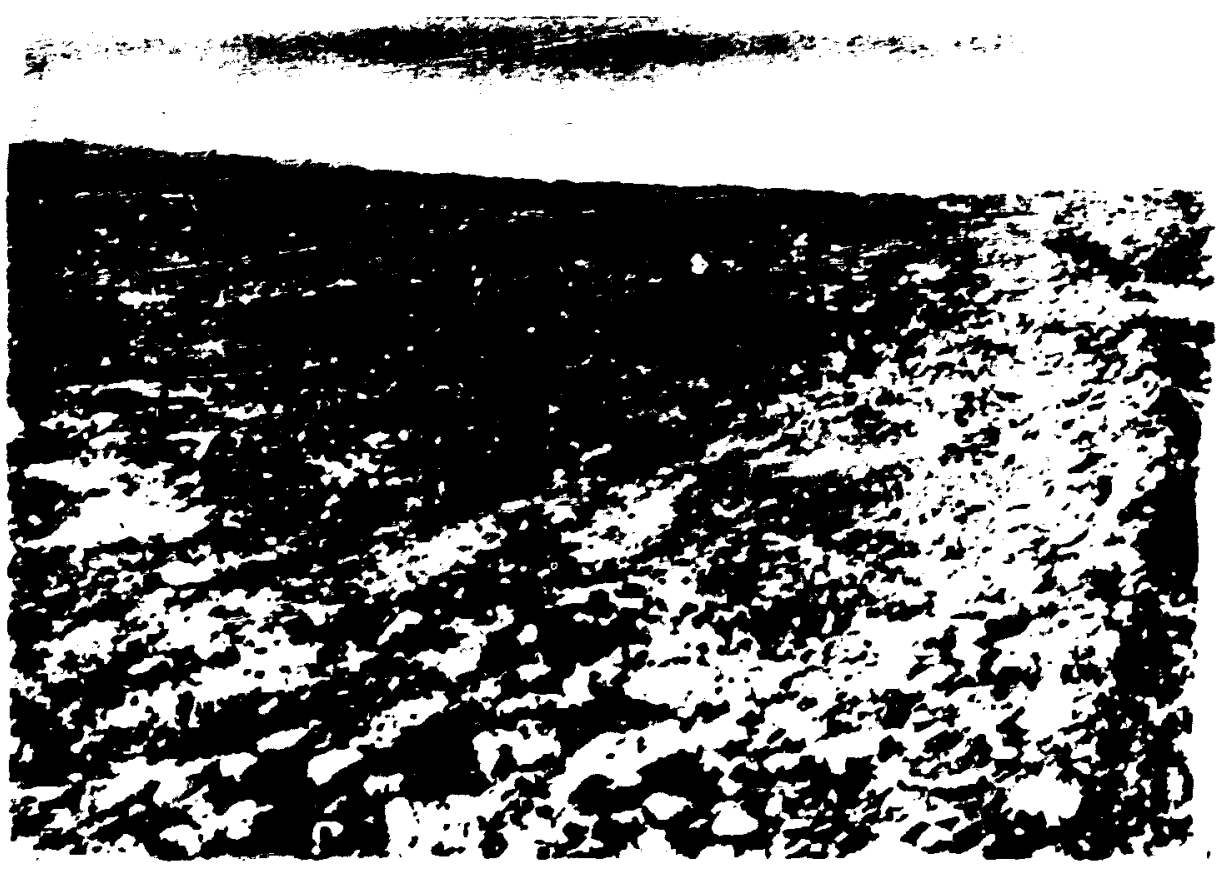

3. Top surface of main tailinga pile noar northeast side. inoking northwest. 


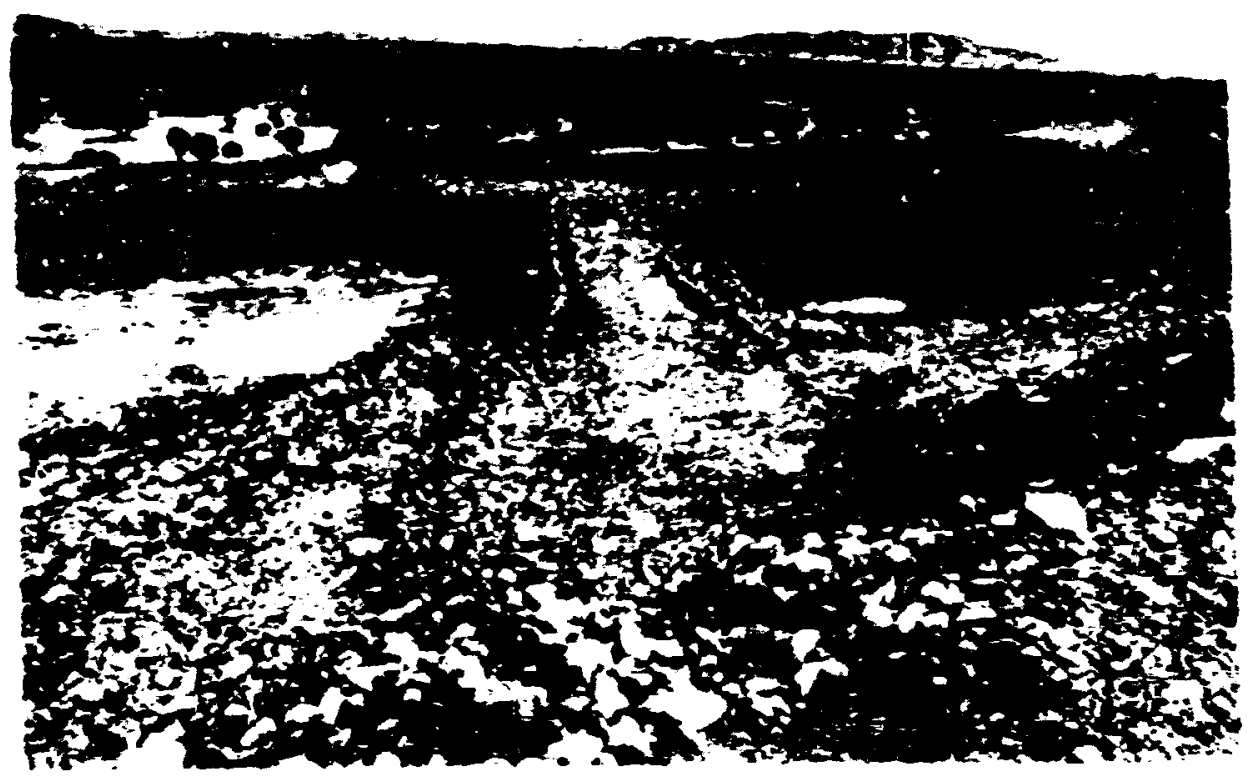

10. Dikes and basins at northeast corner of main tailings pile. Looking southeast.

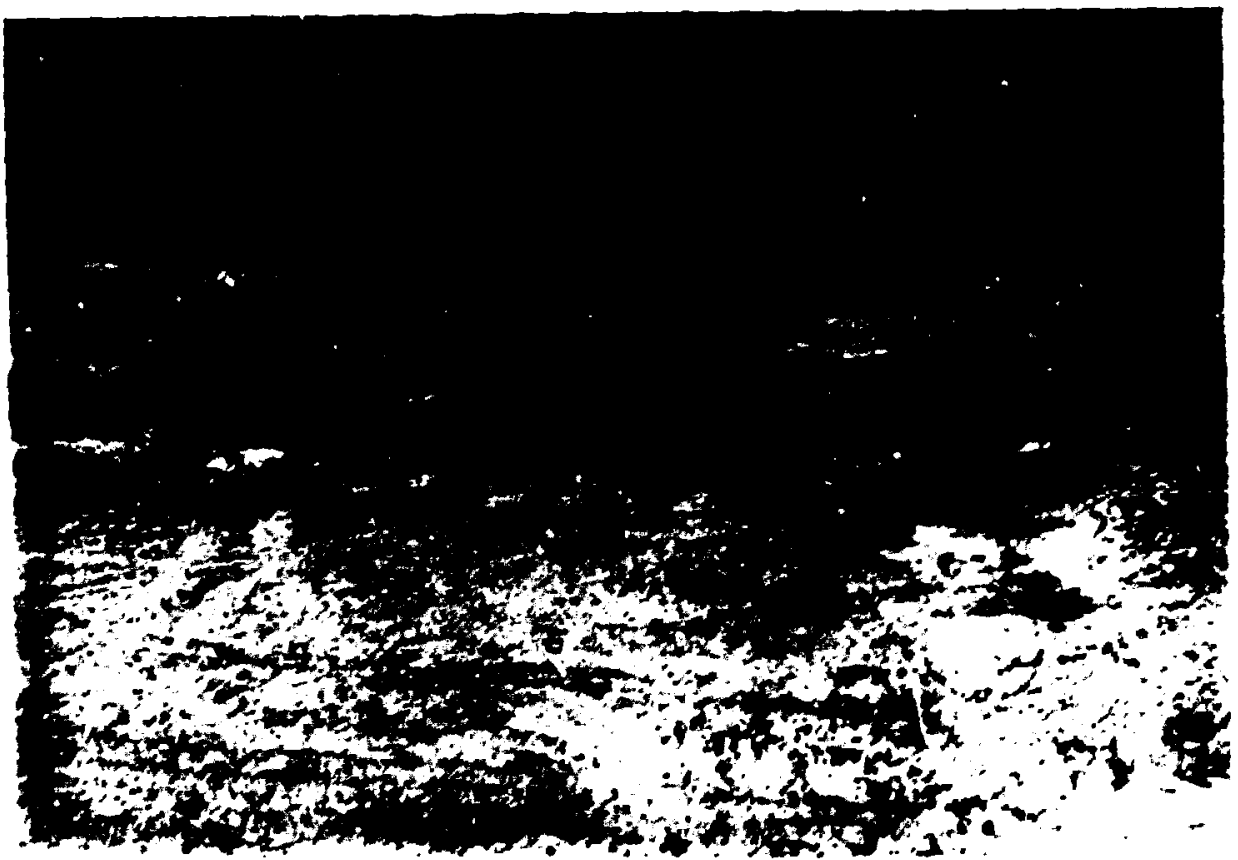

11. Main tailings pile. Looking northwest from near south corner. 


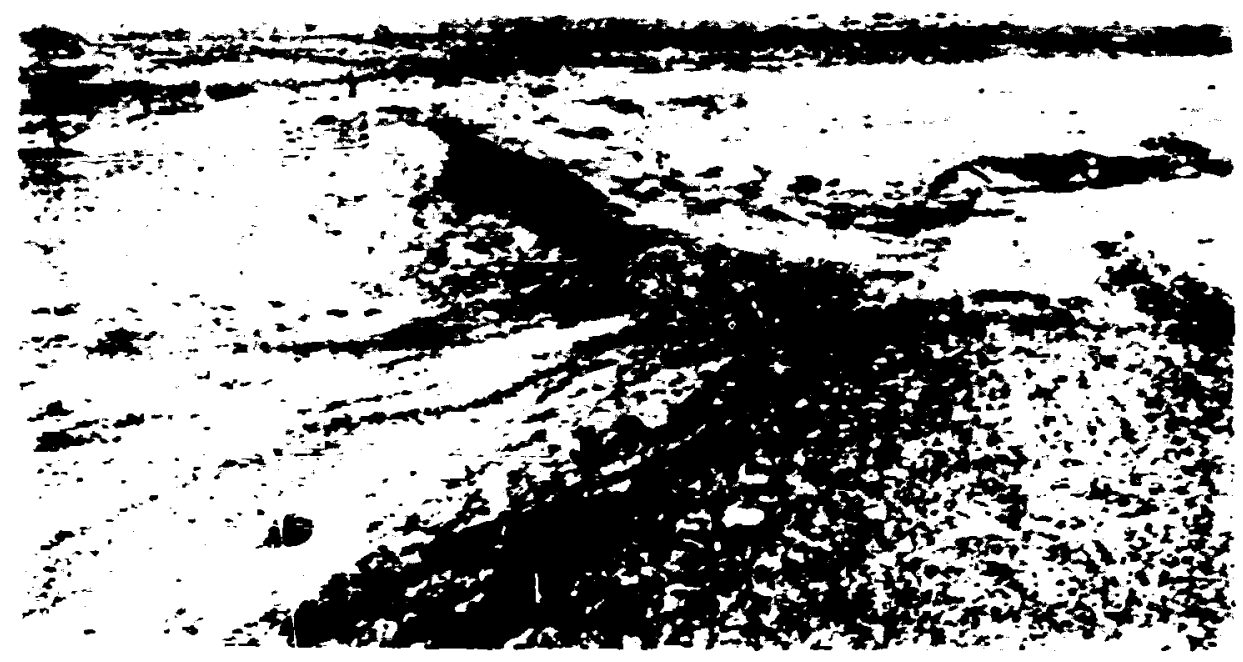

12. Looking south from south corner of main tailings pile.
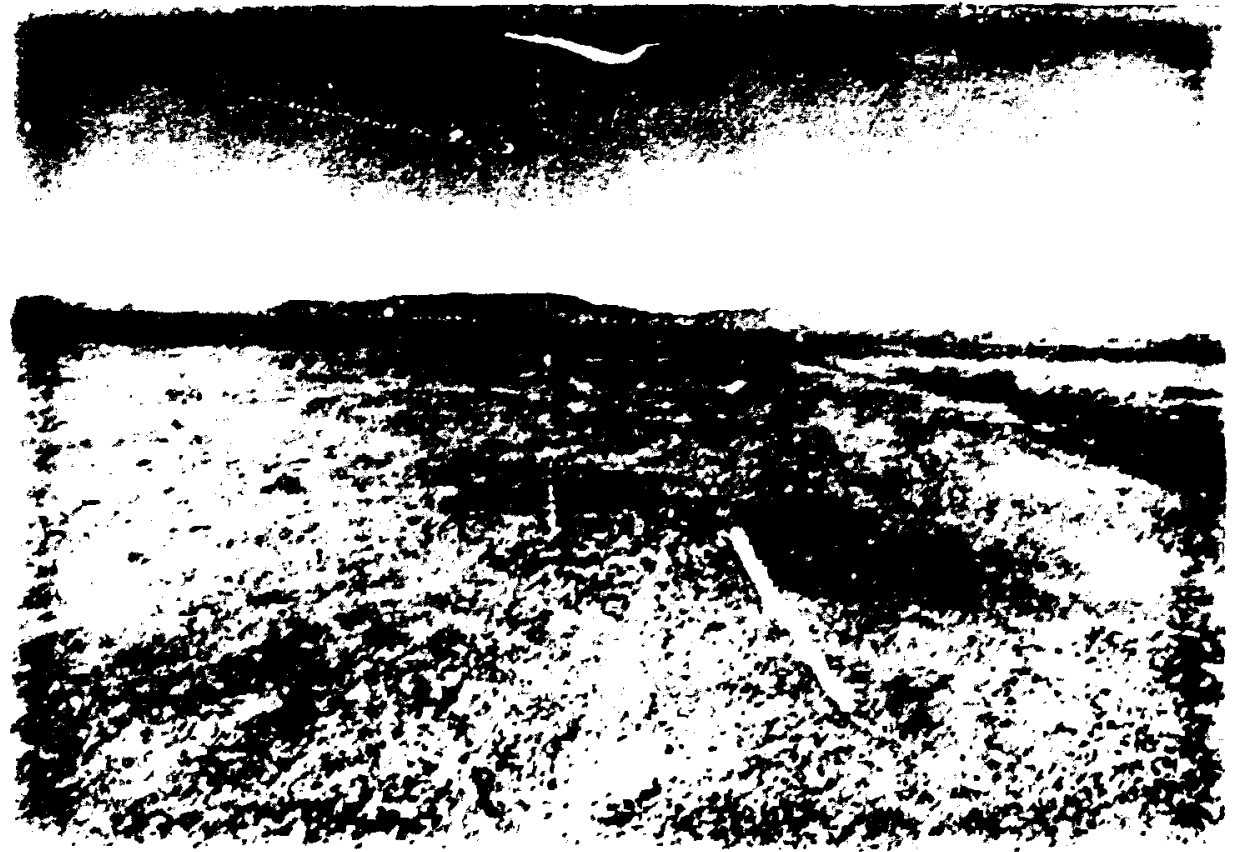

13. Top surface of main tallings pile near southwest side. Looking southeast. 

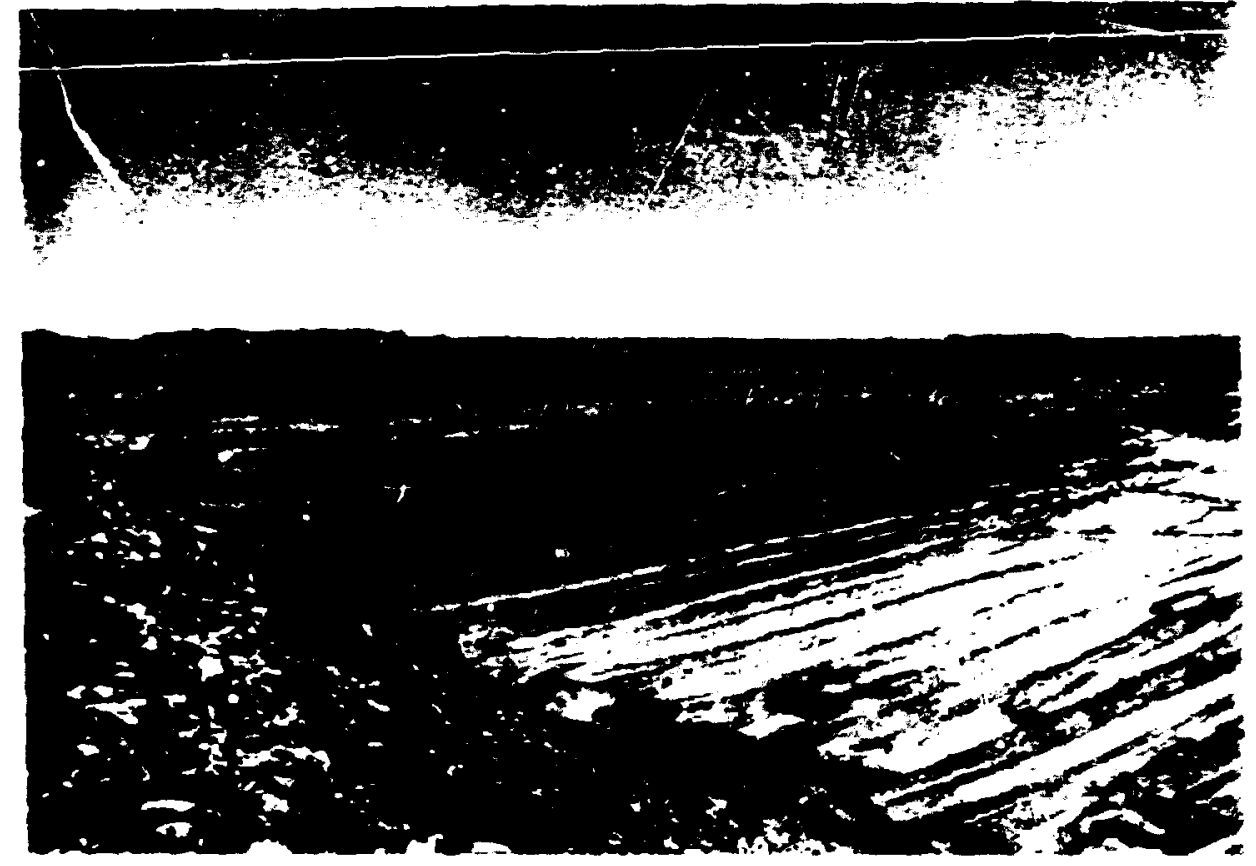

14. Southern tailings area. Looking south from near southwest corner of main tailings pile.
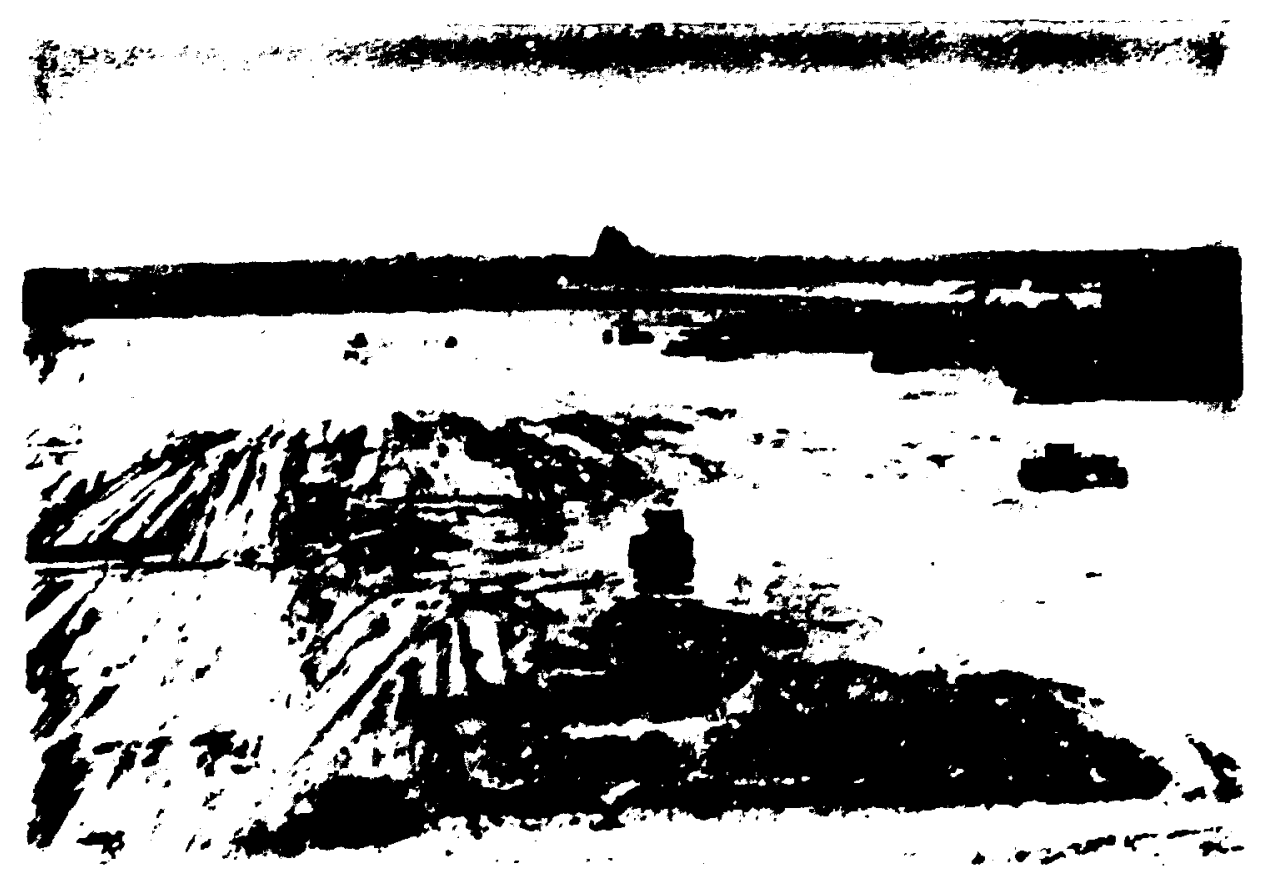

15. Southern tailings area. Looking southwest from near southwest corner of main tailings pile. 
APPENDIY. II

Soil Sampling Techniques and

Radiological Measurements 
Soil Sampling and Measurement of Radionuclide Concentration as a Function of Depth in Soil

A monitoring and sampling procedure was established for this project in conjunction with FB\&DU to measure the radionuclide concertration in soil as a function of depth. A se: of $15-\mathrm{cm}$ ( 6 in.) holes is drilled through the tailings and into the subsoil. A length of polyvinyl chloride (PVC) pipe $(7.6 \mathrm{~cm} 0 . \mathrm{d}$.), sealed on one end, is lowered into the hole, and measurements are made of gamma-ray intensities as a function of depth. A $15 \mathrm{~cm}$-long Geiger-Mueller tube shielded with lead-containing collimating slits is positioned inside the PVC tube for measurements. Signals from this tube are counted using a portable scaler. ${ }^{1}$ After gamma ray vs depth profiles are determined, the position of the interface between tailings and subsoil is estimated. The drilling rig is moved approximately $1 . \hat{c} \mathrm{~m}$ ( $4 \mathrm{ft}$ ), and another hole is drilled with an auger bit to the interface level. Samples of soil core are then collectec as a function of depth using a split-spoon sampler ieach core section is $0.6 \mathrm{~m}$ long).

Most of the penetrating gamma radiation monitored is attributabie to ${ }^{226} \mathrm{Ra}$ and its daughters. Therefore, a calibratiun $f:= \pm \Omega r$ for ${ }^{226} \mathrm{Ra}$ concentration was determined for the collimated gamma-ray probe by comparing the response of this unit (counts per unit time) with a measured value for the radium concentration ( $p$ icocuries per gram) in several soil samples determined by a gamma spectroscopy technique. A least squares fit of FB\&DU data (first probe) from this comparison yields the equation

$$
R=0.528(C-16)
$$

For tiils case, $R$ is the ${ }^{226} R a$ activity in picocuries per gram and $C$ is the observed response of the collimated gamma-ray detector in counts per minute.

The above expression is useful in estimating the overall distribution of radioactivity in the tailings as well as the total quantity of radium in the tailings area. Surface soil samples are obtainec by 
remoyal of an approximately 3-cm-deep layer of soil from an area of about $25 \times 25 \mathrm{~cm}$. The same procedure is used to obtain samples $15 \mathrm{~cm}$ (6 in.) below the surface except that the top 15-cm layer of soil is discarded, and the sample is removed from the next $3-\mathrm{cm}$ layer.

Each sample is dried for $24 \mathrm{hr}$ at $110^{\circ} \mathrm{C}$ in order to remove moisture. The samples are then pulverized in a high speed rotary crusher and sieved to remove particles larger than $500 \mu \mathrm{m}$. The soil is dispensed into twelve $30-\mathrm{ml}$ polyethylene ials of the type used for liquid scintillation counting.

Each vial is weigied to the nearest gram, sealed tightly, and lateled.

The sealed sample vials are stored for a period sufficient to allow attainment of equilibrium between ${ }^{226} \mathrm{Ra}$ and its daughters. Radon-222, which has a radioactive half ife of 3.8 days, will reach the same activity as its long-lived parent, ${ }^{226} \mathrm{Ra}$, in about 30 days. The shortliva:- progeny of ${ }^{22} R n$ will have reached equilibrium within the same time. Determiration of the activity of any of the daughters in the sample will reflect $2<\varepsilon_{R a}$ activity. After equilibration of radon daughters, the 12 sample vials (or smaller number) are inserted into a sample carousel or holder (Figua II-I) that is placed on a Ge(Li) detector for counting as described in the section on gamma spectroscopy below'.

Field Laboratory Facilities and Equipment

A 20 it mobile laboratory van is used to drtermine radon and radon progeny concentrations, gamma-ray intensities, arid for weighing, packaging, and storing soil samples. This yan contains an alpha spectroscopy counting system for air samples along with air sampling equipment; a Johnston Laboratory : adon monitor complete with Lucas flasks and evacuatiun manifold; gamma-ray detectors; mir-ellanenus electronic testing equipment; and standard calibration sources. A trailer-mounted, gasoline-powered $12 \mathrm{~kW}$ motor generator is pulled by the van to supply electrical power in remote locations. A voltage stabilizer is used to privide rer!ilated power for instruments. 


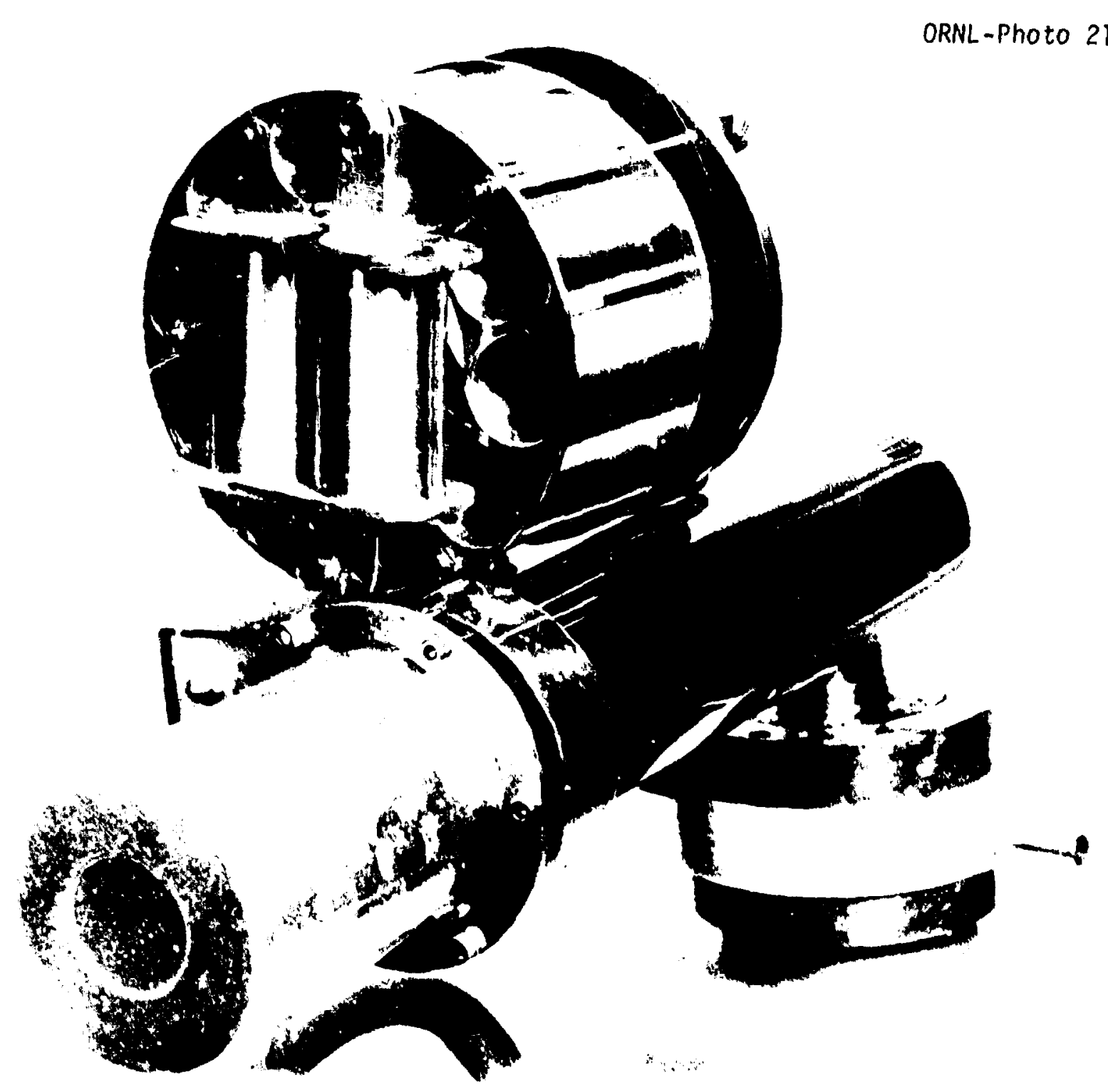

Fig. II-l. Nolder fc" Ge(Li) detector system samples. 
The second field laboratory used in the project is an $8 \times 35 \mathrm{ft}$ air-conditioned semitrailer with running water, tools, miscellaneous supplies, two gama counting systems, and computer. It serves as a counting room, office, and workshop. This trailer requi es electrical power from an external source, but it wan generally be placed in service within a few hours.

\section{Gama Spectroscopy Systens}

Two complete counting systews are used in the semitrailer counting laboratory. A Harshaw integral $3 \times 3$ in. NaI (TI) crystal, a high sensitivity detector, is used to scan all samples for a preliminary estimate of ${ }^{226} \mathrm{Ra}$ activity. This detector is placed in a "fickle barrel" type shield, lined with copper and cadmic to shield fluorescence $x$-rays. Signals from the crystal are sorted by a computer-based (PDP11) pulse-height analyzer. The computer is programmed to control all functions of the ana!yzer and counter, to analyze the data, and to print out a statistically weighted average of the ${ }^{226} \mathrm{Ra}$ activity per unit mass. One advantage of this counting arrangement is that it permits quick sorting; samples can be scanned at the rate of four to five per hour (minimum counting period is $10 \mathrm{~min}$ ). An energy calibration of the $\mathrm{NaI}$ crystal and analyzer is obtained by standardizing with ${ }^{57} \mathrm{Co},{ }^{137} \mathrm{Cs}$, and ${ }^{60} \mathrm{Co}$. A daily $\mathrm{log}$ is kept of the linearity of the analog-to-digital converter $(A D C)$ and adjustments are made when necessary to assure that the energ' level is maintained at $3.8 \mathrm{keV}$ per channel. An efficiency calibration is obtained thruagh daily counting of a uranium standard* (0.05\% uranium mixed with dunite, particle size $=500 \mathrm{um}$ ). Radium-226 is in equilibrium with the uranium, and this isotope and its daughters provide a source of gamma-ray iines for calibration.

Low-energy photons are difficult to resolve accurately using a $\mathrm{NaI}$ detector due to compton scattering of photons in the crystal. In the

*Standard uranium sample obtained from the former Atomic Energy Commission New Brunswick Laboratory. 
interest of time, rapid screening of samples is undertaken and preliminary ${ }^{226} \mathrm{Ra}$ concentrations are determined by observing signals from three high-energy photons of $214 \mathrm{Bi}$, which is one of the short-lived daughters of radon. The energies of these photons are 609, 1120, and $1764 \mathrm{keV}$. In order to accomplish screening, a code was written for the PDP-11 computer which controls data acquisition for the NaI system. The reduction of data is simplified by subtracting the Compton contribution from a region comprising the photopeaks of interest. The Compton contribution is deterwined by taking the average counts in three channels on each side of the photopeak region of interest; this value times the total nuber of channels comprising each photopeak region is subtracted from the total numer of counts in the region. The net value is then compared to the instrument's response to the above-mentioned counting standard whose concentration of ${ }^{226} \mathrm{Ra}$ is known. The concentration of ${ }^{226} \mathrm{Ra}$ in each soil sample is determined by comparing the count on the sample with the count on the standard.

Final data on ${ }^{226}$ Ra concentration in soil samples are determined by counting all samples with a hijh resolution $\mathrm{Ge}(\mathrm{Li})$ detector. This high resolution counting system consists of a horizontally mounted $50-\mathrm{cm}^{3}$ Ge(Li) crystal positioned on a platform for movement into and out of lead shield (Fig. II-2). The detector is used to obtain a complete photon spectrum of the soil samples. Signals from the crystal are routed to a 4096-channel pulse height analyzer and counted for a period long enough to evaluate the ${ }^{226} \mathrm{Ra}$ concentration to a statistical accuracy of $\pm 5 \%$ or better. The spectra are recorded on magnetic tape and stored for complete analysis by computer later.

The computer also is programmeri to sort out peaks from ${ }^{232}$ Th daughters including the 909 and $967 \mathrm{keV}$ peaks from $228 \mathrm{AC}$, the $239 \mathrm{keV}$ from $212 \mathrm{~Pb}$, and the 2614 and $583 \mathrm{keV}$ peaks from ${ }^{208} \mathrm{Tl}$. These permit measurements of the ${ }^{232}$ Th concentration and data are reported for a limited number of samples.

Energy calibration of the Ge(Li) detector is controlled through the use of isotopic sources of ${ }^{37} \mathrm{Co},{ }^{22} \mathrm{Na},{ }^{137} \mathrm{Cs},{ }^{60} \mathrm{Co},{ }^{88 \mathrm{Y}}$, and ${ }^{40 \mathrm{~K}}$. A calibration check is completed each day prior to beginning sample 


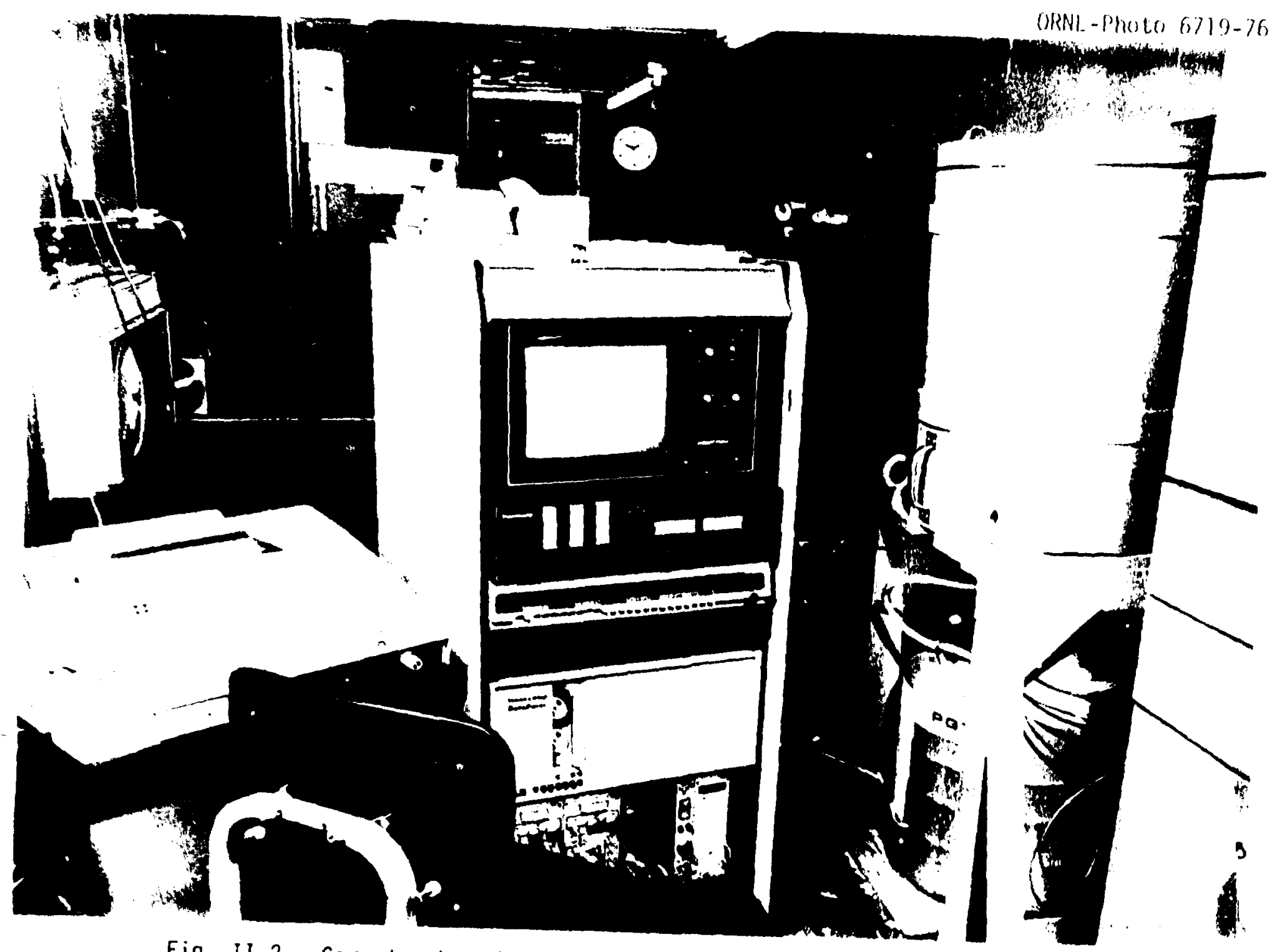

Fig. II-2. Computer based channel analyzer and Ge(Li) counting system. 
counting. In order to maintain linearity of the $A D C$, a spectrum stabilizer is utilized. This instrument is adjusted so that two individual photon energies are detected and maintained in two channels at separate ends of the scale. These two calibration points help maintain an energy span of $1 \mathrm{keV}$ per channel. Efficiency calibration is obtained through the use of the same uranium ore standard samples as for the NaI crystal. An analysis of the counting data is accomplished through a linear leastsquares fitting routine. Net adjusted areas under photo peaks of interest are compared with an extensive radionuclide library. ${ }^{2}$ Data from the computer are presented for each radionuclide as a weighted mean with standard deviation.

\section{External Gamma-Ray Detector}

A gama radiation survey is made on and around the mill site and tailings pile. The instrument used for these measurements is a "Phil" gamma-ray dosimeter. 3 The basic unit is a $15-\mathrm{cm}-(6-i n$.$) long 30-\mathrm{mg} /$ $\mathrm{cm}^{2}$ glass-walled organic-filled Geiger-Mueller (G-M) tube with an energy compensation shield made of tin and lead. Pulses from this unit are counted with a battery-powered portable scaler. Typically, G-M counters are not used for dosimeters because of a peak response at low photon energies. However, erforated layers of tin $(1.0 \mathrm{~mm})$, and lead $(0.1 \mathrm{~cm})$, are used as an energy compensation filter to flatten this peaked response at photon energies below about $200 \mathrm{keV}$. Sealed sources of ${ }^{137} \mathrm{Cs}$ and ${ }^{226} \mathrm{Ra}$ are used for calibration. It was found that the response of this detector is: $1 \mathrm{mR} / \mathrm{hr}=3400$ counts $/ \mathrm{min}$.

For each gamma-exposure rate measurement, at least three 1-min counts are recorded. The mean of these readings (less instrument background) is used to determine the exposure rate to external garma rays. 


\section{Radon Daughter Sampler*}

Radon daughter concentrations are measured with a sampling and counting instrument which has been in use at ORNL for several years," and it was also used in the remedial action program in Grand Junction. 5 The filter counter for this sampling device, shown in Fig. II-3, utilizes a modified gas flow alpha counter for housing a $600-\mathrm{s}^{2}$ licon diode. Normally, this type detector is operated in a vacuum chamber. However, in this case, it was found that by flowing helium at atmospheric pressure through the assembly, absorption of alpha particles is small relative to absorption in air. Furthermore, it is not necessary to cycle the bias voltage of the diode because there are no changes in pressure. Alpha particle pulses are recorded with a 100-channel analyzer. A small alpha source standard is used for standardizing the energy scale. Air that is monitored for radon daughters is sampled at the rate of 12 to 14 liters/min. An absolute calibration of the airflow is provided through a comparison of the sampler's mass flow meter and a wet test meter. Samples are normally collected for $10 \mathrm{~min}$, and the first count of the filter is started at 2 min after removal of the sample and continued for $10 \mathrm{~min}$. For this case, a determination is made of the number of counts due to the decay of $218 \mathrm{Po}$ (RaA) and $214 \mathrm{Po}$ ( $R a C^{\prime}$ ). A second count is started $15 \mathrm{~min}$ after removal of the sample and continued for $15 \mathrm{~min}$. In this case, counts are recorded from the decay of $214 \mathrm{po}$. Data from the counter are stored in a pulse height analyzer and reduced by computer. The code for this analysis is explained in detail elsewhere. ${ }^{6}$ Results of the analysis of data using this code are presented as concentrations of RaA, RaB, and RaC'. In addition, a value for the working level concentration is also provided along witl an estimate of the error associated with each reported value.

\footnotetext{
*This section and the following section contain descriptions of devices and methodologies typically used in the radiological surveys of milling facilities. They are included in each report in this series. However, in some instances, such as at Monument Valley, the measurements were not possible.
} 
ORNL-Photo $1077-78$

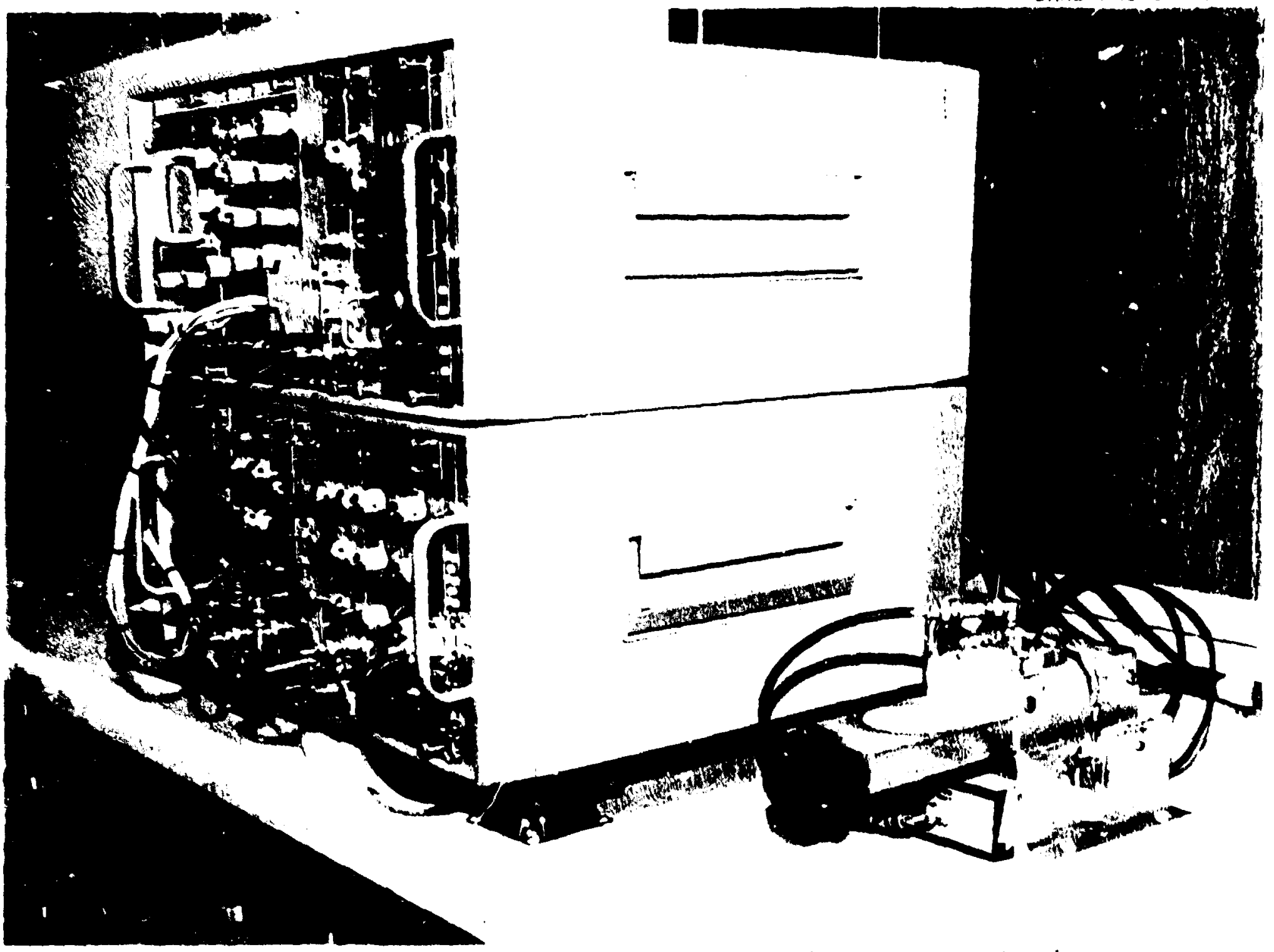

Fig. II-3. System used for measurement of radon daughter concentrations. 


\section{Radon Monitor}

The instrument used to measure radon concentrations in air consists of 95-ml Lucas chamber and a readout unit.* Each chamber is evacuated to approximately $1 \mathrm{mg}$ and then opened to atmospheric pressure in the area where a radon measurement is required. No filtration is used for sampled air. The short-lived daughters of radon drawn into the chamber are allowed to decay for 3 to $4 \mathrm{hr}$ prior to counting the flask. Comparison of the results from this instrument and the radon progeny monitor provide an estimate of the degree of equilibrium between radon and its daughters in the selected locations where air samoles are taken.

*LLRC-2 Low Leve? Radon Counting System manufactured by Johnston Laboratories, Inc., Baltimore, Md. 


\section{APPENDIX II REFERENCES}

1. J. H. Thorngate and J. E. Parks, "A Portatle Scaler," Heatth Phys. 12, 385-393 (1965).

2. J. F. Emery and F. F. Dyer, "Multi-Element Determination in Environmental Neutron Activation Analysis Using MONSTR," Proceedings of the Second International Conference on Nuclear Methods and Environmental Research, CONF-740701, held at the University of Missouri, Columbia, Mo., July 29-31, 1974.

3. E. B. Wagner and G. S. Hurst, "A Geiger-Mueller $\gamma$-Ray Dosimeter with Low Neutron Sensitivity," Health Phys. 5, 20-26 (1967).

4. P. T. Perdue, W. H. Shinpaugh, J. H. Thorngate and J. A. Auxier, "A Convenient Counter for Measuring Alpha Activity of Smear and Air Samples," Health Phys. 26, 114-116 (1974).

5. G. D. Kerr, "Measurements of Radon Daughter Concentrations in Air," pp. 202-207 in Dosimetry for Hroman Exposures and Radiol sgical Impact, ORNL-4979 (July 1974).

6. G. D. Kerr, Measurement of Radon Progeny Concentrations in Air by Alpha-Particle Spectrometry, ORNL-TM-4924 (July 1975). 
APPENDIX III

Water Sampling and Analysis

Water samples are obtained at appropriate points on and around the mill site, labeled and stored for later analysis. Each sample is centrifuged and filtered through a $0.45-\mu \mathrm{m}$ filter to remove suspended solids. The samples are then analyzed by radiochemical techniques as described in this appendix. 
Procedure for the Sequential Determination of ${ }^{226} \mathrm{Ra},{ }^{230} \mathrm{Th}$, and $210 \mathrm{~Pb}$ in Water from Uranium Mill Tailings Siles

P. M. Lantz

Health and Safety Research Division

Oak Ridge National Laboratory

Oak Ridge, Tennessee

\subsection{Radium-226}

1.1 Filter the 21.0 liter water sampie using a vacuum flask and \$42 Whatman filter paper to remove suspended particles.

1.2 Reduce the volume of the water sample, to which $10 \mathrm{ml}$ of concentrated $\mathrm{HNO}_{3}$ has been added, to less than $250 \mathrm{ml}$ by evaporation.

1.3 Transfer the solution to a 250-m1, long-neck, tapered-joint, flat-bottom Pyrex boiling flask. Insert a Teflon-coated magnetic stirring bar. Add $37 \mathrm{ml}$ of concentrated $\mathrm{HNO}_{3}$ to make the final concentration $3 \%$ Insert the modified, female, tapered joint with gas diffuser and side arm with stopcock. Seal off the gas inlet and close the stopcock to assure containment of $222 \mathrm{Rn}$ in the flask. Store for at least 30 days to await attainment of ${ }^{226} \mathrm{Ra}-222 \mathrm{Rn}$ equilibrium.

1.4 Next, connect the 250-ml de-emanation flask to a helium source and the radon trapping system. Attach an evacuated Lucas chamber. Flush the system with helium gas while bypassing the flask. Stop the gas flow. Immerse the unfired Vycor radon concentrator in a liquid nitrogen bath. Be sure the upstream exit for helium gas is open. Start the magnetic stirrer. Open the flask side arm stopcock to the system and start helium gas flowing through the liquid at a rate not to exceed 2.8 liters/hr. The radon-helium stream is dried and stripped of organic condensable components by $\mathrm{KOH}$ and ascarite traps. Radon is condensed on the Vycor at liquid nitrogen temperaturc and thus separated from the helium gas carrier. 
1.5 Stop the de-emanation process after $30 \mathrm{~min}$. Having shut off the gas flow, close the helium exit. Isolate the radon trap and the evacuated Lucas chamber from the remainder of the system via stopcocks.

1.6 Open the Lucas chamber stopcock and remove the liquid nitrogen from the radon trap to allow the gaseous radon to diffuse into the chamber. To hasten the $d^{\text {" }}$ fusion, the trap may be gently flamed.

1.7 Bypassing the flask, use a controlled stream of helium to flush residual radon into the Lucas chamber until near atmospheric pressure has been reached. Stop the gas flow and close the stopcock on the Lucas chamber.

1.8 After a delay of 3.0 to $3.5 \mathrm{hr}$ to permit the ${ }^{222} \mathrm{Rn}$ to reach equilibrium with its daughters, place the Lucas chamber over a photomultiplier tube and count the gross alpha for $30 \mathrm{~min}$.

1.9 Subtract the Lucas chamber background, counted under the same conditions, from the gross count. Divide the net count by three to obtain the ${ }^{222} \mathrm{Rn}$ count at that time. Correct the count for time elapsed since de-emanation was terminated and the efficiency of the Lucas chamber for converting alpha discharges to scintillations ( $285 \%$ ). Report the ${ }^{226}$ Ra in equilibrium with ${ }^{222}$ Rn as picocuries per liter.

\subsection{Thorium-230}

2.1 Transfer one-half of the water sample remaining from the radon de-emanation process $\left(3 H_{H N O}\right)$ to a Pyrex beaker for volume reduction on a magnetic stirrer hot plate.

2.2 Add $0.7 \mathrm{~g} \mathrm{Al}\left(\mathrm{NO}_{3}\right)_{3} \cdot 9 \mathrm{H}_{2} \mathrm{O}, 2.0 \mathrm{ml}(20 \mathrm{mg}) \mathrm{Pb}$ carrier, $1.0 \mathrm{ml}$ $\left(20.9 \mathrm{mg}\right.$ ) Bi carrier and 5,000 to $10,000 \mathrm{cpm}$ of ${ }^{234} \mathrm{Th}$ tracer to the water sample before reducing the volume to approximately $20 \mathrm{ml}$.

2.3 Should the sample solution contain undissolved salts, separate liquid and solids by use of centrifuge. Dissolve the 
solids by heating with a minimum vi une of distilled water or dilute $\mathrm{HNO}_{3}$. Conbine the dissolved solid with the original supernate. Should silicic acid form in the solution during volume reduction, as evidenced by its deposition on the beaker walls, cool the solution to room temperature and centrifuge. Add an equal volume of concentrated $\mathrm{HNO}_{3}$ to the supernate. Wash the solids with a small volume $(5.0 \mathrm{ml})$ of $8 \% \mathrm{HNO}_{3}$ and centrifuge. Combine the wash with the adjusted supernate. Discard the solids. Keep the solution cool in an ice bath during precipitation of hydroxides with an excess of ammonium hydroxide to minimize the formation of silicic acid from dissolved silicates. Let stand 5 to 10 min. Centrifuge, pour off the supernatant liquid, and wash the precipitate with dilute anmonium hydroxide. Discard the supernatant and wash liquids. Dissolve the solids in 10-20 ml of $8 \because \mathrm{HNO}_{3}$. Should the solution contain suspended silicic acid, centrifuge, wash the solids with $5 \mathrm{ml}$ of $8 \because \mathrm{HNO}_{3}$ and combine the supernatant liquids. Discard the solids.

2.4 Transfer the $8 \mathrm{KHNH_{3 }}$ solution to a conditioned Dowex $4 \times 1$ anion exchange column $5 \mathrm{~mm}$ i.d. $\times 10 \mathrm{~cm}$ long ( $2.0 \mathrm{ml}$ vol.). The column is conditioned by passing through it at least 5 column volumes $(10 \mathrm{ml})$ of $8 \because \mathrm{HNO}_{3}$. The anion-complexed thorium adsorbs on the rejin column to the exciusion of the cations. Wash the column with $10 \mathrm{ml}$ of $8: \mathrm{HNO}_{3}$ to remove residual bismuth. Combine the effluent and wash soiutions, and save them for lead and bismuth recovery.

25 Strip the thurium from the column with $5.0 \mathrm{ml}$ of distilled water followed by $10 \mathrm{ml}$ of $6: \mathrm{HCl}$.

2.6 Convert the chloride to the nitrate by adding an excess of $\mathrm{HNO}_{3}$ and reducing the solution to near dryness on a hot

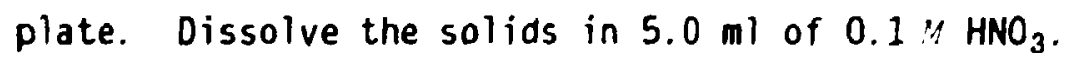

2.7 Transfer the $0.1 \mathrm{MNO}_{3}$ solution to a conditioned Dowex $5 \mathrm{C} \times$ $1 \mathrm{~mm}$ cation exchange $2.5 \mathrm{~mm}$ i.d. $\times 7 \mathrm{~cm}$ long $(\sim 0.4 \mathrm{ml}$ vol.). The column is conditioned by passing $5.0 \mathrm{ml} 8 \mathrm{AHNO}_{3}$ through 
$i i$ and then washing it free of excess acid with distilled water as indicated by litmus paper.

2.8 Wash the column with $5.0 \mathrm{ml}$ of $2.4 \mathrm{hCl}$ to remove traces of bismuth and other weakly bound cations.

2.9 Strip the thorium with $5.0 \mathrm{ml}$ of $8 \mathrm{NHO}_{3}$ and reduce the volume of the solution to a few drops by evaporation.

2.10 Transfer the solution with a suitable pipette onto a 2-in. stainless-steel disc supported on a hot plate by a steel washer 0.75 in. i.d. $\times 1.5$ in. $0 . \dot{c}$. Dry slowly to minimize the deposit area at the center of the disc. Fire the disc to red heat with $a$ gas torch to remove carbonaceous materials.

2.11 Determine the thorium yield by counting the ${ }^{234}$ Th beta with in end window counter and compare it with a mounting of like count of the ${ }^{234} \mathrm{Th}$ tracer used in the anaiysis.

2.12 Determirie the ${ }^{230}$ Th alpha disintegrations per minute (dpm) by pulse-height anziysis using a diode pickup in a helium atmosphere. Compare the counts of ${ }^{230} \mathrm{Th}$ alpha in the sample with those in a ${ }^{230}$ Th standard mounting whose dpm is known.

2.13 To correct for the contribution of $230 \mathrm{Th}$ which may be in the ${ }^{234}$ Th tracer, pulse analyze the ${ }^{234}$ Th mounting. Subtract the contribution from the tracer after correcting for yield to obtain the net ${ }^{230} \mathrm{Th}$ content of the water sample.

2.15 Calculations

$$
{ }^{230} \operatorname{Th}(p C i / 1 i \text { ter })=\frac{A B}{C D E F},
$$

where

$$
\begin{aligned}
& A=\text { Water sample net alpha }(\mathrm{cpm}) \\
& B={ }^{230} \mathrm{Th} \text { standard (dpm) } \\
& C=230 \mathrm{Th} \text { standard }(\mathrm{cpm}) \\
& D=\text { Fraition of } 234 \mathrm{Th} \text { tracer re:overed } \\
& E=\text { Volume of samp !e (liter) } \\
& F=2.22 \mathrm{~d} /(\mathrm{m} \cdot \mathrm{p}(\mathrm{i})
\end{aligned}
$$




\subsection{Lead-210}

3.1 Evaporate the Dowex $4 \times 1$ effluent and wash from Step 2.4 to $220 \mathrm{ml}$. Cool and slowly add amonium hydroxide, while stirring in an ice baih, until hydroxice precipitation barely starts. Add 1 to 2 drops of concentrated $\mathrm{HNO}_{3}$ to each $10 \mathrm{ml}$ of solution to give an acidity of 0.2 to 0.4 .

3.2 Slowly bubble $\mathrm{H}_{2} \mathrm{~S}$ through the chilled solution to precipitate metal sulfides. Let the mixture stand 10 to $15 \mathrm{~min}$ and centrifuge. Discard the supernate. Wash the sulfides with 5 to $10 \mathrm{ml}$ of $\mathrm{H}_{2} \mathrm{~S}$-saturated $0.2 \because \mathrm{HNO}_{3}$ solution. Centrifuge and discard the wash.

3.3 Dissolve the sulfide precipitate in a minimum of concentrated $\mathrm{HNO}_{3}$ by heating in a hot water bath. Dilute with 5 to $10 \mathrm{ml}$ of distilled water and filter out the suspended sulfur on \#42 Whatman filter paper. Wash out the centrifuge tube and filter with 5 to $10 \mathrm{ml}$ of distilled water.

3.4 Tiansfer the solution to a centrifuge tube and precipitate the hydroxides with an excess of ammonium hydroxide. Digest 10 min in a hot water bath. Cool, centrifuge, nd wash the precipitate with 5 to $10 \mathrm{ml}$ of dilute $\mathrm{NH}_{4} \mathrm{OH}$. Oiscard the supernatant and wash liquids.

3.5 Dissolve the hydroxides in a minimum of concentrated $\mathrm{HNO}_{3}$ and dilute 2 ) $10 \mathrm{ml}$. Add $0.5 \mathrm{ml}$ of concentrated $\mathrm{H}_{2} \mathrm{SO}_{4}$ to precipitate $\mathrm{PbSC}_{4}$. Digest $15 \mathrm{~min}$ in a hot water bath, cool, centrifuge, and wash the $\mathrm{PbSO}_{4}$ with distilled water. Save the supernatant and wash liquids for bismuth recovery.

3.6 Transfer the $\mathrm{PbSO}_{4} \mathrm{~s}$ ! : rry onto a tared $\# 4 \hat{\imath}$ Whatman filter paper disc which is supported by the perforated fixed plate of a Hirsch funnel. Dry the $\mathrm{PbSO}_{1}$ and paper with eth.l alcohol followed by ethyl ether.

3.7 Weigh the filter paper and $\mathrm{PbSO}_{4}$ to determine the yield of $210 \mathrm{~Pb}$. Store the $21 \mathrm{PbSO}_{4}$ sample for 30 days to allow the $210 \mathrm{~Pb}$ to reach quilibrium with its $210 \mathrm{Bi}$ daught?r. The ${ }^{210} \mathrm{Bi}$ beta is counted in a low-level gas-proportional counter with a 
1-mil-thick polystyrene cover to shield out any stray alpha emissions.

3.8 Add pellets of $\mathrm{NaOH}$ to the bismuth solution from Step 3.5 to precipitate kismuth hydroxide. Digest for $10 \mathrm{~min}$ in a hot water bath, cool, and centrifuge. Wash the precipitate with $10 \mathrm{ml}$ of distilled water. Discard supernatant and wash liquids.

3.9 Dissolve the solids in a minimum of $\mathrm{HNO}_{3}$. Add 3-4 drops of concentrated $\mathrm{HCl}$ and dilute to $240 \mathrm{ml}$ with hot distilled water to pricipitate $\mathrm{BiOCl}$. jugest for $\mathbf{2 5} \mathrm{min}$ in a hot water bath or until the precipitate has settled.

3.10 Pour the irot, supernatant liquid through a tared \#42 Whatman filter paper ;upported by a perforated, fixed-plate, Hirsch funnel. Slurry the BiOCl onto the filter naper disc with small portions of hot distilled water. By means of a stirring rod, guide the deposit to the center of the disc. Dry with ethyl alcohol and ethyl ether.

3.11 Weigh the BiOCl and filter paper in order to determine yield.

3.12 Count the 5.01 day $210^{\circ i}$ beta, which is in equilibrium with $210 \mathrm{~Pb}$, in a low-level, gas-propertional counter. The counting efficiency of the counter is determined by counting several similar mountings having known $210 \mathrm{Bi}$ disintegration rates, with varying weights of $\mathrm{BiOCl}$ from which a calibration curve is constructed.

3.13 Refer to the calibration curve and convert cpm to dpm by means of an efficiency factor for the weight of sample in question.

3.14 Calculation

$$
210 \mathrm{~Pb} \rightarrow 210 \mathrm{Bi}(\mathrm{pCi} / \text { liter })=\frac{\mathrm{AB}}{\mathrm{CDEF}},
$$

where

$$
\begin{aligned}
A= & \text { Beta count minus background }(\mathrm{cpm}) \\
B= & \text { Cori ction for decay from } \mathrm{Pb} \text { separation time } \\
& \text { to suunting time }
\end{aligned}
$$


$C=$ Counter efficiency

$D=$ Fraction of $B i$ recovered

$E=$ Volume of sample (litei)

$F=2.22 d /(m \cdot p C i)$

\subsection{Reagents}

4.1 hiuminum nitrate.

4.2 Lead carrier, $10 \mathrm{mg} / \mathrm{ml}$. Dissolved $8.0 \mathrm{~g} \mathrm{~Pb}\left(\mathrm{NO}_{3}\right)_{2}$ in dilute $\mathrm{HNO}_{3}$ and dilute to $500 \mathrm{ml}$ with water.

4.3 Bismuth carrier, $20.9 \mathrm{mg} / \mathrm{ml}$. Dissolve $5.225 \mathrm{~g}$ bismuth metal in concentrated $\mathrm{HNO}_{3}$ and dilute to $250 \mathrm{ml}$ with water.

4.4 Thorium tracer, ${ }^{234} \mathrm{Th}$. Pretreat a $30 \%$ Adogen $364-x y l$ ene solution by extracting it with an equal volume portion of $2 \mathrm{M} \mathrm{HMO}_{3}$ for $2 \mathrm{~min}$. Dissolve $5.0 \mathrm{~g}$ of recently depleted $238 \mathrm{U}$ (as $\mathrm{U}_{3} \mathrm{O}_{8}$ ) in $2 \mathrm{MHNO}_{3}$. Extract the thorium and uranium with an equal volume of pretreated $30 \%$ Adogen 364-Xylene in a separator flask by hand shaking at least $2 \mathrm{~min}$. Separate phases and strip thorium from the solvent with $10 \mathrm{ml}$ of $10 \mathrm{M} \mathrm{HCl}$. Convert the chloride solution to $2 \mathrm{HHNO}_{3}$ solution for a repeat extraction with solvent to remove traces of uranium. The second $10 \mathrm{M} \mathrm{HCl}$ strip is again converted to the nitrate for counting the ${ }^{234} \mathrm{Th}$ beta on a siainless steel disc. The mounting should be examined in a pulse-height alpha ana!vier for the presence of ${ }^{230} \mathrm{Th}$. Should the ${ }^{230} \mathrm{Th}$ level be sni: : raic, then another source of depleted $238 \mathrm{U}$ should be sought, or alternatively extract the ${ }^{234} \mathrm{Th}$ from a batch of $238 \mathrm{U}$ from wich the thorium had been extracted 1 to 2 months previously.

4.5 Ammonium hydroxide, concentrated.

4.6 Nitric acid, concentrated.

4.7 Hydrochloric acid, concentrated.

4.8 Sodium hydroxide pellets.

4.9 Sulfuric acid, concentrated. 


\section{10 Hydrogen sulfide gas.}

4.11 Dowex $4 \times 1$ and Dowex $50 \times 1$ ex:hange resins.

\subsection{Apparatus}

5.1 Radon de-emanation train with radon concentrator , and Lucas chamber.

5.2 Radon photomult llier counter.

5.3 Modified ${ }^{\dagger} 250-\mathrm{ml}$, flat-bottom, boiling flasks.

5.4 Other counting equipment--G-M beta counter; low-level, gasproportional beta counter; pulse-height spectral alpha analyzer.

5.5 Stainless-steel alpha counting discs.

5.6 Laboratory centrifuge.

5.7 Pyrex centrifuge tubes, $50 \mathrm{ml}$.

5.8 Beakers, assorted.

5.9 Ion exchange columns.

5. 10 Dowex $4 \times 1$ and Dowex $50 \times 1$ exchange resins.

5. 11 Hirsch fixed plate funnel.

*The radon concentrator consists of a $20-\mathrm{cm}-10 n g \mathrm{U}$-tube constructed from $6 \mathrm{~mm}$ o.d. Pyrex glass tubing. Ten centimeters of the U-section is fillea with 20 to 40 in. unfired Vycor which has a large surface to volume ratio. When the tube is immersed in liquid nitrogen and radonladen helium gas passes through the tube, the condensable radcn adheres to the Vycor surface. The stripped helium gas exits the system. Upon removal of the coolant the radon vapor diffuses through 10 to $15 \mathrm{~cm}$ of cupillary tubing to the evacuated Lucas chamber. Flushing the U-tube and attached capillary tubing with 20 to $30 \mathrm{ml}$ of helium transfers essentially $100 \%$ of the radon to the Lucas chamber. Since the efficiency of Lucas chambers for counting alphas may vary from 75 to $85 \%$, it is necessary to calibrate each chamber with an equilibrated ${ }^{22 \epsilon} \mathrm{Ra}$ standard solution.

The radium-radon equilibrating flask consists of a flat-bottom 250-ml boiling flask with a female $24 / 40$ tapered joint. A saber-type sintered gla:s gas diffuser is sealed into a male $24 / 40$ taper joint section so that when it is inserted in the flask it will extend well into the equilibrating solution. A suitable inlet gas connection is provided on the ordosite end of the diffuser tube. Onto the shoulder of the male $24 / 40$ joirit is sealed a short length of small bore ( $5 \mathrm{mr}, i d$. ) glass tubing with a glass stopcock termi $A^{+}$ir.; $i$ th a connector suitable for hooking up with the radon trapoing system. 